Florida International University FIU Digital Commons

4-20-2012

\title{
Explaining Investor Preferences: The Significance of Socio-demographic, Ideological, and Attitudinal Factors
}

Abdul Beydoun

Florida International University, abeyd002@fiu.edu

DOI: $10.25148 /$ etd.FI12072702

Follow this and additional works at: https://digitalcommons.fiu.edu/etd

\section{Recommended Citation}

Beydoun, Abdul, "Explaining Investor Preferences: The Significance of Socio-demographic, Ideological, and Attitudinal Factors" (2012). FIU Electronic Theses and Dissertations. 664.

https://digitalcommons.fiu.edu/etd/664 


\section{FLORIDA INTERNATIONAL UNIVERSITY}

Miami, Florida

EXPLAINING INVESTOR PREFERENCES: THE SIGNIFICANCE OF SOCIO-

DEMOGRAPHIC, IDEOLOGICAL, AND ATTITUDINAL FACTORS

A dissertation submitted in partial fulfillment of

the requirements for the degree of

DOCTOR OF PHILOSOPHY

in

BUSINESS ADMINISTRATION

by

Abdul-Rahman Beydoun 
To: Dean Joyce Elam

College of Business Administration

This dissertation, written by Abdul-Rahman Beydoun, and entitled Explaining Investor Preferences: The Significance of Socio-demographic, Ideological, and Attitudinal Factors, having been approved in respect to style and intellectual content, is referred to you for judgment.

We have read this dissertation and recommend that it be approved.

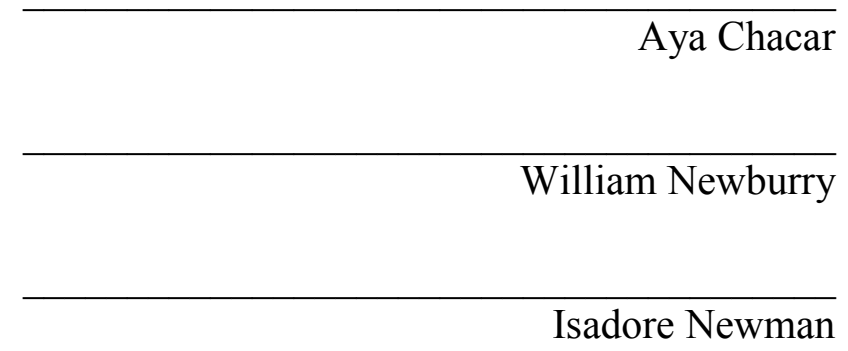

Karen Paul, Major Professor

Date of Defense: April 20, 2012

The dissertation of Abdul-Rahman Beydoun is approved.

Dean Joyce Elam

College of Business Administration

Dean Lakshmi N. Reddi

University Graduate School

Florida International University, 2012 


\section{DEDICATION}

This dissertation is dedicated to my mother for her love, support, and prayers, to my late father, who instilled in me a passion for life-long learning, and to my brothers, and sisters, especially my brother Elias, for his continuous support and encouragement. 


\section{ACKNOWLEDGMENTS}

I would like express my deepest gratitude to Professor Karen Paul for her exceptional efforts in guiding and directing me through the writing process. Her feedback was invaluable in completing this dissertation. She taught me how to be a researcher more than anybody else, and I will always be grateful to her support. This dissertation would not have been possible without the guidance she provided to me through this journey. Also, I sincerely thank each of the other members of my dissertation committee. Professor Isadore Newman provided me with insightful suggestions especially in the methodology and data analysis sections. Also, I am very grateful to Professor Aya Chacar and to Professor William Newbury for their continuous support, direction, and encouragement.

I would like to thank all the faculty members of the Department of Management and International Business. They have been always helpful and provided me with great comments and suggestions. In particular, I would like to thank Professor Galen Kroeck for his valuable support throughout my doctoral studies. I would like to thank my colleagues at the Ph.D. program at Florida International University, with special thanks to Abrahim Soleimani, Kun Yang, Wei He, Pai ChenKuo, and Armando Borda and his family.

Finally, I am thankful to my parents, brothers, and sisters, who provide me with endless support and love. I consider myself lucky to have such a supportive family, and I am glad to express how much they are important in my life, and how much I care about them. 


\title{
ABSTRACT OF THE DISSERTATION \\ EXPLAINING INVESTOR PREFERENCES: THE SIGNIFICANCE OF SOCIO- DEMOGRAPHIC, IDEOLOGICAL AND ATTITUDINAL FACTORS by
}

\author{
Abdul-Rahman Beydoun \\ Florida International University, 2012 \\ Miami, Florida \\ Professor Karen Paul, Major Professor
}

Previous research on investor preferences focused mainly on the relationship between socio-demographic variables and risk tolerance. This study extends the research in this area by focusing on three aspects of investor preferences: risk tolerance, time horizon, and estate intentions. The objective is to provide a more comprehensive model of investor preferences, including both psychological and attitudinal variables. This study addresses the following: Are socio-demographic variables sufficient to predict investor preferences? Is there a difference between males and females? How much additional variance is explained by including political ideology, positive psychology attitudes, and pro-social attitudes? Are these attitudinal variables simply additive or are they interactive?

Data were collected from MBA students and senior undergraduate students in a major research university in South Florida. A scale was developed to measure estate intentions, a construct that has never been examined in management studies. The findings supported the expectation that psychological variables would be positively correlated with the dependent variables. However, I expected that pro-social attitudes would be a moderator variable, and this expectation was not realized. This dissertation contributes to the investor preferences field in several ways. First, it demonstrates the 
importance of psychological and attitudinal variables in explaining investor preferences. I also found differences between males and females regarding risk tolerance. This study can provide financial advisers with a deeper understanding of the importance of psychological and attitudinal variables in determining investor behavior. Finally, the results of this study augment and expand stakeholder theory. This study brings the investor into the stakeholder model, enhancing the descriptive, explanatory, and predictive capabilities of stakeholder theory. Future research could replicate this study using real investors in different locations for cultural variation, or using a panel of respondents for a longitudinal study. 


\section{INTRODUCTION AND THE RESEARCH PROBLEM}

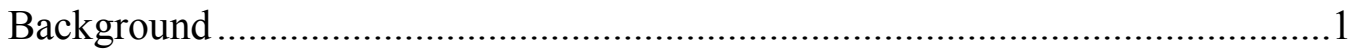

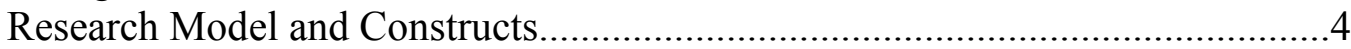

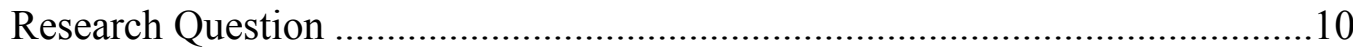

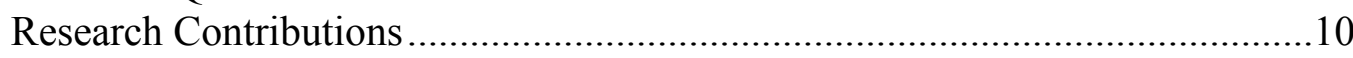

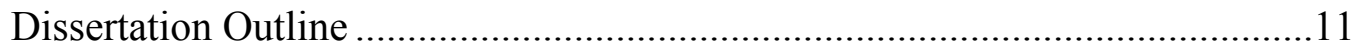

\section{LITERATURE REVIEW}

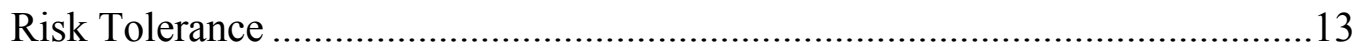

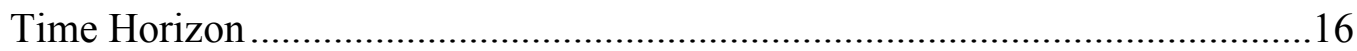

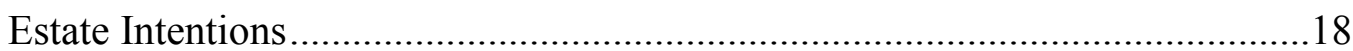

Socio-demographic Variables .....................................................................19

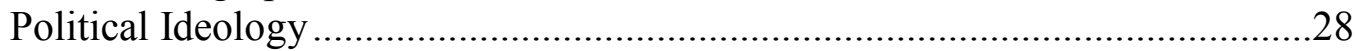

Background and Meaning of Positive Psychology ............................................32

Pro-social Attitudes and Investor Preferences .................................................41

III. RESEARCH DESIGN AND METHODOLOGY

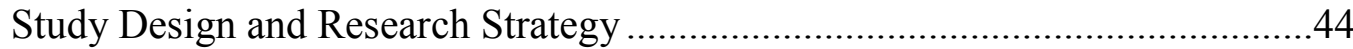

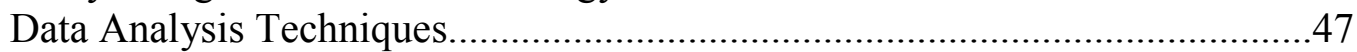

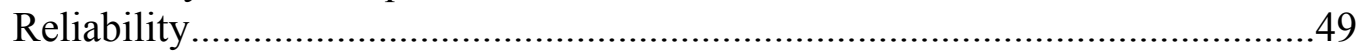

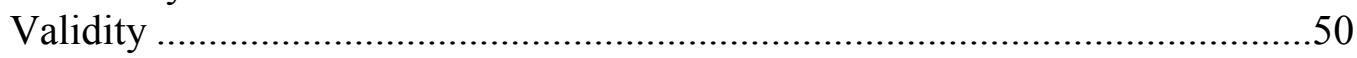

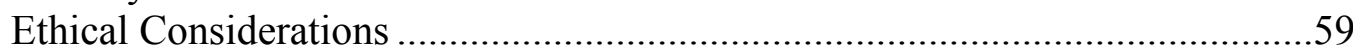

\section{ANALYSIS AND PRESENTATION OF THE RESULTS}

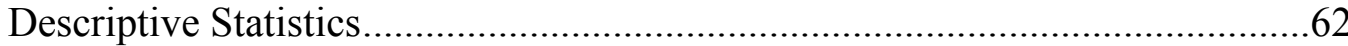

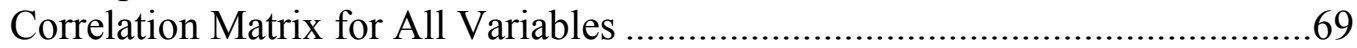

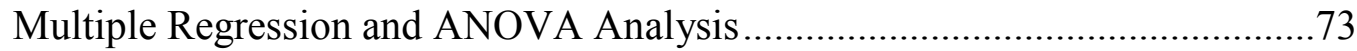

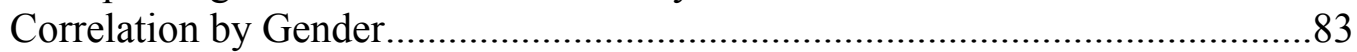

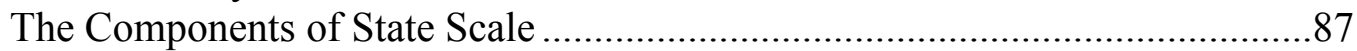

\section{DISCUSSION AND CONCLUSION}

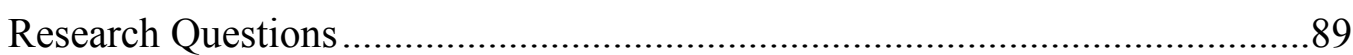

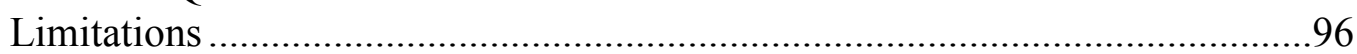

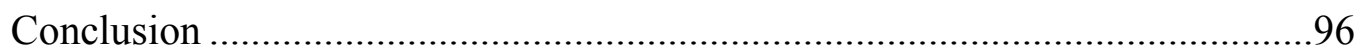

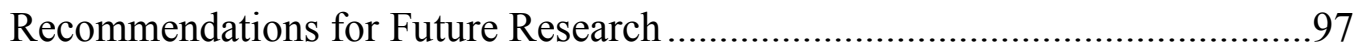

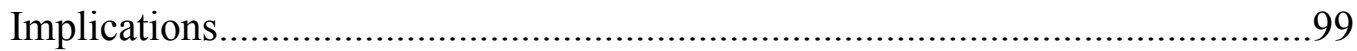

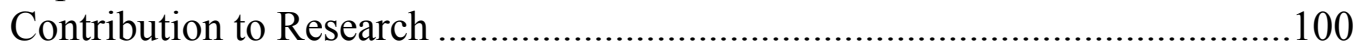

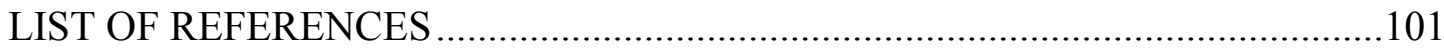

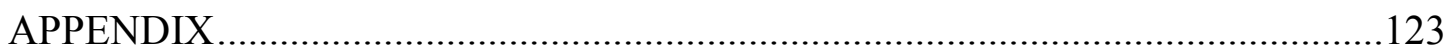

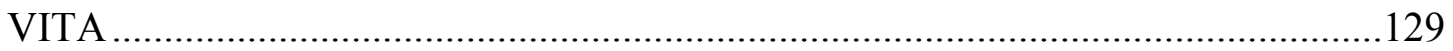




\section{LIST OF TABLES}

1. Factors from Principal Component Analysis ..........................................................50

2. List of Abbreviations for the Variables Used in the Study ......................................57

3. Descriptive Statistics for All Variables in the Study ..............................................63

4. Skewness and Kurtosis Values for the Continuous Variables ....................................64

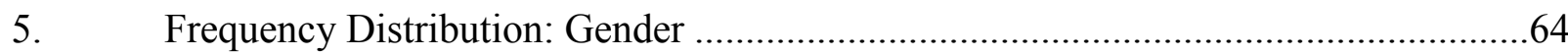

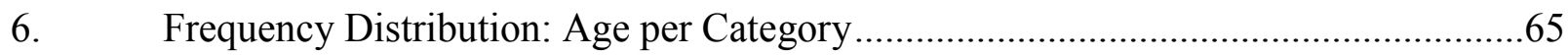

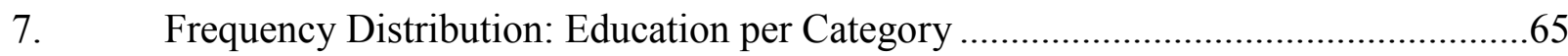

8. Frequency Distribution: Household Income per Category .......................................66

9. Frequency Distribution: Work Experience per Category ….....................................66

10. Frequency Distribution: Investment Experience per Category..................................67

11. Correlation Matrix among Dependent and Independent Variables ............................70

12. Multiple Regression Analysis Predicting Risk Tolerance with Socio-demographic

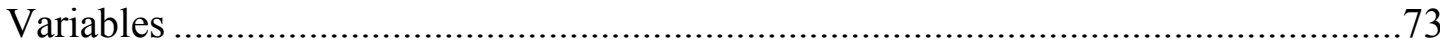

13. Multiple Regression Analysis Predicting Time Horizon with Socio-demographic Variables .73

14. Multiple Regression Analysis Predicting Estate Intentions with Socio-demographic Variables

15. Multiple Regression Analysis Predicting Risk Tolerance with Socio-demographic and Attitudinal Variables .76

16. Multiple Regression Analysis Predicting Time Horizon with Socio-demographic Variables and Attitudinal Variables. .76

17. Multiple Regression Analysis Predicting Estate Intentions with Socio-demographic

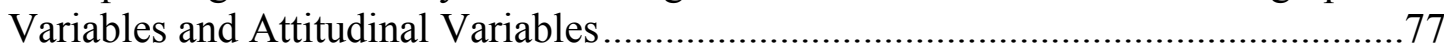

18. Pro-social Attitudes as a Moderator Variable to Predict Risk Tolerance ......................78

19. Pro-social Attitudes as a Moderator Variable to Predict Time Horizon......................79 
20. Pro-social Attitudes as a Moderator Variable to Predict Estate Intentions..................80

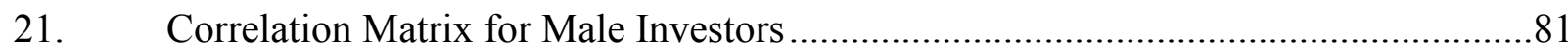

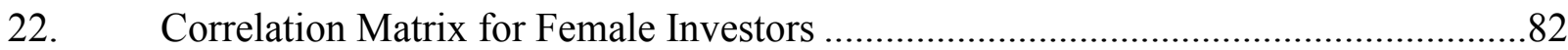

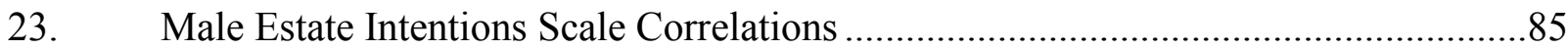

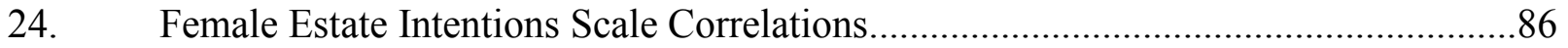




\section{LIST OF ABBREVIATIONS}

AGE

Age

GEN

Gender

EDU

Education

WOK

Work Experience

INC

Household Income

INV

Investment Experience

HOP

Hope

IDEO

Ideology

PRO

Pro-social Attitudes

RISK

Risk Tolerance

TIME

Time Horizon

EST

Estate Intentions

HOPR

Interaction between Hope and Pro-social Attitudes

OPPR

Interaction between Openness and Pro-social Attitudes

IDPRO

Interaction between Ideology and Pro-social Attitudes

AGEPRO

Interaction between Age and Pro-social Attitudes

EDPRO

Interaction between Education and Pro-Social Attitudes

INCPRO

Interaction between Income and Pro-social Attitudes

WORKPRO

Interaction between Work and Pro-social Attitudes

INVPRO

Interaction between Investment and Pro-social Attitudes 


\section{CHAPTER I}

\section{INTRODUCTION AND THE RESEARCH PROBLEM}

Introduction

Most financial advice is based on the idea that the goals of investors are limited to dimensions such as the level of risk desired, time horizon, life cycle considerations, liquidity preferences, estate intentions, and other similar variables. Some research considers the preferences characteristic of different types of investors using simple socio-demographic variables, whereas other research considers the effects of economic variables such as inflation rate and business cycle on investor preferences (Faff, Mulino, \& Chai, 2008; Moreschi, 2005; Roszkowski, Snelbecker, \& Leimberg, 1993).

In the field of finance, Portfolio Theory, also known as "conventional" or "rational" theory, has formed the basis for most studies of investor preferences. This theory assumes that investors are rational, which means that the aim of the investors is to maximize risk adjusted financial returns over a given time horizon. According to Beal, Goyen, and Philips (2005), rational theory does not admit any influences on the investment decision apart from maximizing returns, given the individual's particular level of risk aversion. According to Statman (2004), rationality represents the basic foundation of modern finance with the assumption that investors require higher returns to compensate for higher risk. Despite the fact that the concept of rationality has dominated the field of finance over the last four decades, Beal et al. (2005) note that investors do not uniformly exhibit rationality, as demonstrated by a limited number of studies in the field of behavioral finance. For example, Peterson (2002) draws on the psychology literature to show that anticipation of reward (price appreciation) generates a positive abject (emotion, mood, or attitude) that drives increased risk-taking behavior. However, the number of behavioral and attitude studies is still limited, 
and fails to capture important variables for investor preferences beyond those relating to financial risk and reward.

Investors should be of central importance to management studies, but they have seldom been studied. The classic statement of an investor's imputed perspective is provided in the oft-cited article entitled "The Social Responsibility of Business Is to Increase Its Profits" (Friedman, 1970). However, in the past thirty years stakeholder theory has become widely accepted among management scholars (Mitchell, Agle, \& Wood, 1997), providing a contrasting view to Friedman's perspective (Freeman, 1984). Stakeholder theory emphasizes the existence of multiple constituencies having interests that management must consider at any given time. The classic statement of this perspective is the seminal book by Freeman (1984). A classic illustration of this perspective is the pyramid of corporate social responsibility put forth by Carroll (1991). A distinction is often made between primary stakeholders and secondary stakeholders. Primary stakeholders generally include employees, customers or clients, lenders, and investors, and may include suppliers, communities, and government regulators. Primary stakeholders have a continuing and essential interest in the corporation. Secondary stakeholders often include trade associations and citizen groups, and may include the media, religious organizations, and other groups that may or may not have an interest in the corporation at any given time. Stakeholder theory is often used to provide a contrasting view to the perspective that the interests of investors should be the dominant, perhaps the only, goal of management. Each tradition has formed the basis for numerous empirical studies and much theoretical elaboration over the past three decades.

However, there is an odd lacunae in the stakeholder literature. Little work has been done on the interests of investors as primary stakeholders, and the studies that have been done have focused mainly on socially responsible investors, or ethical investors, rather than investors as a whole. This may be because the conventional theory emphasized the imputed 
interests of investors to the exclusion of any other stakeholder, so in response stakeholder theorists de-emphasized this constituency, or it may be because there are difficulties in defining just who is an investor. Does the day trader qualify? With financial advisors, planners, and managers playing such an important gatekeeping role, should their preferences be emphasized more than individual investors? Do individual investors even matter, in that most holdings are institutional?

Little research within the field of management has focused on investors except for socially responsible investors as a special category, separate and distinct from most investors. The focus on socially responsible investment (SRI) has grown rapidly, especially in the last two decades. SRI is based on criteria that are more comprehensive than those used in conventional investment. These criteria include social, environmental, corporate governance, and ethical concerns, in addition to the conventional financial dimension. This emphasis on SRI fails to reflect the actual importance of ethical, environmental, and governance variables for investor preferences because most investors are not SRI investors. Bollen (2007) has demonstrated that investors may be motivated by societal and personal values in addition to standard risk-reward optimization goals, so research on investor preferences should be expanded to include the values and attitudes of conventional investors as well as the SRI type. The current dissertation considers attitudinal aspects of investor preferences.

Lydenberg (2007) notes that the gap between ethical investors and rational investors has become narrower as investors in general have become more sensitized to the importance of ethics, governance, and environmental issues. He states that there are three kinds of investors: Universal Investors, Social Investors, and Rational Investors. Lydenberg refers to Universal Investors as those investors whose investments are diversified across different assets in the whole economy. Hawley and Williams (2007) also use the term "universal owners" to correspond to Lydenberg's "Universal Investors." Performance of the portfolio of 
universal owners depends on the performance of the economy as a whole. Accordingly, universal owners have an interest in improving the macro-level economic, social, and environmental conditions which both affect and are affected by the investment choices they make (Kiernan, Goyen, \& Philips, 2007).

In Lydenberg's model Social Investors are those investors who consider social and environmental implications when they make investment decisions. Rational Investors correspond to the type of investors assumed in the dominant financial literature on investor preferences. Rational Investors emphasize diversification, assume an efficient market, and look for an optimal level of risk and return. Furthermore, Lydenberg (2007) argues that theoretically there is no difference between the investment strategies of Universal Investors and SRI Investors since both types require a consideration of both social and financial return. A contrary argument is presented by Nilsson $(2008,2009)$ who argues that investors may also be motivated by pro-social attitudes, such as avoiding investment in companies which produce harmful products, and that explains why some investors choose to invest in particular companies or mutual funds. This dissertation examines investor preferences using a purposeful sample considering several attitudinal factors never before linked to investor preferences as well as socio-demographic variables. The investor preferences tested in this study are risk tolerance, time horizon, and estate intentions.

Research Models and Constructs

This dissertation is based on the idea that, in addition to socio-demographic variables, other variables, including political ideology, positive psychology attitudes, and pro-social attitudes, will affect investor preferences. Two models will be tested. Model 1 is based on the idea that socio-demographic factors are the main determinants of investor preferences, consistent with the conventional finance approach. Model 2 is based on the idea that inclusion of political ideology, positive psychology attitudes, and pro-social attitudes, along 
with socio-demographic factors, will have more explanatory power for investor preferences. Two variations of Model 2 will be tested. The first variation is an additive model, whereas the second is an interactive model.

The following discussion describes the constructs examined in the conceptual model (see Figure1.1) and the impact of each of these constructs on investor preferences. Consistent with previous studies, the first variables proposed in this study are the socio-demographic factors that might influence investor preferences. Extant research suggests that differences in investor values are associated with socio-demographic variables such as age, gender, education, income, and work experience (e.g., Getzner \& Grabner-Krauter, 2004; Rosen, Sandler, \& Shani, 1991). For example, SRI investors have been found to be more educated, proportionately more female, and younger than other investors (Rosen et al., 1991; Hayes, 2001). This is consistent with Schueth (2003), who argues that SRI in the U.S. is influenced by general improvements in education levels and the wider involvement of women in the equities market.

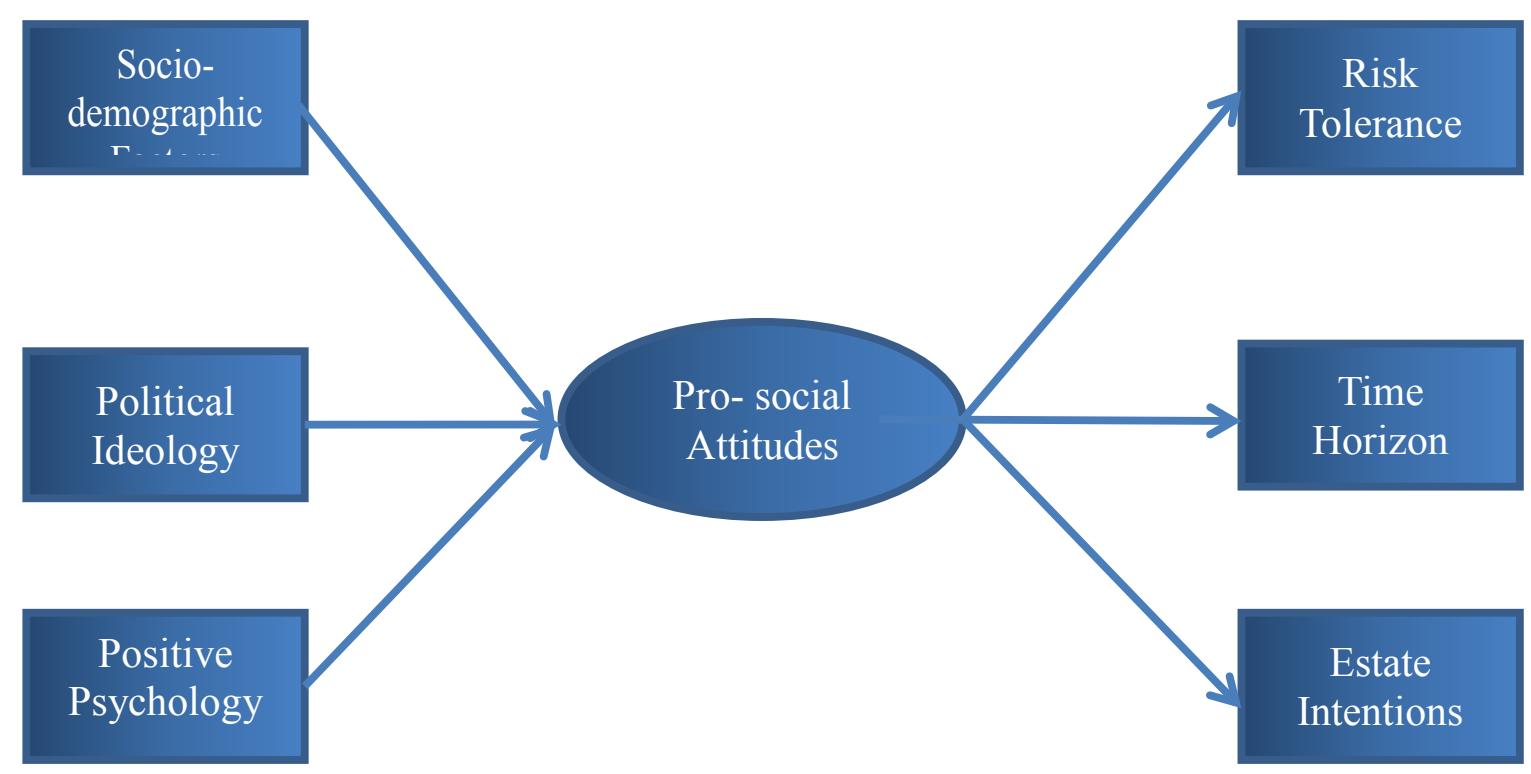

Figure 1. The Effect of Socio-demographic, Political Ideology, and Positive Psychological Attitudes on Investor Preferences as Moderated by Pro-social Attitudes. 
However, when McLachlen and Gardner (2004) examined the effect of age, educational level, and income on SRI in Australia, they found some differences between socially responsible investors and conventional investors. The differences were in areas such as attitudes toward ethical issues and in decision-making styles. Since most existing studies have found that socio-demographic factors affect financial decision-making, I anticipate they will affect investor preferences.

Interest in positive psychology has grown as a result of the movement initiated by Martin Seligman and his colleagues in 1998 (Gable \& Haidt, 2005). The aim of positive psychology is to focus on human strengths and virtues, rather than focusing on mental illness and deviant behavior. Seligman and Csikszentmihalyi (2000) define positive psychology as, "the science of positive subjective experience, positive individual traits, and positive institutions" (2000, p. 5). According to Cameron (2003), psychology has the following three foci: 1) positive experiences such as happiness, pleasure, joy, and fulfillment; 2) positive individual traits such as character, talents, and interests; and 3) positive institutions such as families, schools, business, communities, and societies.

The growing literature on positive psychology has attracted the attention of many scholars (Synder, Lopez, \& Pedrotti, 2010; Seligman, 2002). A variety of individual characteristics are discussed under the domain of positive psychology including emotion (Snyder, Lopez, Shorey, Rand, \& Feldman, 2003), gratitude (Emmons \& Shelton, 2002), spirituality (Zinnbauer \& Mahoney, 2005) hope, optimism, and resiliency (Luthans, Avolio, Avey, \& Norman, 2007; Nelson \& Cooper, 2007). Several studies have linked hope, optimism, and resiliency to higher levels of job satisfaction, work happiness, and organizational commitment (Youssef \& Luthans, 2007). Nielsen, Randall, Yarker, and Brenner (2008) found a positive relationship of positive psychology states such as optimism, 
kindness, humor, and generosity with job satisfaction. Giacalone, Paul, and Jurkiewicz (2005) investigated the impact of positive psychology attitudes on consumer sensitivity to corporate social responsibility (CSCSP). The authors conducted two independent studies using four constructs. These positive psychology dimensions significantly predicted CSCSP.

Based on the literature review (e.g., Luthans \& Youssef, 2007; Luthans et. al., 2007; Nelson \& Cooper, 2007), this study focuses on three positive psychological "capacities" derived from Seligman and Csikszentmihalyi's (2000) definition of positive psychology. Hope, optimism, and resilience are the three capacities chosen for this study. To my knowledge, there has been no research that has applied the domain of positive psychology to investor preferences.

The second factor I consider is political ideology, a construct seldom included in either management or finance studies. Empirical results show that political ideology has a profound effect on various aspects of individual behavior. For example, numerous studies in politics as well as in environmental studies have examined the effects of political ideology on support for environmental reform. The results show that individuals vary in their support for environmental reform based on their political ideology, with liberals more willing to support environmental reform than conservatives (Buttel \& Flinn, 1976, 1978). Several studies in the field of consumer behavior and corporate social performance have demonstrated the effect of political ideology on consumer preferences. For example, Paul, Zalka, Downes, Perry, and Friday (1997), and Zalka, Downes, and Paul (1997) found that, in the United States, liberals were more sensitive to corporate social performance (CSP) than conservatives. Mohai and Byrant (1998) found a positive effect of political liberalism on the perceived seriousness of environmental problems. I expect more liberal respondents to score higher on risk tolerance, time horizon, and estate intentions because they have more confidence in the future and are 
more at ease with the unknown, whereas conservatives tend to be wary of the future and averse to ambiguity, as will be discussed.

I also consider the effect of pro-social attitudes on investor preferences. Lydenberg (2007) suggests that some attitudes which used to be linked only to SRI investors are now shared by most investors, because the social aspect has become increasingly important for a growing proportion of institutional and individual investors. Therefore, I test the effect of pro-social attitudes on investor preferences. Sparkes and Cowton (2004) argue that investors who place high consideration on social issues and view high ethical standards as important for firms are more likely to be influenced by social variables in their investment decisions. In an experimental study, Lewis and Webley (1994) have found that green attitudes were important for interest in ethical investments. Nilsson $(2008,2009)$ provides data to support this argument, an argument disputed by Lydenberg (2007).

Attempts have been made in the marketing and consumer behavior literature to identify how an individual's social attitudes stimulate buying from firms that demonstrate concern about social issues (e.g., Laroche, Bergeron, \& Barbaro-Forleo, 2001; Manaktola \& Jauhari, 2007; Roberts, 1996). For example, Laroche et al. (2001), in an exploratory study, found that consumers were willing to pay a higher price for environmentally friendly products. Cleveland, Laroche, and Papadopoulos (2009) have conducted a study to measure consumer attitudes regarding companies that were sensitive to environmental issues. The results show that $92 \%$ of the consumers had positive attitudes toward these companies. The conclusion to be drawn from these studies is that consumers assert they take into consideration environmental issues when they purchase, and say they are willing to spend more for green products. In this dissertation I extend this argument to investor preferences, anticipating a positive relationship between pro-social attitudes and investor preferences, arguing that pro-social attitudes will be associated with greater risk tolerance, a longer time 
horizon, and more attention given to estate intentions, the dependent variables considered in this study.

Investor risk tolerance is the maximum amount of investment risk someone is comfortable in taking (Joo \& Grable, 2004). Individual risk tolerance is a primary determinant of asset allocation choices, security choices, and goal planning strategies. According to portfolio theory, an investor's exposure to risk can be reduced through diversification. Consequently, any decision based on non-economic factors involves lower returns and higher risk (Fama, 1976) as a consequence of the lower level of diversification. Accordingly, investors who score high on pro-social attitudes might not be able to achieve the goal of maximizing returns, since they might exclude some companies from their portfolio, therefore, lower the level of diversification, implying a higher tolerance for risk. Even whole industries might be excluded, e.g., oil companies, defense contractors, tobacco companies, prison privatization companies.

Time horizon refers to the anticipated time span the investor will need before beginning to use investment returns (Garman \& Forgue, 1997; Hallman \& Rosenbloom, 1987). Over the last three decades many studies have shown that SRI adds value to the investment over the long-term. However, this research tends to focus on mutual fund and institutional investors. For example, Waddock and Graves (1997) found a positive link between the portfolio performance of investors and SRI. They argue that this relationship, in part, might be attributed to the long-term performance of SRI compared to the market as a whole. This finding was supported by Cox, Brammer, and Millington (2004), who examined institutional shareholding in the United Kingdom, showing a positive relationship between long-term institutional investment and corporate social performance. Ryan and Schneider (2002) argue that institutional investors (e.g., pension funds, life insurance, charitable funds) typically have a long investment horizon. Since the financial benefits of SRI are expected to 
be more in the long term than in the short term, institutional investors may tend to prefer SRI. Since firms recognized as ethical give signals to the market about the quality of their management (Cullis, Lewis, \& Winnett, 1992), they might experience reputational benefits. This logic implies that SRI, because it operates with a longer time horizon than conventional investment, is more attractive to ethically minded investors than it is for the stereotypical "rational investor." Unlike most SRI studies, this study focuses on the individual investor.

Estate intentions include plans to use investment principal and earnings to benefit heirs. I argue that investors who score high on pro-social attitudes will place higher value on leaving a bequest. This expectation is consistent with the positive psychological attributes discussed above. Since this variable has not been studied before, I constructed a new scale to measure estate intentions.

Research Questions

Based on the above discussion, I propose the following research questions to direct this study:

- Are socio-demographic variables sufficient to predict investor preferences? Is there a difference between males and females?

- How much additional variance is explained by attitudinal variables, including political ideology, positive psychology attitudes, and pro-social attitudes?

- Are these attitudinal variables simply additive or are they interactive?

Research Contributions

This exploratory study contributes to the knowledge of investor preferences in several ways:

- Most previous studies on investor preferences have focused on socio-demographic variables to explain investor behavior. Attitudinal variables have received little attention. This study addresses a gap in the investor preferences literature, developing 
a model for investor preferences that includes factors such as political ideology, positive psychology attitudes, and pro-social attitudes. Although there is much written about these factors independently in different disciplines, this study links these perspectives by considering the relationship among them in an empirical model and examining their interactive and additive effect on investor preferences.

- The sample used in this exploratory study consists of graduate students or senior undergraduates in the business school. The intent was to obtain as representative a sample of real investors as much as possible. Most of the students in the sample have work experience and almost half have investment experience. This represents an effort to study a population of investors and potential investors, but must be regarded as an intentional sample not representative of the whole population.

- This research will help financial decision-making and financial advising to be accomplished on a more complete, more comprehensive, and more up to date basis.

- I contribute to the stakeholder perspective by studying individual investors, rather than focusing on ethical investors or SRI mutual funds.

- I test the adequacy of competing models, one asserting the generality of similar prosocial attitudes among the majority of investors (Lydenberg, 2007), while the other asserts the differentiation of investors with pro-social attitudes from other investors (Nilsson, 2008, 2009).

- Finally, this study develops, tests, and validates a scale to measure estate intentions, a new construct in management studies.

Dissertation Outline

This dissertation is organized as follows: Chapter I provides an overview of the research, the research question, justification of the study, and the proposed model. Chapter II provides a review of the literature related to this study. Chapter III presents the methodology 
used, including the survey instrument, the validity and reliability of the survey instrument, analysis techniques, and data collection. Chapter IV presents the descriptive statistics and the findings of the study. Chapter $\mathrm{V}$ discusses the findings and provides the conclusions, limitations, and areas for future research, as well as the theoretical and practical implications. 


\section{CHAPTER II}

\section{LITERATURE REVIEW}

\section{Risk Tolerance}

Risk tolerance is a widely used term in personal financial planning. Risk tolerance is defined as the maximum amount of uncertainty or investment return volatility that the investor is willing to accept when making a financial decision (Faff et al., 2008; Grable, 2000; Grable, Lytton, \& O’Neill, 2004). The investor's attitude towards risk, in other words, is defined as the maximum amount of uncertainty or investment return volatility that the investor is willing to accept when making a financial decision (Faff et al., 2008; Grable, 2000; Joo \& Grable, 2004; Grable \& Roszkowski, 2008). Risk tolerance is the opposite of risk aversion (Brennan \& Kraus, 1976; Gron \& Winton 2001; Walls \& Dyer, 1996). According to Baker and Haslem "the balancing of risk and return represents the classic dilemma faced by investors" (1974, p. 469). Thus, choices regarding investment products, asset allocation plans, and portfolio accumulation strategies are attributed to risk tolerance. It is clear that investors vary in the degree of financial risk they are willing to take. Since financial risk tolerance is related more generally to the willingness to take risk, risk tolerance is considered to be the main determinant in developing an investment plan, especially for asset allocation. Brinson, Hood, and Beebower (1986) found that over 90\% percent of the variability in portfolio returns could be explained by asset allocation, which is based mainly on risk tolerance. Riley and Chow (1992) found that steady increases in equity among investors younger than 65 indicate greater risk tolerance. At the same time, they found that risk tolerance decreased after the age of 65 as retirement income becomes an issue. Furthermore, they found that as income and wealth increased, the allocation of risky assets increased. Also, they found a positive relationship between the level of education and risk tolerance. The lowest level of risk tolerance was among divorced and separated households. 
However, measuring risk tolerance is a complex process, and risk tolerance has been measured using several techniques. These techniques can be separated into measures based on observing risky behavior and measures using surveys to ask questions that gauge one's willingness to assume risk in given situations (Hanna, Gutter, \& Fan 2001; Hanna \& Lindamood, 2004). Many studies infer financial risk tolerance from behavior such as ownership of risky assets or the ratio of risky assets to total wealth (Cohn, Lewellen, Lease, \& Schlarbaum 1975; Fama \& Schwert, 1977; Friend \& Blume, 1975; Morin \& Suarez, 1983; McInish, Ramaswami, \& Srivastava, 1993; Schooley \& Worden, 1996). Studies based on behavior are often influenced by self-selection bias and do not typically consider other factors that would prevent ownership of risky assets such as lack of exposure to information about financial markets. Roszkowski et al. (1993) argue that there is no objective measure for risk tolerance. There is a strong correlation between socio-demographic characteristics and risk tolerance (Joo \& Grable, 2004). As noted previously, research shows that socio-demographic characteristics, economic characteristics, and expectations or opinions have significant effects on financial decision-making. Consequently, I expect age, gender, education, household income, work experience, and investment experience to affect risk tolerance, investing in a longer time horizon, and placing more value on leaving a bequest to heirs, charity, and religious organizations.

In their seminal work on dividend policy, Miller and Modigliani (1961) described investors as rational, saying "Rational investors always prefer more wealth to less and are indifferent as to whether a given increment to their wealth takes the form of cash payments or an increase in the market value of their holdings of shares." Accordingly, rationality in finance is based on the premise that higher risk will be rewarded with higher reward (return) known as the risk-return tradeoff. The standard finance literature makes the assumption that within efficient stock markets, investment risk should best be understood and measured in the 
framework of diversified portfolios. When compared with the overall market, this type of risk is known as market risk (Markowitz 1952, 1999; Sharpe, 1964).

To summarize, since the early 1960s the finance literature has been built on the assumption that investors are rational, seeking to maximize return. Accordingly, rational theory denies other influences on investor decisions apart from maximizing returns. While rationality has dominated the finance discipline in the last four decades, rational theory has been criticized because the assumptions of efficient market and investor rationality are questionable and the theory often lacks predictive power (Statman, 2005). For example, Sortino and Satchell (2001) found that investors do not seek the highest return for a given level of risk, as portfolio theory assumes, but rather to satisfice. Furthermore, it is well documented in psychology that decision-makers have a tendency to be overly optimistic. Excessive optimism occurs when individuals overestimate their abilities. In general, men suffer from these traits more than women. According to Barber and Odean (2001), overconfidence in finance is manifested in excessively frequent trading. Research has shown that overconfident investors trade excessively, and that men are more overconfident than women (Gervais, Heaton, \& Odean, 2003). However, net return falls as trading increases. Peterson (2002) draws on the psychology literature to show that anticipation of reward (price appreciation) generates a positive affect (emotion, or attitude) that drives increased risktaking behavior. Pasewark and Riley (2009) used an experimental design to investigate the role of personal values in an investment decision. Participants were asked to choose between two different kinds of bonds, one issued by a tobacco company and the other issued by a nontobacco company. The results showed that when the rate of return on a tobacco-related investment exceeded the rate of return on an investment not involving tobacco by $1 \%$, the intensity of participant concerns about the societal effects of their investment decisions was especially important in determining investment choices. This finding indicates that traditional 
wealth-maximization approaches, which do not consider the personal values of the investor, omit an important factor that affects investment decisions.

Scholars from cognitive and experimental psychology (Kahneman \& Lovallo, 1993; Griffin \&Tversky, 1992) have also criticized the arguments of rational theory. They argue that rationality is not correct in predicting investor behavior, because individuals most often work in less than a fully rational manner and make decisions on the basis of incomplete information. Kahneman and Tversky (1979) developed a new theory related to risk taking behavior known as prospect theory. This theory departs from the assumptions of rationality in judgment and choice, giving more weight to the cognitive limitation of human decision makers. It asserts that there are continual biases motivated by emotional (affective) and cognitive (mental processes) factors that influence a person's choices under specific situations as pointed out in Ricciardi and Simon (2000). Shefrin and Statman (1994) state that cognitive biases and emotion affect investors, thus detracting from the traditionally assumed rational behavior. Investors often manage their stocks individually rather than as portfolios, but are reluctant to realize losses, possibly because they use mental accounts, and selling a stock at a loss closes each account with a finality that allows no recovery of value and causes emotional distress.

Time Horizon

Time horizon refers to the time period associated with accomplishing an investment objective. An investor who can invest money for decades can own a riskier portfolio than someone who needs the money in the near future. Time horizon can be divided into the categories of short, medium, and long term. There is no standard definition for these groups, but, roughly speaking, investment for less than three years is considered short time investment, investment between three and ten years is considered medium term investment, and investment for more than ten years is considered long term investment. 
In the finance literature time horizon always linked to asset allocation. Theoretically, it is generally assumed that risk grows as the time horizon increases (Butler \& Domian, 1991; Kritzman, 1994; Thaler \& Williamson, 1994). Thorley (1995) and Bierman (1997) analyzed historical data on returns of asset classes and found that as the investment time horizon lengthened, investors should have allocated higher levels of equity to their portfolios. This is consistent with professional financial advisors, who encourage younger people to invest more heavily in stocks for long-term investment goals such as saving towards their pension. Professional financial advisers often recommend that investors allocate 100 minus the investor's age to equities. For example, a 20 year old investor should allocate $80 \%$ of his investment to equity investment. Bodie and Crane (1997) conducted a study to examine investor's behavior using a survey containing information on the composition of the respondents' total assets holding. Findings showed that actual investor behavior is consistent with the prediction of the economic theories and the professional financial advisors. The respondents kept a proportion of their investment in cash, and this cash proportion declined with age, but rose as their wealth increased.

On the other hand, some scholars argue that time horizon has no influence on asset allocation. The capital asset pricing model (CAPM) assumes that any rational investor facing the same risk aversion will choose the same share of risky assets (e.g., equity) in the portfolio independent of the investor's age and time horizon. Early work by Samuelson (1969) argues that portfolio allocation is independent of the time horizon. When Bodie, Merton, and Samuelson (1992) extended previous studies by adding the individual's anticipated years of work expectancy to the analysis, the results supported this view. Young workers, those with most of their career ahead of them, were willing to take more risk. Therefore, they added more equity investment stocks to their portfolios. If risky equity ends up in unfavorable results, younger investors will have sufficient working time to compensate for the losses. On 
the other hand, individuals closer to retirement age have less anticipated work time to recover from their losses, and tend to have less risky equity investments in their portfolios. The results also support the argument that wealthy investors are willing to add more risky assets to their portfolio investment. Canner, Mankiw, and Weil (1997) argue it is not rational to assume that all investors will behave in the same way independent of their age and investment time horizon. I expect time horizon to be affected by both socio-demographic variables and attitudinal variables as discussed below.

Estate Intentions

This variable has not been studied before. However, there are studies of philanthropy and giving to charity that might be useful. Individuals donate money to charity, to their religious organizations, or to family members for several reasons, such as helping people in need or to feel good about themselves as a result of donating. A growing literature examines the determinants of charitable giving to others. Previous research on philanthropy and charitable giving shows several factors related to giving such as income, marital status, gender, and age (Borgonovi, 2008; Wiepking \& Maas, 2009). Research in this area has been conducted in different disciplines such as economics, psychology, marketing, and sociology, but most studies have been conducted by economists, who mainly focus on rational choice. However, since rational choice theory cannot explain individual donations to collective goods (Andreoni, \& Petrie, 2004), I need to build on other disciplines such as psychology or sociology to explain this behavior. Personal values, such as the feeling of a warm glow that one gets when giving, are important in explaining donors' behavior. Psychologists (Schervish \& Havens, 1997) focus on investigating the effect of many cognitive and emotional characteristics of individuals on charitable giving. Finally, sociologists (Janoski, Musick, \& Wilson, 1998; Wiepking \& Maas, 2009; Wilson \& Musick, 1997, 1998) argue that, in addition to cost and personality characteristics, social restriction influences charitable giving. 
I expect estate intentions to be affected by both socio-demographic variables and the attitudinal variables discussed below.

Socio-demographic Variables

Socio-demographic variables such as age, gender, income level, and education have been widely used in consumer behavior and investment studies to capture differences in consumer or investor behavior (Laroche et al., 2001; Joo, \& Grable, 2004; Palsson, 1996). In finance several studies have used socio-demographic variables for segmenting consumers and investors in financial services (Harrison, 1995). In mutual fund investments Campbell (2006) found that people with lower education and lower income were more likely to make suboptimal financial decisions. Anderson, Cox, and Fulcher (1976) have investigated the manner by which consumers employ selection criteria for a bank (e.g., convenience vs. service orientation). The results show that socio-demographic variables are important determinants in the selection process. Service-oriented customers are more likely to have a working spouse and higher income. Palsson (1996) shows that age is positively correlated with risk tolerance. Younger people tend to hold investment portfolios with higher levels of risk than older people. Regarding gender differences, several studies have found that men are more risk tolerant and more overconfident than women (Barber \& Odean, 2001; Loibl \& Hira, 2009; Lascu, Babb, \& Phillips, 1997).

Although scholars in behavioral finance have started to pay more attention to the influence of socio-demographic variables on investor behavior, most of the studies related to this topic have been conducted in the consumer behavior area, mainly green purchasing. For example, Laroche et al. (2001) found that a segment of consumers is willing to pay more for environmental friendly products, and that segment consists mainly of married females with at least one child at home. Furthermore, several studies in consumer behavior have examined the effect of socio-demographic variables on information searching behavior (Loibl \& Hira, 
2009). In their study of investor information search, Lin and Lee (2004) found younger age positively related to greater investor information search. Loibl and Hira (2009) found that higher educated male investors with higher earnings were more likely to practice a highinformation search strategy. The consumer behavior literature demonstrates the role of sociodemographic variables in segmenting consumers with environmentally and socially conscious behavior (Nilsson, 2008, 2009). Nilsson identifies three segments of investors. The "primarily concerned about profit" are to a larger extent male and less educated than the other two groups. The "primarily concerned about social responsibility" are mainly well-educated females, and women also comprise the majority of "socially responsible and return driven." Other research shows that socially responsible individuals tend to have higher income (Lyons \& Breakwell, 1994; Vining \& Ebreo, 1990), be more proportionately female (Laroche et al., 2001), younger, and better educated (Diamantopoulos, Schlegelmilch, Sinkovics, \& Bohlen, (2003). These four socio-demographic variables, along with work experience and investment experience, are included in this study as explanatory variables of pro-social behavior and investor preferences using the reasoning that follows.

Age

In the finance literature studies of risk tolerance and age have produced mixed results. Empirical studies can be classified into three groups: (a) those research endeavors that found a relationship between age and risk tolerance, (b) research that did not find a relationship, and (c) research with inconclusive findings (Grable \& Lytton, 1999).

The relationship between age and green marketing support has been examined by several scholars (Roberts \& Bacon, 1997; Samdahl \& Robertson, 1989; Van Liere \& Dunlap, 1981). The findings have shown that younger people are more sensitive to environmental and social issues. The most common argument is that those who have grown up in a time period in which environmental and social issues have been salient are more likely to have positive 
attitudes regarding these issues. Therefore, I believe that younger people will score higher on the pro-social attitudes scale.

Studies regarding age and risk tolerance can be traced back to the early 1960s. For example, Wallach and Kogan (1961) found that younger people were more risk tolerant than older individuals. This finding is widely accepted by scholars and many professional advisors (Bajtelsmit \& Van Derhei, 1997; Bakshi \& Chen, 1994; McInish, 1982; Morin \& Suarez, 1983; Van de Venter \& Michayluk, 2009). This can be explained by the fact that because younger investors have more years to live, they expect to recover from any losses that might result from risky investment. In addition, when individuals invest for retirement, they will accept more risk in a long term objective because this will lead to greater wealth in retirement (Hanna \& Chen, 1997). There are several studies that have found a negative, but not linear, relationship between age and risk tolerance. Riley and Chow (1992) examined the influence of asset aversion on asset allocation in a sample of U.S. households. The results showed that risk tolerance increased with age until 65 , then decreased significantly. Based on U.S. financial diary panel data, McInish et al. (1993) examined the relationship between age and holding risky assets. The results showed no significant relationship between net worth and risk attitudes for those individuals younger than 35 years old, but significant results for individuals age 35 and older. Based on this argument I expect younger investors to be more risk tolerant.

Age also influences the time horizon of investment (Klos, Weber, \& Weber, 2005). Since a longer time horizon results in more time to accumulate value and to replenish investment losses, investors with longer time horizons can generally accept a higher level of risk and greater allocation to risky assets, which in turn should contribute to higher expected returns over the entire time horizon. Therefore, I argue that younger investors will express 
preferences for a longer time horizon, because they have more time to recover in case any losses are occurred.

Concerning age and estate intentions, I turn to several studies of philanthropic behavior. Several studies have found a positive relationship between age and amount of donations. Older individuals are more likely to donate more to charity (Alpizar, Carlsson, \& Johansson-Stenman, 2008). However, several other studies find a curvilinear relationship between age and donations, where the donation level increases up to certain age, and then starts to decrease after that age (Lyons \& Nivison-Smith, 2006; Simmons \& Emanuele, 2004; Tiehen, 2001). Auten and Joulfaian (1996) found higher donations among those aged 40 to 84 than among those younger or older. Andreoni and Miller (2002) found a positive relationship until age 75, after which a decrease was observed. Daneshvary and Luksetich (1997) examined the relationship between age differences in giving and charity. The results showed that the level of giving did not decline after age 65 for people of a higher level income, but there was a decline for individuals with lower income. Feldman and Slemrod (2007) examined the relationship between age and donations, but found no significant relationship existed between these two variables when controlling for age, marital status, and education. Duncan (1999) found the relationship between age and philanthropy varied by gender, and that older married women gave more. Based on this argument I expect older respondents to place greater value on leaving a bequest.

To summarize, I expect age to be positively related to pro-social attitudes, risk tolerance, and estate intentions, and negatively associated with time horizon. Gender

Gender is the second socio-demographic factor in this study. Several studies have found women to be more environmentally friendly than men (Anderson \& Cunningham, 1972; Laroche et al., 2001). Most researchers have found that women are more likely than 
men to hold attitudes consistent with the green movement (Hounshell \& Liggett, 1973; Stern, Dietz, \& Kalof, 1993; Van Liere \& Dunlap, 1981). A number of studies support the belief that women are more ethical decision makers than men (Ruegger \& King, 1992; Serwinck, 1992). However, when Tsalikis and Ortiz-Buonafina (1990) examined how men and women process ethical information, the results showed gender had no effect. Although research regarding environmental concern, green attitudes, and pro-social attitudes yields ambiguous results about the gender differences (Van Liere \& Dunlap, 1981), I expect women to score higher on pro-social attitudes. This is consistent with previous studies that showed that females express stronger intentions for pro-environmental and social issues (e.g., Stern et al., 1993; Laroche et al., 2001).

A large body of literature has examined the relationship between gender differences and risk taking. Most of the studies have shown that females are less risk tolerant than males (Bajtelsmit, Bernasek, \& Jianakoplos, 1999; Grable, 2000; Powell \& Ansic, 1997). The Surveys of Consumer Finances (1995), have been an important source of data for these studies. For example, Sunden and Surette (1998) and Bajtelsmit, Bernasek, and Jianakoplos (1999) used these data for a retirement savings analysis, while Jianakoplos and Bernasek (1998) used them to examine the effect of gender differences on financial decision making. The findings showed single men to be more risk tolerant than single women. While the balance of literature would seem to support a greater level of risk aversion by women, there are contradictory results. Grable and Joo (2000) and Hanna, Gutter, and Fan (1998) found that gender differences were not significant in predicting risk tolerance. Yao, Gutter, and Hanna (2005) conducted an experimental study that found under controlled economic conditions, female subjects did not generally make less risky financial decisions than males.

Empirical findings on gender differences and giving have produced mixed results. Several studies found that males were more likely to donate more to charity more than female 
(Andreoni \& Miller, 2002; Bekkers \& Schuyt, 2008). Several other studies found that females were more likely to give, but did not give a higher amount than males (Lyons \& NivisonSmith, 2006). Knoke (1990) found that males contributed more to professional societies, recreational organizations, and women's organizations than females. Brown and Ferris (2007) found that males gave more than females to religious organizations. I expect females to score higher on pro-social attitudes, lower on risk tolerance, higher on time horizon, and higher on estate intentions.

Income

Income is the third socio-demographic factor in this study. Previous studies have shown a positive relationship between income and environmental behavior. The most common interpretation for this is that individuals at higher income levels are able to bear the increased cost associated with green products (Straughan \& Roberts, 1999). A number of studies in consumer behavior have found a positive correlation between income and environmental consciousness (e.g., Anderson \& Cunningham, 1972; Kassarjian, 1971; Kinnear, Taylor, \& Ahmed 1974; Newell \& Green, 1997; Samdahl \& Robertson, 1989; Van Liere \& Dunlap, 1981). Newell and Green (1997) have examined the interaction effect of income and education on environmental issues. The results show that as income and education increased the sensitivity of consumers toward environmental issues increased. Income is generally thought to be positively related to pro-social attitudes. Several studies in consumer behavior have shown a positive relationship between income and purchasing green products (Laroche et al., 2001). Therefore, I expect individuals with higher household income to score higher on pro-social attitudes.

Empirical findings indicate a positive relationship between income and wealth, and the level of risk tolerance (Cohn et al., 1975; Grable \& Lytton, 1999; Riley \& Chow, 1992) Malkiel states "The risks you can afford to take depend on your total financial situation, 
including the types and sources of your income exclusive of investment income" (1973, p. 401). Mclnish et al. (1993) found a positive relationship between risk tolerance and both net worth and income, with wealthy investors holding a higher proportion of risky assets. Wealthier individuals had a greater willingness to invest in equities, whereas the poor were risk adverse (Bajtelsmit, 2006, Lusardi \& Mitchell, 2010). Extending these arguments to investor preferences, I expect wealthier individuals to be more risk tolerant and to invest with a longer time horizon.

Higher income households donate proportionately higher amounts than lower income households (Jones \& Posnett, 1991; Smith \& Beik, 1982). Several studies have shown that individuals who make more income and those who have more wealth will donate more to charity (Andreoni \& Miller, 2002). On the other hand, Feldman and Slemrod (2007) found that the relationship between income and likelihood of giving is not a linear relationship. The effect of income decreases at a higher income level. When James and Sharpe (2007) analyzed the national data set of 16,442 households, the results was a U-shaped curve relationship, with the highest share of giving among both poor and wealthy individuals, and a lower share of giving for the middle income.

I expect to find a positive relationship of income with pro-social attitudes, risk tolerance, time horizon, and estate intentions.

Education

A large number of studies have investigated the impact of education on environmental consciousness. The better-educated tend to score higher on all components of the environmental domain, probably reflecting the fact that "the very nature of ecology with its complex interactions between organisms and environment serves to make its subject matter difficult to understand and assimilate', (Maloney, Ward, \& Braucht, 1975, p. 585). This might be attributed to the fact that more educated people understand the issues involved in 
the environment more fully, and therefore are concerned about the environment's quality. The majority of the studies that examine the relationship between education and environmental issues find a positive association (Aaker \& Bagozzi, 1982; Leonard-Barton, 1981; Van Liere \& Dunlap, 1981). However, one study found a negative relationship between education and support for environmental issues (Samdahl \& Robertson, 1989), while Kinnear et al. (1974) found no significant relationship. Previous studies have found that higher educational level is positively related to pro-social attitudes (Nilsson, 2008). Therefore, I expect investors with a higher level of education to score higher on the pro-social attitude scale.

Education is a factor that impacts a person's ability to evaluate risk inherent in the investment process, especially among individuals with higher levels of education (Baker \& Haslem, 1974; Haliassos \& Bertaut, 1995; Sung \& Hanna, 1996). Educated people are more likely to understand the risk associated with investment, therefore have a higher financial risk tolerance.

Previous studies have shown that the higher educated are more likely to volunteer, to give blood and to engage in philanthropy, and also are more generous donors than the less educated (Putnam, 2001; Bekkers \& Schuyt, 2008; Brooks, 2004). Bekkers and Schuyt (2008) state that education promotes pro-social behavior for the following reasons: (1) higher education enhances human capital, (2) training in specific fields of education enhances communication skills, and (3) specialized training gives access to networks that promote prosocial behavior. Schervish and Havens (1997) found a positive relationship between higher levels of education and giving. Yen (2002) examined the role of education on religious giving, showing a positive correlation between education and religious giving for Protestants, but not for Catholics. However, Brooks (2004) found no relationship between education and charitable giving. 
I expect level of education to be positively correlated with pro-social attitudes, risk tolerance, time horizon, and placing more value on leaving a bequest.

Work Experience

Work experience may play a role in the level of risk an individual is willing to accept. According to Roszkowski et al. (1993), risk tolerance can be categorized into different levels based on different occupations. Leonard (1995) found that self-employed individuals, salespersons, and people employed by private firms (rather than government) tend to be more risk tolerant (both generally and in relation to personal finance issues). There also is a general consensus among researchers and practitioners that individuals employed professionally are more likely to have higher levels of risk tolerance than those employed in non-professional occupations (Grey \& Gordon, 1978; Haliassos \& Bertaut, 1995). This is consistent with the idea that work experience enables individuals to understand and accept risk. Accordingly, I expect individuals with more work experience to be more risk tolerant.

Several studies have shown that charitable giving is positively associated with employment (Feldman \& Slemrod, 2007; Lyons \& Nivison-Smith, 2006; Pharoah \& Tanner, 1997). Weerts \& Ronca (2007) examined the characteristics that distinguished inactive alumni from those who serve or volunteered at the colleges or universities from which they graduated. The results showed employment status was a critical factor. Also, the type of employment influences the individual willingness to donate. Several studies in the United Kingdom and Ireland have shown that those who are self-employed are less generous than full time employees (Banks \& Tanner, 1999; Pharoah \& Tanner, 1997). Bekkers (2004) examined the relationship between number of hours an individual worked and giving to charity. The results showed that employees who worked more hours donated more to charity. Individuals who worked for non-profit organizations were more likely to engage in philanthropic activities and other forms of helping behavior (Houston, 2006). 
Based on these observations, I expect work experience to be positively associated with pro-social attitudes, risk taking, time horizon, and placing value on leaving a bequest. Political Ideology

Ideology refers to the set of beliefs that are used to capture a person's values that shapes opinions and attitudes towards various aspects of social life, ranging from politics and economics to religion (Jost, 2006). Consistent with previous studies (Napier \& Jost, 2008; Jost, Nosek, \& Gosling, 2008) I will use just one dimension to identify political ideology (left-right or liberal-conservative). In the United States someone can have a conservative political ideology (typically represented by the Republican Party in U.S.) or a liberal political ideology (typically represented by the Democratic Party in U.S.) or be somewhere in between. On the broad ideology spectrum, "conservatives" are on the right, "liberals" are on the left, and "moderates" are in the middle.

Over the years scholars from many disciplines have examined the differences between liberals and conservatives. For example, in psychology, empirical findings have shown that liberals score higher than conservatives on several personality traits, including openness, cognitive flexibility, and integrative complexity (e.g., Sidanius, 1988; Tetlock, 1983, 1986; Tetlock, Bernzweig, \& Gallant, 1985). Conservatives tend to possess stronger personal needs for order, structure, closure, and decisiveness in comparison with liberals. Jost, Glaser, Kruglanski, and Sulloway (2003) conducted a meta-analysis to examine the psychological motives that contribute to conservatism. The findings confirm that several psychological variables predict political conservatism. Political conservatism in large part stems from the desire to reduce uncertainties and fear (Jost et. al., 2008; Van Hiel, Pandelaere, \& Duriez, 2004). Carney, Jost, Gosling, and Potter (2008) state that differences between these two ideologies might be related to different personal attributes that work as the main determinants and motivators for economic and financial behavior. 
The question of how political values affect investors' behavior should be an important issue in today's environment, even though Jost (2006) argues that for more than a generation social scientists have doubted that ideology is an important driving force in our life. In finance and other related disciplines several studies have examined the determinants of investor preferences, but without regard for ideology, and have produced mixed and ambiguous results (Barber \& Odean, 2001; Graham \& Kumar, 2006). In recent years a few scholars have started to pay more attention to the role ideology plays in investment. Kaustia and Torstila (2010) have found that political views affect the decision of individual investors on whether to participate in the stock market. Hutton, Jiang, and Kumar (2011) have found that Republican managers who follow conservative personal ideologies choose a more conservative corporate policy.

Standard finance theories assume that an investor's main concern is about the risk and return of the portfolio. However, Fama and French (2007) have argued that investors have different financial tastes just as they have different tastes for assets as consumption goods. These tastes could possibly be behind biases expressed in SRI. Consistent with these arguments, empirical findings, mainly from psychology and behavioral finance, show that personal attributes influence investor behavior. Carney et al. (2008) demonstrated differences between liberals and conservatives resulted from individual psychological needs and motives along two main dimensions: open mindedness vs. closed mindedness. Conservatives are less tolerant of ambiguity, uncertainty, and complexity (Wilson, 1973; Gillies \& Campbell, 1985; McAllister \& Anderson, 1991), and are more sensitive to the possibility of a loss (Wilson, 1973), while liberals are more willing to embrace change and seek novelty (Jost et al., 2003). Thus, personal ideology, associated with other personal attributes, can be an important determinant of various economic and financial decisions. 
Hong and Kostovetsky (2011) examined the influence of political values on fund managers. The results show fund managers identified as Democrats and who donated to the Democratic Party had a lower percentage in their portfolios of stocks not favored in SRI (guns, alcohol, and tobacco) and favored stocks with social value. In a following study, Hong and Kostovetsky (2011) also found significant differences between Democratic and Republican managers in their portfolio holdings of socially responsible companies. They found that mutual fund managers who made donations to Democrats held more of their portfolios (relative to Republican donors) in companies appearing more socially responsible. Bonaparte, Kumar, and Page (2010) found that individuals became more optimistic towards the financial market and perceived the market to be less risky and more undervalued when their own party was in power. They found when the opposite party was in power, investors made worse mutual fund decisions and picked funds with a higher expense ratio.

I expect that the personal political ideologies of the investors are likely to influence their financial and economic decisions. I argue that liberal investors are more likely to score higher on the pro-social attitude scale and to show more interest in social issues than conservative investors. One result of this is that liberal investors might derive utility from avoiding investing in companies that conflict with their ethical and personal values. In addition, investors with strong political values might believe that companies inconsistent with their values might face losses in the future.

Extant studies in psychology and political sciences have shown that ideological differences can affect attitudes toward risk and uncertainty. Individuals with a liberal ideology are likely to be more risk tolerant and to exhibit less cautious behavior than individuals with a conservative ideology. Hutton, Jiang, and Kumar (2011) have found that differences in personal ideology are likely to translate into heterogeneity in the level of financial behavior which, in turn, could affect attitudes toward debt, investment, and 
dividends. Using a risk tolerance measure that captures an individual's attitude toward risk, Kam and Simas (2010) found that Republicans had significantly lower levels of risk tolerance than Democrats. Chin and Parwada (2009) examined the impact of political preferences on money managers' portfolio decisions during the 2000 presidential election. The results show that money managers placed larger bets on stocks that were favored by the potential victory of their preferred candidate. This is consistent with behavioral consistency theory.

Cronqvist, Makhija, and Yonker (2012) applied the theory of behavioral consistency to corporate finance by studying the personal leverage of CEOs (as in their choice of mortgage for their primary residences) and the corporate leverage of the firms they manage. The results show that firms behave consistently with how their CEOs behave personally in the context of leverage choices. Chyz (2010) showed that managers who were aggressive in their personal income tax decisions also tended to avoid corporate taxes. Hutton, Jiang and Kumar (2011) examined whether the personal ideologies of managers, as captured by their political orientation, influenced corporate policy. The results show that Republican CEOs pursued more conservative corporate policies than Democratic CEOs. Republican managers had lower levels of corporate debt, lower expenditure capital, lower R\&D expenditures, and less risky investments, but higher levels of dividend payouts, retained earnings, and profitability.

Hong and Kostovetsky (2011) examined how the personal values of corporate managers and money managers influenced their professional decisions. The results showed that mutual fund managers with a Republican orientation invested more in industries less congruent with SRI values. (e.g., defense, guns, tobacco). Conversely, managers with Democratic backgrounds showed stronger preferences for socially responsible firms. Zalka et al. (1997) examined the effect of political ideology in the USA, Great Britain, and South Africa. The results showed that liberals were more sensitive to corporate social responsibility 
than conservatives. Mohai and Byrant (1998) found a positive effect of political liberalism on the perceived seriousness of environmental problems.

Linking these arguments to political ideology, I expect that liberal investors will score higher in pro-social attitudes, will be more risk tolerant, will invest with a longer time horizon, and will place more value on leaving a bequest. Conversely, I expect that conservative investors will be less risk tolerant, will invest with a shorter time horizon, and place less value on leaving a bequest.

The Background and Meaning of Positive Psychology

Positive psychology, a new emphasis in the discipline of psychology, dates from 1998 when Martin Seligman, President of the American Psychological Association (APA), called attention to this field of study (Luthans, Avolio, \& Walumbwa, 2005).

In his presidential speech to the APA, Seligman emphasized that the field of psychology needs to use scientific methods to study and discover the strengths that allow individuals, groups, and organizations to thrive and prosper (Seligman \& Csikszentmihalyi, 2000). Sheldon and King (2001) describe positive psychology as the scientific study of human strength and virtue, developed in reaction to an imbalance in the focus of clinical research. While clinical research in psychology focused on studying what was wrong with individuals, families, groups, and institutions, little time was spent studying the positives. Not enough time or attention was spent on what was right with people, or the positive aspects in their lives (e.g., joy, happiness, and hope). This emphasis and focus on bad over good, weak over strong, has commonly been justified in the field of psychology in the following ways: 1) People who suffer should be given priority, 2) After World War II, psychology's main focus became centered on distress and diseases, and 3) This focus was the main interest of the founders of the field. In an extensive review of literature, Baumeister, Bratslavsky, Finkenauer, and Vohs (2001) found that bad is stronger than good, as a general principle, 
across a broad range of psychological phenomena. Negative events create more of an impact than positive events. Information about bad things is processed more thoroughly than information about good things.

The aim of positive psychology is to complement traditional psychology rather than to replace it. The main assumption of positive psychology is that since goodness and excellence are real phenomena, they can be analyzed and archived like any of the other states in psychology. Positive psychology focuses on the following three main points: 1) positive experiences such as happiness, pleasure, joy and fulfillment, 2) positive individual traits such as character, talents, and interests, and 3) positive institutions such as families, schools, business communities, and societies (Lopez \& Snyder, 2003; Seligman, 2002). The positive psychology movement grew very fast from its beginnings (Seligman \& Csikszentmihalyi, 2000). This is clear from the many books and articles that were published in the following decade (Lopez \& Snyder, 2003; Park, Peterson \& Seligman, 2004; Schmuck \& Sheldon, 2001; Snyder et al., 2010), in addition to dozens of conferences during this same period including researchers from all over the world and from several different academic disciplines.

As mentioned above, positive psychology is not a revolution against what already exists, but rather an attempt to clarify and understand human positives and strengths in the same way that we understand human ills and weaknesses. By emphasizing the positive dimensions of psychology, both academicians and practitioners can have a more balanced view over the full spectrum of life experience. Sheldon, Frederickson, Rathunde, Csikszentmihalyi, and Haidt (2000) define positive psychology as the scientific study of optimal human functioning. It aims to discover and promote factors that allow individuals, communities, and societies to thrive and flourish. Research on positive psychology covers a broad range of topics from different disciplines and at different levels. Some of the topics covered in positive psychology research are attachment, optimism, hope, love, emotional 
intelligence, intrinsic motivation, and gratitude. Early motivation theories can best be described as positively oriented (e.g., Herzberg, 1966; Maslow, 1954; McGregor, 1967), as are some contemporary theories and research on topics such as job satisfaction, organizational commitment, positive affectivity, core self-evaluations, organizational citizenship, humor, self-determination, and organizational justice (Luthans et al., 2007).

Many scholars have extended the seminal work of positive psychology disciplines. In the field of organizational behavior, Luthans (2002) has built upon positive psychology theories in the work place, calling this focus Positive Organizational Behavior (POB). POB focuses on positive individual states such as hope, optimism, resiliency, and self-efficacy. Several studies have examined the effect of optimism (Seligman, 1998) or hope on performance (Peterson and Luthans, 2003), while others have focused on overall psychological states such as resiliency (Luthans et al., 2007). At the same time, a parallel development by a group of researchers at the University of Michigan has started to add to the positive psychology movement at an organizational level, calling this approach Positive Organizational Scholarship (POS) (Cameron, 2003). Like positive psychology, POS does not aim to replace existing research, but instead to focus more on the positive phenomena within organizations such as positive deviance, extraordinary performance, positive spirals, and flourishing.

To date, there has been no study based on positive psychology regarding pro-social attitudes and investor preferences. Thus, this is an exploratory study of the impact of positive psychology on pro-social attitudes and investor preferences. Based on the review of the literature, the chosen psychological states for this study are hope, optimism, and resiliency. This study uses these states within the core construct of positive psychology to explore whether they are related to pro-social attitudes and investor preferences. Considerable prior research has demonstrated each of these positive psychological constructs to be conceptually 
independent with discriminant valid measures (Bryant \& Cvengros, 2004; Luthans \& Jensen, 2002; Magaletta \& Oliver, 1999; Snyder, 2000; Snyder, Rand, King, Feldman, \& Woodword, 2002). It is important to note that these constructs are generally seem as psychological states, not psychological traits. Psychological states involve behavior that any individual can acquire through learning and experience. On the other hand, psychological traits cannot be acquired, since they are something the individual either has or does not have. However, an argument could be made for a genetic basis for positive psychology traits. The argument could also be made that positive psychology depends on circumstances. The same individuals may exhibit positive psychology traits when they are healthy and prosperous and exhibit negative traits when they are unhealthy and poor. However, the dominant perspective appears to be the one asserting that positive psychology attributes can be learned and changed, hence are more like attitudes than like demographic variables.

Optimism

In positive psychology, most of the work conducted on optimism as a psychological state was based on the work of Seligman. Seligman (1998) defined optimism as an attributional style that explains positive events in terms of personal, permanent, and pervasive causes and negative events in terms of external, temporary, and situation-specific ones. Bailey, Eng, Frisch, \& Snyder (2007) state that the concept of optimism has been part of Western thought for more than 200 years. In the last three decades, optimism has generated new areas of research in clinical psychology as well as in social and personality studies. Chang, Maydeu-Olivares, \& D'Zurilla (1997) have argued that the research in this area suffers from the problem of finding a widely accepted definition for optimism. According to Seligman, optimism has two dimensions: temporal permanence and scope of pervasiveness. Permanence regards time. When a bad event occurs, the optimist will see it only as a temporary situation, whereas a pessimist will view it as permanent. Pervasiveness is about 
space. People who make specific explanations about bad events are optimistic, while people who make universal explanations about bad events are pessimistic. On the other hand, pessimism does the opposite. It leads individuals to attribute positive events to temporary events and situation specific causes. Conversely, positive individuals internalize negative events and attribute them to permanent and pervasive causes. According to Schneider (2001), optimism is amenable to development through a three-step process, including leniency for the past, appreciation for the present, and opportunity for the future. A review of psychology literature shows that the subject of optimism has attracted the attention of many scholars. Optimism is considered a positive emotion, while emotions such as fear, anger, and sadness are considered negative emotions. Previous studies regarding emotions have shown that emotion can be used as a source of information even if the emotions are produced by unrelated events (Forgas, 1995; Lerner, Small, \& Loewenstein, 2004; Schwarz \& Clore, 1996).

Several studies in psychology (Direnfeld \& Roberts, 2006; Johnson \& Tversky, 1983) have shown that positive emotions trigger recall of positive information and optimistic assessments, while negative emotions trigger recall of negative information and pessimistic assessments. Positive emotions can play a role in leading individuals to make more positive evaluations of a situation (Carver, 2003; Isen \& Shalker, 1982) and to take more risks (Leith \& Baumeister, 1996). Schwarz and Clore $(1983,2003)$ argue that our emotions provide information about the world around us. Positive emotions signal that things are going well and that the environment is safe. These conditions may encourage individuals to try novel things. Fredrickson states that " broaden-and-build theory posits that experience of positive emotions broaden people's momentary thought-action repertoires, which in turn serves to build their enduring personal resources, ranging from physical and intellectual resources to 
social and psychological resources" ( 2001, p. 218). Accordingly, positive emotions are essential for human strength and flourishing.

In management, organizational behavior studies have shown a positive relationship between optimism and performance at the workplace (Luthans et al., 2005). Optimism has also been found to predict higher performance in sales, leadership, and facets of business (Chemers, Hu, \& Garcia, 2000; Wunderley, Reddy, \& Dember, 1998). Totterdell, Wood, and Wall (2006) found optimism to be a key moderating factor in the relationship between job characteristics and job strain. Their study indicated that production workers with higher levels of optimism were endowed with added protection against symptoms of stress in the workplace. Leung, Moneta, and McBrice (2005) found that optimism was a key contributor to subjective well-being because it fosters self-esteem, relationship harmony, and positive perceptions of financial conditions. In entrepreneurship, optimism has been linked to psychological well-being and coping behaviors. For example, Kuratko (2005) found optimism to be a key factor for determining success in entrepreneurship. Optimism has also been linked to risk preferences. Petrakis found that "Entrepreneurs with high levels of optimism usually form high expectation about their actions and they are connected with high risk perception" (2005, p. 233). I argue that optimistic investors have a high level of expectations regarding their investments. They expect their investments in firms to meet their expectations about making changes in the environment and at the same time give them higher returns or at least returns that are similar to the standard benchmark. They believe they are able to control their activities and that those activities will give them more satisfaction. Furthermore, they expect their activities will initiate change. For example, they believe that boycotting irresponsible firms will promote pressure on these firms to change their behaviors and adopt more favorable, progressive corporate practices in regard to corporate governance, employment, and community development (Gardberg \& Newburry, 2010). Consequently, we 
anticipate that investors experiencing positive emotions will score higher on pro-social attitudes and focus on the positive aspects of investing, e.g., be more risk tolerant, more focused on the long-term, and more inclined to value leaving a bequest.

Hope

In positive psychology hope is defined as "a positive motivational state that is based on an interactively derived sense of successful (1) agency (goal-directed energy) and (2) pathways (planning to meet goals)" (Snyder et al., 1991). Hope has two main components: hope's agency or "willpower" component provides the determination to achieve goals, whereas its pathways or "waypower" component promotes the creation of alternative paths to replace those that may have been blocked in the process of pursuing those goals. Hope becomes an enduring psychological state when a person attributes permanent and universal causes to good events and attributes temporary and specific causes to bad events (Seligman, 2002).

As with other constructs examined in this study, the relationship between hope and investor preferences has received little or no attention in prior research. However, evidence from research on other dependent variables such as employee performance shows that hope might provide an employee with positive resources to deal with stress (Folkman \& Moskowitz, 2000). Furthermore, studies show that hope is positively correlated with job commitment and job satisfaction (Luthans \& Jensen, 2002; Youssef \& Luthans, 2007). Peterson and Luthans (2003) found a positive relationship between hope and performance, and hope and employee satisfaction. Hope has been related to performance in various behavioral domains as well. Previous studies have shown that hope is positively associated with better performance at the work place (Adams et al., 2003; Curry, Snyder, Cook, Ruby, \& Rehm, 1997; Luthans, Avolio, Walumbwa, \& Li, 2005; Luthans \& Jensen, 2002; Luthans, Van Wyk, \& Walumbwa, 2004; Peterson \& Luthans, 2003; Youssef \& Luthans, 2007). 
Furthermore, hope has also been found to be associated with better athletic performance (Curry et al., 1997). Even in medicine, studies show that people with higher levels of hope have been found to be more inclined than people of lower levels of hope to practice disease prevention (Floyd \& McDermott, 1998). Previous studies have shown that those who are hopeful are likely to be motivated and more confident and are likely to have alternative pathways when obstacles occur (Adams et al., 2003; Luthans \& Jensen, 2002; Peterson \& Luthans, 2003).

Luthans and Jensen (2002) examined the relationship between hope and environmental uncertainty. They argue that employees with high hope are especially needed in today's turbulent environment. They suggest that that developing hope in employees of an organization facing an uncertain environment will make them more effective performers. In a longitudinal study of 308 white collar employees, Andersson, Giacalone, and Jurkiewicz (2007) found that employees with stronger hope and gratitude had a greater sense of responsibility toward employee and societal issues. Envick (2004) extended the use of positive psychology into entrepreneurship studies. He argued that the entrepreneur who is likely to be more successful will have the energy to achieve business goals (willpower), as well as the ability to identify different avenues to reach those goals (waypower). Any loss of hope that results from decreasing willpower or waypower will have a negative effect for the entire business.

If I apply this argument to investment preferences, I can say that any loss of hope will increase fear of losing the investment or having its value diminished. Furthermore, I expect investors with high hope to score high on pro-social attitudes because they intend to invest in firms that meet their moral philosophy and ethical principles, while at the same time maximizing their returns, or, at least, earning financial returns equal to the standard benchmark. Investors who score high on pro-social attitudes may anticipate that boycotting 
irresponsible firms might affect the firm's employee morale, public image, and consumer response, which might affect stock price, and, consequently, require firms to adopt more responsible corporate practices in regard to corporate governance, employment, and community development. The argument is similar to the one developed for optimism. Therefore, I expect that investors high in hope will score high on pro-social attitudes, be more risk tolerant, have a longer time horizon, and place higher value on leaving a bequest. Resiliency

Luthans defines resiliency as "the capacity to rebound or bounce back from adversity, conflict, failure, or even positive events, progress, and increased responsibility” (2002, p. 702). Masten (2001) was among the first who studied resiliency in a clinical setting. Interested in child psychology, he focused on children who flourished after being exposed to extremely adverse conditions. The findings show that children exhibit recovery unless major protective systems for human development are destroyed or damaged. While acknowledging that adversity must be present in order for resiliency to be developed, these researchers also posit that resiliency can promote a productive response. Several times in their life ordinary individuals will be faced with situations where they develop new capabilities through learning and training. Resiliency is a learnable capacity that can be developed over time (Masten, 2001). Researchers consider resiliency a common adaptational response to adverse events (Bonanno, 2004; Masten, 2001) and applicable to the positive development of individuals in organizational settings (Luthans, Vogelgesang, \& Lester, 2006). Resiliency allows adversities and setbacks to be viewed as opportunities for learning, growth, and development. Resiliency engages creative and flexible adaptive mechanisms, guided by ethical values and strong belief systems, toward the achievement of personally and organizationally meaningful goals. Block and Kremen (1996), Coutu, (2002), and Masten (2001) suggest that highly resilient individuals tend to be more effective in a variety of life 
experiences, including adjustment and development under a variety of life-course threatening conditions. Entrepreneurship studies have shown that resilience is a psychological state shared by successful entrepreneurs (Timmons \& Spinelli, 2007). Timmons and Spinelli (2007) state that entrepreneurs respond to change and learn from their mistakes. They do not blame others for their mistakes, but rather use failure as a lesson.

Although resiliency has been recognized in the positive psychology movement, it has been given limited attention in management studies (Hamel \& Välikangas, 2003; Reivich \& Shatte, 2002). However, scholars from management, especially from the organization behavior discipline, have started to pay more attention to resiliency. Luthans et al. (2007) found resiliency, in conjunction with other individual psychological constructs such as hope, optimism, and self-efficacy, may promote attitudes that lead to positive organizational change. Resiliency has been found to be positively related to several desirable attitudinal outcomes such as accomplishment, job satisfaction and organizational commitment (Luthans et al., 2007). Luthans et al. (2007) have examined the effect of resiliency on employee satisfaction in China. They found that by developing resiliency in conjunction with hope and optimism, Chinese employees may overcome the stress and uncertainty they face as their societal changes. Furthermore, the relationship between positive psychology and desirable attitudinal outcomes such as job satisfaction and organizational commitment has been empirically supported (Luthans et al., 2007). I expect that investors high in resilience will score higher in pro-social attitudes, will be more risk tolerant, will have a longer time horizon, and will place higher value on leaving a bequest.

Pro-social Attitudes and Investor Preferences

In consumer behavior the term "pro-social attitudes" refers to consumer attitudes towards socially positioned products such as green products (Cowe \& Williams, 2001; Mayo, 2005; Nilsson, 2008). Extending this argument to investment in mutual funds, Nilsson (2008) 
has argued that pro-social attitudes are related to the investor's concern for social issues. Studies examining the effect of social attitudes on investor behavior have been limited to SRI, finding a small but fairly consistent positive relationship between pro-social attitudes and SRI. On the other hand, Lydenberg (2007) argues that differences between conventional investors and socially responsible investors are diminishing, because both are motivated by similar values.

In the last two decades, consumers, mainly in Western countries, have started to show more concern about ecological and social issues. This concern is not limited to a particular group of people such as liberal consumers, but extends to the whole population. For example, Peattie (1995) has found that $90 \%$ of the populations in Western countries are generally concerned about the environmental issue and 50\% are concerned about ethical and corporate issues. Scholars who examine individual behaviors in psychology, sociology, and economics have started to pay more attention to moral motives in addition to economic motives (Etzioni, 1988).

Despite the importance of social concern in Western countries, little research has been done on its relationship to investor behavior or preferences. This study aims to explain variations in investor preferences through a mindset called pro-social attitudes. I anticipate that pro-social attitudes will be positively correlated with investor preferences. Previous research examining the determinants of investor behavior in general is very limited. However, some studies have examined the influence of socio -demographic variables on investor behavior (Getzner \& Grabner-Krauter, 2004; McLachlan \& Gardner, 2004; Rosen et al., 1991). In marketing and consumer behavior socio-demographic variables have been used in many studies (Anderson \& Cunningham, 1972), after examining the attitudes and behaviors of green consumers (Laroche et al., 2001; Manaktola \& Jauhari, 2007; Berger \& Corbin, 1992; Creyer, 1997; Shaw \& Clarke, 1999). Therefore, in this study I will look to the 
literature in consumer behavior and marketing to build a new model of investor preferences that incorporates attitudinal and psychological variables. I argue that pro-social attitudes moderate the relationship between the independent variables and investor preferences. There is broad consensus that the benefit of social investment accrues in the long run rather than the short run. I anticipate that investors who score high in pro-social attitudes will be more risk tolerant, will invest with a longer time horizon, and will place more value on leaving a bequest. 


\section{CHAPTER III}

\section{RESEARCH DESIGN AND METHODOLOGY}

Chapter 3 describes the methodological framework for the study design, measurement, and analysis process. The first section describes the basic study design and research strategy. The second section examines the specific measures for each of the dissertation constructs. Then I detail the sampling and data collection techniques used in the study, as well as the empirical methods used to evaluate the study data. Finally, a summary concludes the chapter.

Research Design

The primary purpose of this study is to develop a comprehensive model for investor preferences. The model considers the impact of socio-demographic, psychological, and attitudinal variables on investor preferences. Previous studies have focused mainly on how socio-demographic variables are related either to risk tolerance or to time horizon. To my knowledge, there is no study to date that considers the value investors place on leaving a bequest, which is included in this study.

Ex-post facto design was used in this study. According to Kerlinger and Lee (2000), "Ex post facto is systematic empirical inquiry in which the scientist does not have direct control of independent variables because their manifestations have already occurred. Inferences about relations among variables are made, without direct intervention, from concomitant variation of independent and dependent variables" (p. 379).

Another distinction that is made about ex post facto research is that it contains an attribute or assigned variable which can only demonstrate relationships, not causation. Concerning research design, Newman, Newman, Brown, and McNeely (2006) state that true experimental design, and only true experimental design, can demonstrate causation. Therefore, no causal statement can be made about ex facto research. 
The three major weaknesses in conducting a study using ex post facto research are:

1. the inability to manipulate independent variables

2. the lack of power to randomize, and

3. the risk of importer interpretation which is due to lack of control (Kerlinger \& Lee 2000, p. 390).

Data Collection

Data were collected from a sample of MBA students and seniors in the undergraduate business program at a major university in South Florida. The survey was distributed to 450 students in several classes during the period January 15, 2010 to April 10, 2011. Student samples in social sciences have been used extensively as a surrogate for business people (Dubinsky \& Rudelius, 1980). I used both graduating seniors and MBA students for several reasons. First, MBA students are commonly used as a proxy for business people and have been found in prior research to share a high degree of congruence with business professionals (Dubinsky \& Rudelius, 1980). Second, many of the participants in this study, both undergraduate and MBA students, had work experience (either full time or part time). In addition, use of both undergraduate and MBA students allowed the use of education as a variable. According to Ferber (1977), using students as a proxy for business people is appropriate if the study is exploratory and if items are related to respondents. This study meets these two criteria. In management studies Beekun and Badawi (2005) used MBA students as surrogates for business people to explore the relationship between moral philosophies and behavioral intentions. In consumer behavior studies, the use of student samples in research has been extensive. Enis, Cox, and Stafford (1972) reported that over half of the consumer-behavior studies used student subjects. Cunningham, Anderson, and Murphy (1974) reviewed a wide variety of business journals and reported that between $20 \%$ and $33 \%$ of the consumer-research findings used student subjects, and over $75 \%$ of these were 
convenience samples. Furthermore, the subjects for these studies generally were selected from business schools, giving added validity, because those who are business students today are expected to be the future managers. Furthermore, in this study, using a relatively large sample of 450 subjects should minimize sampling error and increase the reliability of the study. However, I recognize that the use of a student sample may limit the generalizabilty of this study. Accordingly, I recommend that future studies include real investors.

Survey Response Rate

All students in the selected classes were asked to participate in the study ( $\mathrm{N}=460)$. Before I distributed the survey I clearly identified to each class the importance of the study for both academicians and practitioners. However, examination of the detailed data revealed that ten surveys were not appropriate for further analysis because some pages were left without any responses to survey questions. Removing these cases resulted in a total of 450 usable surveys, which represented a $98 \%$ response rate. I assured the participants of their anonymity and that the findings of the study would be available for them, and did provide the classes with preliminary findings.

Characteristics of the Sample

Respondents were asked to provide information related to gender, age, education, work experience, and investment experience. The sample was almost equally divided between males and females. Slightly more than half of the surveys $(53.3 \%)$ were received from males, and $46.7 \%$ were received from females. Twenty- three of the respondents were under the age of 20 (5.1\%), 312 were between 20 and 25 (68.6\%), 84 were between 26 and $30(18.4 \%)$, fourteen were between 31 and $35((3.1 \%)$ and 21 respondents were over the age of 35 (4.6\%). Respondents reporting holdings in stock portfolios, retirement accounts, or mutual funds were categorized as having investment experience, while those reporting no such holdings were categorized as not having investment experience. The sample was almost 
evenly divided between those with and without investment experience. Most respondents were studying for the bachelor's degree $(75.9 \%)$, with the others in the MBA program (22.9\%). To assess work experience, respondents were categorized as either having no work experience, having part-time or internship experience, or having full- time work experience. Data Analysis Techniques

In this study I analyzed the data using SPSS version 18. First, I screened the data to check for missing data and outliers. As indicated in the discussion of the sample, ten cases were removed from the data set because they were not eligible for further analysis. Screening the data showed no outliers.

Factor Analysis

Regarding the composite measures in this study, exploratory factor analysis was used to reduce a set of 42 attitudinal variables. Since all scales but estate intentions have a good estimate of validity by several studies, I decided to do factor analysis separately for each scale. Different opinions concerning what constitutes a high loading are found in the literature (Gardner, 2001). Here, the rotated factor loading of 0.5 was chosen as a threshold. The results of the factor analysis showed that not all variables loaded onto their expected factors. The items of the optimism scale loaded on four factors, with none of them loading above the .5 threshold. Accordingly, I decided to delete this factor. Also, the items of the resiliency scales loaded on three factors. The items of one factor had loadings above the threshold point 0.5 . I considered this factor in the analysis, calling it "openness". The factors from principal component analysis, and the eigenvalue of each factor are shown in Table 1. I omitted loadings with values below 0.5 .

Table 1 shows that each resulting factor had a Cronbach alpha $>0.60$, indicating reasonable reliability among items within each factor. Kaiser's criterion and scree plot were selected as technical criteria to determine the number of factors. The Kaiser's criterion 
(eigenvalue greater than 1) was chosen here as the minimum requirement. Additionally, the scree test (Bryman \& Cramer, 2005), which plots the eigenvalues against the number of components, was used. Table 1 gives an overview of the six factors with their items.

The reason I have chosen the varimax method of rotation is because it maximizes the sum of variance of squared loading in the columns of the factor matrix. Nunnally and Bernstein (1994) state "this method tends to produce some factor loadings that are either high or near zero" (p. 332). It is easier to interpret a factor when its loading is either very high or near zero.

\section{Multiple Linear Regression}

I used several statistical techniques such as descriptive, inferential, and correlation statistics. There are several reasons for using multiple linear regression (MLR). First, MLR is flexible and can be used to calculate other statistical procedures such as t-test, F-test, etc. Furthermore, while correlation analysis examines the strength of the relationship between two variables, with MLR I can examine the relationship between several independent variables and the dependent variable. Since more factors are added to the model to explain the variance in the criterion variable, using MLR can help to generate an R square coefficient that allows the research to test if it accounted for a significant amount of variance in predicting criterion variable. McNeil, Newman and Kelly (2011) point out that multiple linear regression can test relationships between categorical variables, between categorical and continuous variables, or between continuous variables. All analyses were conducted using a $0.05 \alpha$ level. A power analysis (Cohen, 1988) was done for an $\mathrm{N}=450, \alpha=.05$, and for a medium size effect (.15) with 7 variables, power $=.99$. For a small size effect $(.020) \mathrm{N}=450, \alpha=.05$ power $=.6$ 


\section{Correlation}

Correlation is a bivariate measure of association (strength) of the relationship between two variables. It varies from 0 (random relationship) to 1 (perfect linear relationship) or -1 (perfect negative linear relationship). The Pearson correlation procedure is appropriate for this study because it helps to determine if, and to what extent, a relationship exists between two variables. The present study involved a search for significance in relationships and involved describing the relationships between variables. Although correlation does not measure cause, the Pearson correlation procedure has been used by several scholars in different disciplines (e.g., Chin-Loy \& Mujtaba, 2007). All analyses were two sided at a 5\% alpha level.

Reliability

If a measurement is reliable, it should be stable enough to provide consistent results with repeated measurements with the same person and same instrument (Cooper \& Schindler, 2006). In order to assess reliability, Cronbach's alpha test was used to determine the degree of consistency amongst the multiple measurements of each factor. Cronbach's alpha measures the inter-item reliability of a scale generated from a number of items. It indicates the extent to which the items are answered in a similar fashion by any respondents and ranges from 0 to 1 . A value higher than 0.6 is considered acceptable in exploratory studies, 0.7 is considered adequate for exploratory purposes, and 0.8 is considered good for confirmatory purposes. Although .7 is typically used as a standard cutoff point (Nunnully \& Bernstein 1994), the higher the coefficient, the more reliable the measure. Another way to consider reliability is to check how well the items of the scale align with the theoretical argument. The results of factor analysis showed that the variables did load onto their expected factors. Accordingly, I can say previous research provides reliable and valid instruments for all of the attitude measures except estate intentions, for which a new scale was developed. 


\section{Content Validity}

According to Leedy and Ormrod, "The validity of a measurement instrument is the extent to which the instrument measures what it is supposed to measure" $(2005$, p. 28). One way of studying content validity is to see how well the items of the scale align with the theoretical literature. In this study the factors loaded as expected based on theory except for optimism and resiliency. In addition, I asked five experts to indicate whether they agreed or not that each items was appropriately matched to the content area. The experts agreed $100 \%$ with the contents of the scales. Finally, the literature review provides a support for the content validity of a measure. All scales except estate intentions were used in previous studies. Nilsson $(2008,2009)$ used the pro-social attitudes scale to examine the impact of prosocial attitudes on financial performance. Wood and Zaichkowsky (2004) used the time horizon scale and risk tolerance scale to characterize segments of individual investors based on their shared investing attitudes and behavior. Luthans et al. (2007) used the hope scale to examine the effect of positive organizational behavior in several contexts. The items in the reconfiguration of the resiliency scale loaded at a satisfactory level, as did the three items of the estate intentions scale. 
Table 1

Factors from Principal Component Analysis with Varimax Rotation

\begin{tabular}{|c|c|c|}
\hline & $\begin{array}{l}\text { Factor } \\
\text { Loadings }\end{array}$ & Eigenvalue \\
\hline \multicolumn{3}{|l|}{ Risk tolerance } \\
\hline $\begin{array}{l}\text { I am prepared to take greater risks (possibility of initial losses) in } \\
\text { order to earn greater future returns. }\end{array}$ & .838 & 2.63 \\
\hline $\begin{array}{l}\text { I feel more comfortable taking risks (possibility of initial losses) } \\
\text { when my investment are performing well. }\end{array}$ & .837 & \\
\hline \multicolumn{3}{|l|}{ Time Horizon } \\
\hline Fluctuations in the stock market DO NOT concern me. & .843 & 1.45 \\
\hline $\begin{array}{l}\text { The constant media reporting of stock market fluctuations does } \\
\text { NOT bother me. }\end{array}$ & .832 & \\
\hline Estate Intentions & & 1.60 \\
\hline Leaving an inheritance to my heirs is an important goal. & 0.57 & \\
\hline $\begin{array}{l}\text { Leaving an inheritance to my religious organization is an important } \\
\text { goal. }\end{array}$ & .607 & \\
\hline $\begin{array}{l}\text { Leaving an inheritance to charitable and philanthropic organizations } \\
\text { is an important goal. }\end{array}$ & .669 & \\
\hline \multicolumn{3}{|l|}{ Hope } \\
\hline $\begin{array}{l}\text { If I should find myself in a jam, I could think of many ways to get } \\
\text { out of it. }\end{array}$ & .55 & 2.764 \\
\hline At the present time, I am energetically pursuing my goals. & .73 & \\
\hline There are lots of ways around any problem that I am facing now. & .53 & \\
\hline Right now I see myself as being pretty successful. & .71 & \\
\hline I can think of many ways to reach my current goals. & .76 & \\
\hline At this time, I am meeting the goals that I have set for myself. & .73 & \\
\hline \multicolumn{3}{|l|}{ Openness } \\
\hline I enjoy dealing with new and unusual situations. & .61 & 4.26 \\
\hline I am regarded as a very energetic person. & .64 & \\
\hline I like to take different paths to familiar places. & .51 & \\
\hline I usually succeed in making a favorable impression on people. & .63 & \\
\hline I like to do new and difficult things. & .63 & \\
\hline I would be willing to describe myself as a pretty strong personality. & .57 & \\
\hline I'm always optimistic about my future. & .57 & \\
\hline \multicolumn{3}{|l|}{ Pro-social Attitudes } \\
\hline $\begin{array}{l}\text { Respect workplace rights (i.e. possibility to freely join trade } \\
\text { unions). }\end{array}$ & .79 & 2.73 \\
\hline $\begin{array}{l}\text { Work actively with environmental issues (i.e. by reducing } \\
\text { environmental effect of products and production). }\end{array}$ & .79 & \\
\hline $\begin{array}{l}\text { Respect human rights (work against discrimination based on race, } \\
\text { gender, or religion). }\end{array}$ & .88 & \\
\hline Do not use unethical business practices (i.e. bribery). & .82 & \\
\hline
\end{tabular}

Study Variables and Development of Measures

The instrument used in this study was developed mainly by adapting different subscales from previous studies in several disciplines. The respondents were asked to give their degree of agreement and disagreement along a five-point Likert-type scale with one as the lowest degree of agreement and five as the highest degree of agreement. Each construct 
except ideology was measured using multiple items, since this improves the reliability of the measurement. The main variables included in the questionnaire were socio-demographic variables, positive psychology attitudes, political ideology, pro-social attitudes, risk tolerance, time horizon, and estate intentions. A copy of the survey instrument is included in Appendix 1.

Positive Psychology

Positive psychology is defined as the scientific study of human strength and virtue (Sheldon \& King, 2001). Many aspects of positive psychology have been studied in the literature, including positive emotion, gratitude, hope, optimism, resiliency, and flourishing. The three resource capacities I believed would contribute to investor preferences were hope, optimism, and resiliency. I anticipated these capacities would be associated with greater risk tolerance, longer time horizon, and placing higher value on leaving a bequest. Because positive psychology is much more comprehensive than these capacities, the particular dimensions used here should not be considered as the only categorizations that constitute positive psychology.

Hope

Snyder, Irving, and Anderson define hope as "a positive motivational state that is based on an interactively derived sense of successful (1) agency (goal-directed energy) and (2) pathways (planning to meet goals)" (1991, p. 287). Hope capitalizes on an individual's self-initiated, goal-directed motivations and behaviors. The construct "Hope" was measured using a scale adapted from Snyder et al. (1997), an eight-item Likert-type scale called the State Hope Scale. Examples of scale items include "At the present time, I am energetically pursuing my goals" (agency) and "If I should find myself in a jam, I could think of many ways to get out of it" (pathways). Synder et al. (1997) reports that the Cronbach's alpha for this scale is .87 , indicating good reliability according to Nunnally and Bernstein (1994). Since 
the original scale was developed for children, I dropped a few items from the scale, reducing it from eight to five items. Respondents were asked to agree or disagree with each statement on a five item Likert-type scale with choices ranging from "strongly disagree" to "strongly agree."

Optimism

Most often associated with the work of Martin Seligman, the recognized pioneer of the positive psychology movement, optimism is defined as an "attributional style that explains positive events through personal, permanent, and pervasive causes and negative events through external, temporary, and situation-specific ones" (Seligman, 1998).

To measure optimism I used the scale originally developed by Scheier and Carver (1992) then modified by Shifren and Hooker (1995) to reflect the state-like nature of optimism. Examples of the items used in the twelve-item Likert-type scale include "In uncertain times, I usually expect the best" and "If something can go wrong for me, it will" (reverse scored). The Cronbach's alpha reported by Luthan et al. (2005) for this scale is .79 indicating good reliability according to Nunnally and Bernstein (1994). Respondents were asked to rate on a five- point scale the extent to which they agreed or disagreed with the given statement. Choices ranged from "strongly disagree" to "strongly agree" on a Likert-type scale.

Resiliency

Luthans defined resiliency as "the capacity to rebound or bounce back from adversity, conflict, failure, or even positive events, progress, and increased responsibility" (2002, p. 702). Resiliency was measured by Block and Kremen's (1996) fourteen-item, fourpoint Likert-type Ego-Resiliency Scale. In order to be consistent with other scales I used in this study, I used a five- point Likert-type scale to measure resiliency. The Cronbach's alpha reported by Luthans et al. (2005) for this scale is .79 indicating a good reliability according to 
Nunnally and Bernstein (1994). An example of the items included in the scale is "I enjoy dealing with new and unusual situations." Respondents were asked to rate the extent to which they agreed or disagreed with the given statement, with choices ranging from "strongly disagree" to "strongly agree."

Political Ideology

Ideology refers to the set of beliefs used to capture a person's values that shapes opinions and attitudes towards various aspects of social life, ranging from politics and economics to religion (Converse, 1964; Jost, 2006). Erikson and Tedin have suggested another perspective defining political ideology as a "set of beliefs about the proper order of society and how it can be achieved" (2003, p. 64). Ideology was measured by asking respondents to indicate their ideological orientation on a five-point Likert-type scale ranging from 1 (extremely conservative) to 5 (extremely liberal).

Socio-demographics of Survey Respondents

I examined six socio-demographic variables (age, gender, income level, education, work experience, and investment experience). Previous studies have shown there is correlation between some socio-demographic variables such as age, experience, and education, and some dimensions of investor preferences (e.g., risk tolerance, time horizon). I also anticipated that prior investment experience of individuals might affect their investment preference. Therefore, the respondents were asked to indicate the kind and amount of investments they had. The following discussion explains the rationale behind choosing these socio-demographic variables and how they were operationalized and coded.

Gender

Gender data were requested in the socio-demographic section of the survey instrument and responses were coded either male (1) or female (2). Of the responses I received, 445 contained gender information. The results showed that 243 surveys were 
completed by males (53\%) and 212 surveys completed by females (47\%). As a first step, frequency distributions for gender were obtained and are shown in Chapter 4, Table 4. Age

The second socio-demographic variable considered in this study was age. All 450 subjects provided their age. Data were requested in the socio-demographic section of the survey instrument and responses were coded into five categories: 1) less than 20 years, 2) 20 to 25 years, 3) 26 to 30 years 4) 31 to 35 years, and 5) over 35 . There were 23 participants under 20 years (5.1\%), $313(68 \%)$ between 20 and 25 years, $84(18.5 \%)$ between 31 and 35 years, and 21 (4.6\%) participants older than 35. As a first step, frequency distributions for age groups were obtained and are shown in Chapter 4, Table 5.

Education

The third socio-demographic factor measured was education. Data regarding the level of education were requested in the socio-demographic section of the survey instrument and responses were coded into two categories: 1) undergraduate students, and 2) MBA students. All the 450 completed surveys contained education data for the respondents. There were 348 (77.4\%) working for the bachelor's degree and $102(22.6 \%)$ in the MBA program. As a first step, frequency distributions for education were obtained and are shown for each category in Chapter 4, Table 6.

Household Income

Household income, a continuous variable, was included as an independent variable because, according to MacCrimmon and Wehrung (1990), upper income persons tend to take higher risks than those with lower incomes. Increased levels of income often lead to increased levels of risk tolerance (O'Neill, 1996), because the consequences of investment losses impact high income earners less than low income earners. I also expected a higher level of income would be positively correlated with investment with a longer time horizon 
because higher income persons are not in urgent need to liquidate their investments. I expected household income to be positively associated with placing more value on leaving a bequest, because this value is more relevant for higher income persons. As a first step, frequency distribution for household income groups were obtained, and are shown for each group in Chapter 4, Table 7.

Work Experience

The fourth socio-demographic variable was work experience. Data regarding years of work experience and the type of work experience were requested in the socio-demographic section of the survey instrument and responses were coded into three categories: 1) no work experience, 2) part time or internship, and 3) full time work experience. The results showed that $91(19.9 \%)$ participants had no work experience, $123(26.9 \%)$ participants had part time or internship experience, and $240(52.5 \%)$ participants had full time work experience. As a first step, the frequency distribution for work experience groups was obtained, and is shown for each group in Chapter 4, Table 8.

Investment Experience

The fifth socio-demographic variable measured in this study was investment experience. Data regarding investment experience were requested in the socio-demographic section of the survey instrument and responses were coded into two categories, those without investment experience, and those with investment experience, i.e., mutual fund holdings, a stock portfolio, and/or a retirement plan. The results showed that $183(40 \%)$ participants had no investment experience, and $272(60 \%)$ of the respondents had at least some investment experience. As a the first step, the frequency distribution for investment experience category was obtained, and are shown for each group in Chapter 4, Table 9. 
Pro-social Attitudes

In consumer behavior, the term "pro-social attitudes" refers to consumer attitudes towards socially positioned products such as green products (Cowe \& Williams, 2001; Mayo, 2005; Nilsson, 2008). Extending this argument to investment in mutual funds, Nilsson (2008) argued that pro-social attitudes were related to an investor's concern for social issues. The pro-social attitudes construct has been used heavily in consumer behavior research but operationalized in many different ways. Nilsson (2008) modified the items of a consumer behavior scale to fit the mutual fund context. The current study used Nilsson's (2008) prosocial attitudes scale. Following Nilsson, this study operationalized pro-social items using survey questions that measured a respondent's attitudes regarding social issues such as corruption, human rights, work place rights, and environmental issues. Respondents were asked to rate four issues on a on a five-point Likert-type scale from 1 (not important) to 5 (very important). The scale has high internal reliability, Cronbach's alpha $=.874$.

\section{Risk Tolerance}

Risk is defined as the maximum amount of uncertainty or investment return volatility that the investor is willing to accept when making a financial decision (Faff et al., 2008; Grable, 2000; Grable \& Lytton, 1999). Financial risk tolerance was measured using a fouritem Likert-type scale developed by Wood and Zaichkowsky (2004) which measures individual attitudes toward risk as applied to financial investing. Each of the items used a five-point Likert-type scale with responses ranging from 1, "strongly disagree" to 5 "strongly agree." A sample item from this scale is "I am prepared to take greater risks (possibility of initial losses) in order to earn greater future returns." The Cronbach alpha of this scale $=.71$. Time Horizon

Time horizon refers to the time period associated with accomplishing an investment objective. Time horizon is measured using a five-item Likert-type scale developed by Wood 
and Zaichkowsky (2004), with responses ranging from 1 "strongly disagree" to 5 "strongly agree." A sample item from this scale is "Fluctuations in the stock market do not concern me". The Cronbach alpha of this scale $=.61$.

Estate Intentions

Estate Intentions is a variable that to my knowledge has not been studied before. Therefore, for this exploratory study, respondents were asked to express how much they valued leaving a bequest to different entities. A sample of the questions included in the scale is "Leaving an inheritance to charitable or philanthropic organizations is an important goal." The three questions were rated on a five-point Likert-type scale, choices ranging from 1 "strongly disagree" to 5 "strongly agree." Reliability of the scale was 0.7 indicating good reliability according to Nunnally and Bernstein (1994).

For all attitude scales items of each scale were scattered throughout the questionnaire in order to avoid response bias. A few extra items related to pro-social attitudes were included to reduce social desirability bias.

Study Methodology and Analysis Techniques

Sample

A pretest was conducted among graduate students to identify modifications that needed to be made to the survey instrument. Based on the recommendations of the pre-test subjects, modifications were made to the questionnaire. After the instrument was modified, completion time on average was 20 minutes. The data were collected over the period January, 2011 to April, 2011. Participants were briefed on the general purpose of the study, told that the study was solely for academic purposes, and asked to complete the questionnaire anonymously. The questionnaire was distributed to final-year undergraduate and MBA students at a major university in South Florida. Most respondents had some work experience, and many were employed full time. The socio-demographic characteristics of each sub- 
sample are reported in the "Results" section. Questionnaires were administered in a classroom setting, so the response rate was very high.

Before analysis all distributions were checked for evidence of normality, abnormal skewness, and irregular kurtosis. None of the distributions were found to exhibit unusual characteristics. The descriptive statistics include computing the minimum, maximum, and mean values of the variables. As the first step in data analysis I conducted an exploratory factor analysis in order to determine the underlying dimensions of the dependent and independent variables. I treated several socio-demographic variables as continuous variables although they had been combined into categories in the survey. The relevant data were analyzed using parametric statistical procedures. Reliability tests were conducted on each factor. The results showed that Cronbach alphas were acceptable, as reported above. According to Hair, Black, Anderson, and Tathan (2006) for an exploratory study the Cronbach alpha should be above .7. The parametric techniques used in this study were multiple linear regression and correlation matrices.

\section{Ethical Considerations}

In this research, I took the necessary steps to make sure that this study would not cause any harm or adverse consequences to others. Because the research included human subjects, it was governed by the ethical principles and guidelines contained in the Belmont Report, legislation signed into law in 1979 to resolve ethical problems surrounding the conduct of research with human subjects. The Belmont Report identifies three basic principles relevant to ethics of research involving human subjects- respect for persons, beneficence, and justice. Measures that were taken to assure compliance with each of the Belmont Principles are discussed below. 
Respect for Persons-Assurance of Autonomy for Individuals

Respect for persons is the first principle in the Belmont report. This requires the researcher to treat all participants as autonomous agents with respect for their decisions and protections for individuals with diminished autonomy. In this study, all participants were assured that their responses would be held in strict confidence. No individual response would be reported. In addition, no one was asked to disclose his/her identity. Furthermore, any report of this research that is made available to the public would not include any individual information by which a participant could be identified. All participants were informed that participation in this study did not mean that they were giving up any of their legal rights. Taking part in this study was voluntary. If participants chose not to be in this study, then they could withdraw at any time without consequences of any kind. Participants might choose not to answer a particular question.

Beneficence-Protecting Participants against Risk of Harm

The second ethical principle in the Belmont Report, beneficence, requires researchers to protect participants against risk of harm. To assure compliance with this requirement, all participants were informed there were no physical, financial, or psychological risks known to be associated with study. Furthermore, no financial or other forms of compensation were offered. However, participants were informed they might benefit from the experience of answering questions related to investor preferences. This experience might broaden their knowledge regarding investor preferences, and at the same time would create areas for future research where academicians and practitioners might benefit. Justice-An Equitable Distribution of Research Benefits and Burdens The third requirement of the Belmont Report, justice, refers to an equitable distribution of research benefits and burdens and an unbiased selection of research subjects at 
an individual and social level. To assure compliance with this requirement, the survey was administered to all the population in each class, and each participant was treated equally. Institutional Review Board (IRB)

The researcher completed IRB Human Subject online course, and received a letter from the IRB representative at Florida International University to allow him to conduct this research. 


\section{CHAPTER IV \\ ANALYSIS AND PRESENTATION OF THE RESULTS}

Introduction

The purpose of this study was to provide a comprehensive model of investor preferences that would include psychological and attitudinal variables in addition to sociodemographic variables. The unit of analysis was the individual investor. In the previous chapter I described the study design, the methodology used to choose my sample, and matching the measures employed to the study constructs. I also discussed the construction of the questionnaire and its administration. In this chapter I discuss the analysis of the data and present the findings. The analysis includes a discussion of the dependent and independent variables using several statistical techniques such as descriptive statistics, correlation analysis, and multiple regression. The data analysis was performed using SPSS version 18. Preceding the model testing, the data were checked for missing values, outliers, data entry accuracy, and variable distribution (see, for example, Tabachnick, Fidell, \& Osterlind, 2001). A total of 450 useable surveys were used in the analysis, representing $98 \%$ of the collected surveys. Field (2005) has recommended that researchers inspect the data for outliers before conducting any analysis. According to Field, a data point is considered an outlier if its Z score is at or above the absolute value of 3.29. Data were examined for outliers, and the results did not show any outlier problem. To check for multicollinearity I looked at the variance inflation factors (VIF). According to Hair, Black, Babin, Anderson, and Tatham (2006), values of VIF that exceed 10 are often regarded as indicative of multicollinearity. None of the VIF scores exceeded 2.5. The results of the statistical analyses presented in this chapter include characteristics of the sample, descriptive analysis, instrumentation reliability and validity analysis, and the results of the multiple linear regressions. 


\section{Descriptive Statistics}

Characteristics of the Sample

All students in the selected classes were asked to participate in the study $(\mathrm{N}=460)$. Before I distributed the survey I clearly described to each class the importance of the study for both academicians and practitioners. However, examination of the detailed data revealed that ten surveys were not appropriate for analysis because some pages were left without responses to survey questions, probably because of lack of attention or interest. Removing these cases resulted in a total of 450 usable surveys, which represented a $98 \%$ response rate. Since participation was voluntary, this high response rate showed that nearly all students were interested in the topic. I assured the participants of their anonymity and that the findings of the study would be available for them. Respondents were asked to provide information related to gender, age, ethnicity, education, household income, work experience, and investment experience. To assess investment experience, respondents reporting holdings in mutual funds, stock portfolios, or retirement accounts, were categorized as having investment experience. Respondents reporting no such holdings were categorized as not having investment experience. To assess work experience, respondents were asked to report either if they had no work experience, part time or internship work experience, and were categorized into the category representing each individual's highest level of work experience with no work experience being the lowest level and full time work experience the highest. In line with these characteristics I assessed the descriptive statistics for all variables used in the study, then assessed the frequency distribution for the socio-demographic variables of gender, age, education, income, work experience, and investment experience. 
Table 2

Descriptive Statistics for All Variables in the Study

\begin{tabular}{llllll}
\hline & $\mathrm{N}$ & Minimum & Maximum & Mean & Std. Deviation \\
\hline GEN & 454 & 1 & 2 & 1.47 & .499 \\
AGE & 454 & 1 & 5 & 2.33 & .815 \\
EDU & 450 & 1 & 2 & 1.23 & .423 \\
INC & 422 & 1 & 5 & 2.89 & 1.377 \\
WORK & 453 & 1 & 2 & 1.80 & .399 \\
INV & 428 & 0 & 1 & .50 & .501 \\
HOPE & 413 & 6 & 23 & 12.16 & 3.445 \\
OPEN & 450 & 4 & 20 & 9.08 & 2.834 \\
IDEO & 451 & 0 & 5 & 2.55 & 1.275 \\
PRO & 416 & 5 & 25 & 19.77 & 4.528 \\
RISK & 453 & 2 & 9 & 5.12 & 1.463 \\
TIME & 420 & 2 & 9 & 5.04 & 1.481 \\
EST & 418 & 3 & 15 & 8.50 & 2.362 \\
\hline
\end{tabular}

Table 2 shows that nearly all respondents answered all the questions. Only in a very few cases did respondents skip some questions such as investment experiences, income, and estate intentions. Since I coded the variables into categories such as income, age, or gender, the score of the statistical parameters (mean and standard deviation) cannot be used to explain the findings.

Normality Distribution of the Continuous Variables

I assessed the normality of the continuous variables by examining the skewness and kurtosis of each variable. A perfectly normal distribution is when the value of the skewness and kurtosis is equal to zero. In social sciences it is rare to have a have a perfectly normal distribution, therefore, for psychometric purposes it is acceptable to have value ranging from negative 2 to positive 2 (Pallant, 2005).

Table 3 shows the skewness and kurtosis values for all of the variables except for age were between a positive 2 and a negative 2 . I considered the variables as having an acceptable degree of normality for parametric testing. 
Table 3

Skewness and Kurtosis Values for the Continuous Variables

\begin{tabular}{|c|c|c|c|c|c|c|c|c|c|}
\hline & \multirow[b]{2}{*}{$\mathrm{N}$} & \multirow{2}{*}{$\begin{array}{l}\text { Mini- } \\
\text { mum }\end{array}$} & \multirow{2}{*}{$\begin{array}{l}\text { Maxi- } \\
\text { mum }\end{array}$} & \multirow[b]{2}{*}{ Mean } & \multirow{2}{*}{$\begin{array}{l}\text { Std. } \\
\text { Deviation }\end{array}$} & \multicolumn{2}{|c|}{ Skewness } & \multicolumn{2}{|l|}{ Kurtosis } \\
\hline & & & & & & Statistic & Std. & rStatistic & Std. Error \\
\hline$\overline{\mathrm{AGE}}$ & 454 & 1 & 5 & 2.33 & .815 & 1.721 & .115 & 3.362 & .229 \\
\hline EDU & 450 & 1 & 2 & 1.233 & .423 & 1.265 & .115 & -.401 & .230 \\
\hline INC & 422 & 1 & 5 & 2.89 & 1.37 & .025 & .119 & -1.239 & .237 \\
\hline WORK & 453 & 1 & 3 & 2.30 & .811 & -.605 & .115 & -1.220 & .229 \\
\hline INV & 428 & 0 & 1 & .50 & .501 & -.009 & .118 & -2.009 & .235 \\
\hline HOPE & 413 & 6 & 23 & 12.159 & 3.4444 & .324 & .120 & -.084 & .240 \\
\hline OPEN & 450 & 4 & 20 & 9.082 & 2.833 & .269 & .115 & .118 & .230 \\
\hline IDEO & 451 & 0 & 5 & 2.55 & 1.275 & -.134 & .115 & -1.113 & .229 \\
\hline PRO & 416 & 5 & 25 & 19.77 & 4.528 & -1.211 & .120 & 1.193 & .239 \\
\hline RISK & 453 & 2 & 9 & 5.123 & 1.462 & .015 & .115 & -.147 & .229 \\
\hline TIME & 420 & 2 & 9 & 5.042 & 1.481 & .302 & .119 & .111 & .238 \\
\hline EST & 418 & 3 & 15 & 8.500 & 2.362 & .126 & .119 & .033 & .238 \\
\hline
\end{tabular}

Frequencies for Socio- demographic Variables

Table 4

Frequency Distribution: Gender

\begin{tabular}{llllll}
\hline & & & & Cumulative \\
& & Frequency & Percent & Valid Percent & Percent \\
\hline Valid & Male & 242 & 53.2 & 53.3 & 53.3 \\
& Female & 212 & 46.6 & 46.7 & 100.0 \\
& Total & 454 & 99.8 & 100.0 & \\
Missing & & 1 & .2 & & \\
Total & & 455 & 100.0 & & \\
\hline
\end{tabular}

From Table 4, we see that 53.2 percent of the respondents were males and 46.6 percent were females. According to the dean's office there is a 50/50 split between males and females in the business program of this university, and this distribution seems reasonable since the males were slightly outnumbered by females in the classes where data were collected.

Table 5 reveals that 23 percent were under age 20,68.6 percent ranged from 20 to 25 , 18.5 percent ranged from 26 to $30,3.1$ percent ranged from 31 to 35 and 4.6 percent were over 35 years of age. This is a very youthful sample, but it seems reasonable because my sample consisted of MBA students and senior undergraduate students in the business school. 
Table 5

Frequency Distribution: Age per Category

\begin{tabular}{llllll}
\hline & & & & & Cumulative \\
& & Frequency & Percent & Valid Percent & Percent \\
\hline Valid & under 20 & 23 & 5.1 & 5.1 & 5.1 \\
& $20-25$ & 312 & 68.6 & 68.7 & 73.8 \\
& $26-30$ & 84 & 18.5 & 18.5 & 92.3 \\
& $31-35$ & 14 & 3.1 & 3.1 & 95.4 \\
& over 35 & 21 & 4.6 & 4.6 & 100.0 \\
& Total & 454 & 99.8 & 100.0 & \\
Missing & & 1 & .2 & & \\
Total & & 455 & 100.0 & & \\
\hline
\end{tabular}

Table 6

Frequency Distribution: Education per Category

\begin{tabular}{llllll}
\hline & & & & & Cumulative \\
& & Frequency & Percent & Valid Percent & Percent \\
\hline Valid & Bachelor & 345 & 75.8 & 76.7 & 76.7 \\
& Master & 105 & 23.1 & 23.3 & 100.0 \\
& Total & 450 & 98.9 & 100.0 & \\
Missing & & 5 & 1.1 & & \\
Total & & 455 & 100.0 & & \\
\hline
\end{tabular}

Table 6 represents the frequency distribution of the educational program in which participants were enrolled. The results show that 75.8 percent of the respondents were studying for their Bachelor's degree, while 23.1 percent were studying for their MBA degree. Only 1.1 percent of the respondents did not answer the question. This implied that the respondents were relatively well educated, and this is expected because the sample is drawn from a student population.

Table 7

Frequency Distribution: Household Income of all Participants

\begin{tabular}{llllll}
\hline & & & & Cumulative \\
& & Frequency & Percent & Valid Percent & \begin{tabular}{l} 
Percent \\
\hline Valid
\end{tabular} \\
& under 20000 & 96 & 21.1 & 22.7 & 22.7 \\
& $21,000-40,000$ & 75 & 16.5 & 17.8 & 40.5 \\
& $41,000-60,000$ & 95 & 20.9 & 22.5 & 63.0 \\
& $61,000-80,000$ & 93 & 20.4 & 22.0 & 85.1 \\
& over 80,000 & 63 & 13.8 & 14.9 & 100.0 \\
Missing & Total & 422 & 92.7 & 100.0 & \\
Total & & 33 & 7.3 & & \\
\hline
\end{tabular}


Respondents were asked to provide data regarding their annual household income.

Table 7 shows that 21.1 percent reported an annual household income less than $\$ 20,000,16.1$ percent reported an annual household income between $\$ 21,000$ and $\$ 40,000,20.4$ percent reported an annual household income between $\$ 61,000$ and $\$ 80,000$ and 13.8 percent reported an annual household income over $\$ 80,000$, with only 7.3 percent of the answers missing. Questions about income are often thought to be intrusive, so the response rate for this question, 92.7 percent, although lower than the other socio-socio-demographic variables, was accepted.

Table 8 shows that 22.2 percent of the respondents had no work experience, 25.1 percent of the respondents had work experience, and 52.3 percent had full time work experience. Only two respondents failed to answer this question.

Table 8

Frequency Distribution: Work Experience per Category

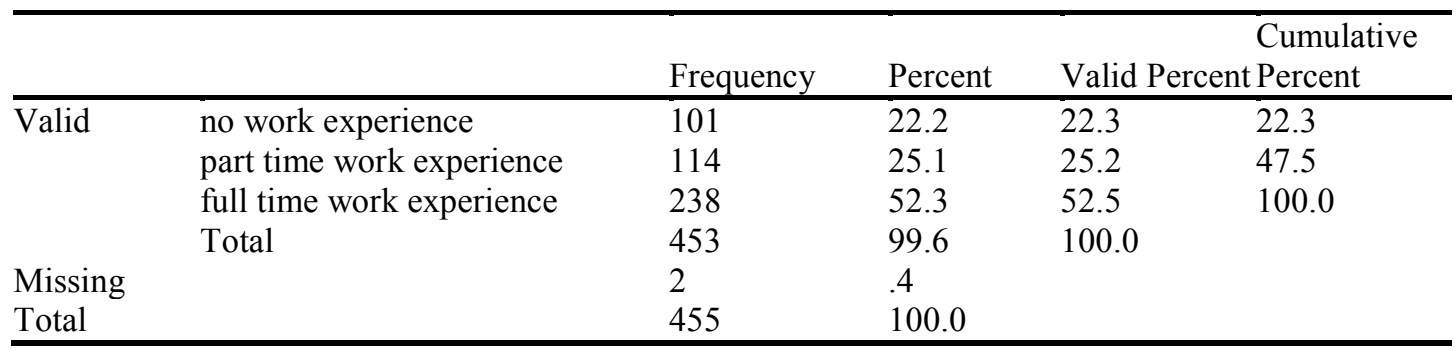

Table 9 summarizes the frequency distribution of investment experience for the respondents. We can see from this Table that respondents were almost equally distributed between those without investment experience (46.8\%) and those with investment experience (47.3). The non-respondents were 5.9 percent. 
Table 9

Frequency Distribution: Investment per Category

\begin{tabular}{llllll}
\hline & & & & & Cumulative \\
& & Frequency & Percent & Valid Percent & Percent \\
\hline Valid & 0 (NO) & 213 & 46.8 & 49.8 & 49.8 \\
& 1 (YES) & 215 & 47.3 & 50.2 & 100.0 \\
& Total & 428 & 94.1 & 100.0 & \\
Missing & & 27 & 5.9 & & \\
Total & & 455 & 100.0 & & \\
\hline
\end{tabular}

Measurement Reliability of Major Constructs

Reliability refers to the consistency of the measurement. A test is considered reliable if we get the same result repeatedly (Mehrens \& Lehmann, 1987). Cronbach's Coefficient alpha (symbolized as $\alpha$ ) is commonly used to test for reliability of multi-item scales as it refers to whether items are sufficiently interrelated and estimates the reliability of internal scale consistency (Bollen, 1990; Cooper \& Emory, 1995). Although 0.7 value is typically used as a cutoff point for alpha to be accepted as a good indicator of internal consistency, in general, scholars have stated that the higher the value of alpha, the more reliable the measure (e.g., Gefen, Straub, \& Boudreau, 2000; Hair et al., 2006; Nunnally \& Bernstein, 1994).

This research begins by examining eight major latent constructs, namely the positive psychology variables of hope, optimism, and resiliency, and also political ideology, prosocial attitudes, risk tolerance, time horizon, and estate intentions. Except for estate intentions, the sub-scales used in this study were taken from existing studies, and were treated as established measures, all meeting the 0.70 alpha cutoff point. Exploratory factor analysis was conducted on all survey scales separately as well as jointly. With two exceptions, which will be discussed further, the results revealed the anticipated factor structure, with items loading highly on the constructs they were intended to measure. Items which loaded on more than one factor were deleted. Two constructs not supported by factor analysis were resiliency and optimism. However, since several of the questions intended to comprise the resiliency 
scale loaded, I took these items and designated a new construct I called openness. A new scale was developed for this study to measure estate intentions by items concerning leaving a bequest to charitable and philanthropic organizations, religious organizations, and family members.

Correlation Matrix for All Variables

The main object of this study was to see if socio-demographic variables were significant to explain variance in investor preferences, and whether adding psychological and attitudinal variables would increase the amount of variance explained in investor preferences. For that reason, I considered the variables of political ideology, pro-social attitudes, hope, and openness. The three aspects of investor preferences were risk tolerance, time horizon, and estate intentions. Therefore, before running the regression to test the relationships between the dependent variables and the independent variables, Pearson's correlations was used to determine the bivariate relationships among all variables and can be seen in Table 10. The results showed the intercorrelation between independent variables ranged from small to moderate, in that 0.1 is small, 0.3 is moderate, and 0.5 is high (Cohen, 1998). Table 10 shows that the correlation between the independent variables ranged from 0.008 to 0.457 . Furthermore, the variance inflation factor (VIF) was used to compute if there were multicollinearity between the independent variables. If the VIF score is around or greater than 10 for any of the independent variables, there is collinearity associated with that variable. In this study none of the variables had a value greater than 1.5 , indicating no multicollinearity. Table 10 shows the results of the correlations among all the variables included in the study. A significant negative correlation was found between gender and education $(r=-.134$, $\mathrm{p} .=.004, \mathrm{n}=450)$, and a significant positive correlation was found between gender and prosocial attitudes $(r=.190, p=.000, n=416)$, indicating that males had a higher level of education than females, and females scored higher on pro-social attitudes. Age was positively correlated 
with education $(\mathrm{r}=.159, \mathrm{p} .=001, \mathrm{n}=450)$, indicating that older respondents had a higher level of education than younger ones. Household income was negatively correlated to gender $(\mathrm{r}=-.099, \mathrm{p}=.004, \mathrm{n}=422)$ and education $(\mathrm{r}=-.106, \mathrm{p}=.03, \mathrm{n}=419)$, and positively correlated with age $(\mathrm{r}=.212, \mathrm{p}=.009, \mathrm{n}=449)$ indicating that females had lower household income but higher education than males, and older respondents had higher household income than younger ones.

Paradoxically, the less educated had higher household income than the more educated, a finding that will be discussed later. Work experience was negatively correlated with gender $(r=-.110, p=0.02, n=453)$, but positively correlated with age $(r=.212, p=.000$, $\mathrm{n}=453)$ and education $(\mathrm{r}=.209, \mathrm{p}=.000, \mathrm{n}=449)$, indicating that males had more work experience than females, older participants had more work experience than younger, and participants with more work experience were more educated. Investment experience was positively correlated with age $(r=.172, p=.000, n=397)$ and household income $(r=.309$, $\mathrm{p}=.000 . \mathrm{n}=397)$, and negatively correlated with work experience $(r=-.216, p=.000, n=426)$, indicating that older participants had more investment experience, and participants with less household income had more investment experience. It is interesting that participants with less work experience reported more investment experience. Investment experience was negatively correlated with openness $(r=-.128, \mathrm{p}=.008, \mathrm{n}=410)$ but positively correlated with hope $(\mathrm{r}=.419, \mathrm{p}=.000, \mathrm{n}=410)$, indicating that participants with more investment experience scored lower on openness but higher on hope. Participants who scored high on openness also scored high on hope. I expected this result because these are two components of positive psychology. 
Table 10

Correlation Matrix for Dependent and Independent Variables Used in Study

\begin{tabular}{|c|c|c|c|c|c|c|c|c|c|c|c|c|c|}
\hline & 1 & 2 & 3 & 4 & 5 & 6 & 7 & 8 & 9 & 10 & 11 & 12 & 13 \\
\hline \multirow[t]{2}{*}{ 1.GEN } & 1 & & & & & & & & & & & & \\
\hline & 454 & & & & & & & & & & & & \\
\hline \multirow[t]{3}{*}{ 2.AGE } & -.043 & 1 & & & & & & & & & & & \\
\hline & .358 & & & & & & & & & & & & \\
\hline & 454 & 454 & & & & & & & & & & & \\
\hline \multirow[t]{3}{*}{$\overline{3 . E D U}$} & $-.134^{* *}$ & $.159^{* *}$ & 1 & & & & & & & & & & \\
\hline & .004 & .001 & & & & & & & & & & & \\
\hline & 450 & 450 & 450 & & & & & & & & & & \\
\hline \multirow[t]{3}{*}{$\overline{4 . I N C}$} & $-.099^{*}$ & $.127^{* *}$ & $-.106^{*}$ & 1 & & & & & & & & & \\
\hline & .043 & .009 & .030 & & & & & & & & & & \\
\hline & 422 & 422 & 419 & 422 & & & & & & & & & \\
\hline \multirow[t]{3}{*}{ 5.WORK } & $-.110^{*}$ & $.212^{* *}$ & $.209^{* *}$ & -.067 & 1 & & & & & & & & \\
\hline & .020 & .000 & .000 & .168 & & & & & & & & & \\
\hline & 453 & 453 & 449 & 422 & 453 & & & & & & & & \\
\hline \multirow[t]{3}{*}{$\overline{6 . I N V}$} & -.082 & $.172^{*}$ & -.052 & $.309^{* *}$ & -.216 & & & & & & & & \\
\hline & .092 & .000 & .286 & .000 & .000 & & & & & & & & \\
\hline & 427 & 427 & 424 & 397 & 426 & & & & & & & & \\
\hline \multirow[t]{3}{*}{ 7.HOPE } & -.038 & -.033 & .017 & -.027 & -.018 & -.071 & 1 & & & & & & \\
\hline & .442 & .504 & .730 & .597 & .719 & .151 & & & & & & & \\
\hline & 412 & 412 & 409 & 382 & 411 & 413 & 413 & & & & & & \\
\hline \multirow{3}{*}{ 8.OPEN } & .046 & $\begin{array}{l}.026 \\
\end{array}$ & -.044 & $\begin{array}{l}-.083 \\
\end{array}$ & -.031 & $-.128^{* *}$ & $.419^{* *}$ & 1 & & & & & \\
\hline & .332 & .588 & .350 & .092 & .512 & .008 & .000 & & & & & & \\
\hline & 449 & 449 & 445 & 417 & 448 & 423 & 410 & 450 & & & & & \\
\hline \multirow[t]{3}{*}{$\overline{9 . I D E O}$} & -.046 & .080 & $.254^{* *}$ & $-.226^{*}$ & $.457^{* *}$ & $-.482^{* *}$ & .020 & .024 & 1 & & & & \\
\hline & .333 & .089 & .000 & .000 & .000 & .000 & .693 & .620 & & & & & \\
\hline & 451 & 451 & 447 & 421 & 451 & 424 & 409 & 446 & 451 & & & & \\
\hline \multirow[t]{3}{*}{ 10.PRO } & $.190^{* *}$ & -.039 & $-.197^{*}$ & .010 & $-.114^{*}$ & .007 & $-.139^{*}$ & -.022 & -.075 & 1 & & & \\
\hline & .000 & .433 & .000 & .850 & .020 & .880 & .005 & .652 & .126 & & & & \\
\hline & 416 & 416 & 413 & 387 & 415 & 416 & 409 & 412 & 413 & 416 & & & \\
\hline \multirow[t]{3}{*}{$\overline{11 . R I S K}$} & .056 & .014 & -.039 & .008 & -.051 & -.034 & $.133^{* *}$ & $.139^{*}$ & -.057 & .009 & 1 & & \\
\hline & .238 & .773 & .413 & .868 & .279 & . 480 & .007 & .003 & .229 & .852 & & & \\
\hline & 452 & 452 & 448 & 421 & 451 & 427 & 412 & 448 & 449 & 415 & 453 & & \\
\hline \multirow[t]{3}{*}{ 12.TIME } & $.110^{*}$ & -.029 & -.074 & -.049 & -.088 & $-.097^{*}$ & $.236^{*}$ & $.152^{*}$ & -.063 & .040 & $.481^{* *}$ & 1 & \\
\hline & .024 & .551 & .131 & .335 & .072 & .048 & .000 & .002 & .200 & .411 & .000 & & \\
\hline & 419 & 419 & 416 & 389 & 418 & 420 & 412 & 416 & 416 & 415 & 419 & 420 & \\
\hline \multirow[t]{3}{*}{$\overline{13 . E S T A T}$} & -.027 & .081 & .042 & -.076 & $\begin{array}{l}-.080 \\
\end{array}$ & -.023 & $.196^{* *}$ & $.117^{*}$ & .062 & -.060 & .000 & .081 & 1 \\
\hline & .583 & .098 & .397 & .136 & .104 & .634 & .000 & .017 & .205 & .226 & .995 & .097 & \\
\hline & 417 & 417 & 414 & 387 & 416 & 418 & 410 & 415 & 414 & 413 & 417 & 417 & 418 \\
\hline
\end{tabular}

** Correlation is significant at the 0.01 level (2-tailed).

* Correlation is significant at the 0.05 level (2-tailed).

Political ideology was positively correlated with education $(r=.254, p=.000, n=447)$, and work experience $(r=.457, p=.000, n=424)$, and negatively correlated to household income $(\mathrm{r}=-.226, \mathrm{p}=.000, \mathrm{~N}=421)$ and investment experience $(\mathrm{r}=-482, \mathrm{p}=.000, \mathrm{n}=424)$. These 
results indicate that liberal respondents were more educated, had more work experience, had less household income, and had less investment experience. Pro-social attitudes were positively correlated to gender, but negatively correlated to education $(r=-.197, p=.000, n=$ 413), work experience $(\mathrm{r}=-114, \mathrm{p}=.02, \mathrm{n}=415)$, and hope $(\mathrm{r}=-.139, \mathrm{p}=.005, \mathrm{n}=409)$, indicating that participants who scored high on pro-social attitudes were proportionately more female, less educated, had less work experience, and had lower scores on the hope scale.

Moving to the dependent variables, risk tolerance was positively correlated with hope $(\mathrm{r}=.133, \mathrm{p}=.003, \mathrm{n}=448)$ and openness $(\mathrm{r}=.419, \mathrm{p}=.000, \mathrm{n}=410)$, indicating that participants who scored high on risk tolerance scored high on hope and openness. Contrary to my expectation, time horizon was negatively correlated to investment experience $(r=-.097$, $\mathrm{p}=.048, \mathrm{n}=420)$. As I expected, time horizon was positively correlated to hope $(\mathrm{r}=.236$, $\mathrm{p}=.002, \mathrm{n}=412)$ and risk tolerance $(\mathrm{r}=.481, \mathrm{p}=.000, \mathrm{n}=419)$, indicating that participants with more investment experience intended to invest with a shorter time horizon, scored high on hope, and were more risk tolerant. Estate intentions were positively correlated to hope $(\mathrm{r}=.196, \mathrm{p}=.000, \mathrm{n}=410)$, indicating that participants who scored high on the hope scale placed a higher value on leaving a bequest.

Multiple Regression and ANOVA Analysis

I used multiple regression and ANOVA analysis to provide additional perspective on the relationships between the independent variables and the dependent variables. The regression model was based on an explanatory factor analysis. Previous studies used sociodemographic variables to predict the dependent variables. I extended the previous research by adding attitudinal variables. Accordingly, I first examined the impact of socio-demographic variables on the investor preferences of risk tolerance, time horizon, and estate intentions. The following multiple regression equations were developed to predict the dependent variables: 
$Y_{(\text {Risk Tolerance) }}=B_{1} x_{1}+B_{2}$ gender $+B_{3}$ age $+B_{4}$ education $+B_{5}$ income $+B_{6}$ work +

$B_{7}$ investment $+B_{8}$ hope $+B_{9 o p e n}+B_{10}$ political ideology $+B_{11}$ pro-social attitudes $+E$

$Y_{\text {(Time Horizon) }}=B_{1} x_{1}+B_{2}$ gender $+B_{3}$ age $+B_{4}$ education $+B_{5}$ income $+B_{6}$ work $+B_{7}$ investment +

$B_{8}$ hope $+B_{9 o p e n}+B_{10}$ political ideology $+B_{11}$ pro-social attitudes $+E$

$Y_{\text {(estate Intention) }}=B_{1} x_{1}+B_{2}$ gender $+B_{3}$ age $+B_{4}$ education $+B_{5}$ income $+B_{6}$ work +

$B_{7}$ investment $+B_{8}$ hope $+B_{9 o p e n}+B_{10}$ political ideology $+B_{11}$ pro-social attitudes $+E$

Summary of Standard Regression Analysis for Variables Predicting Investor Preferences

Socio-demographic Regression Model

Using the enter method, a non-significant model emerged $(F=.706, p=.6455)$, with the adjusted $\mathrm{R}$ square $=-.005$. Results are shown in Tables: 11,12 , and 13 . The following section includes a discussion of the regression analysis for the investment preferences of respondents and socio-demographic variables. SPSS Version 18 was used to assess the calculation. An analysis of the findings of the multiple regressions follows.

Table 11

Multiple Regression Analysis Predicting Risk Tolerance with Socio-demographic Variables

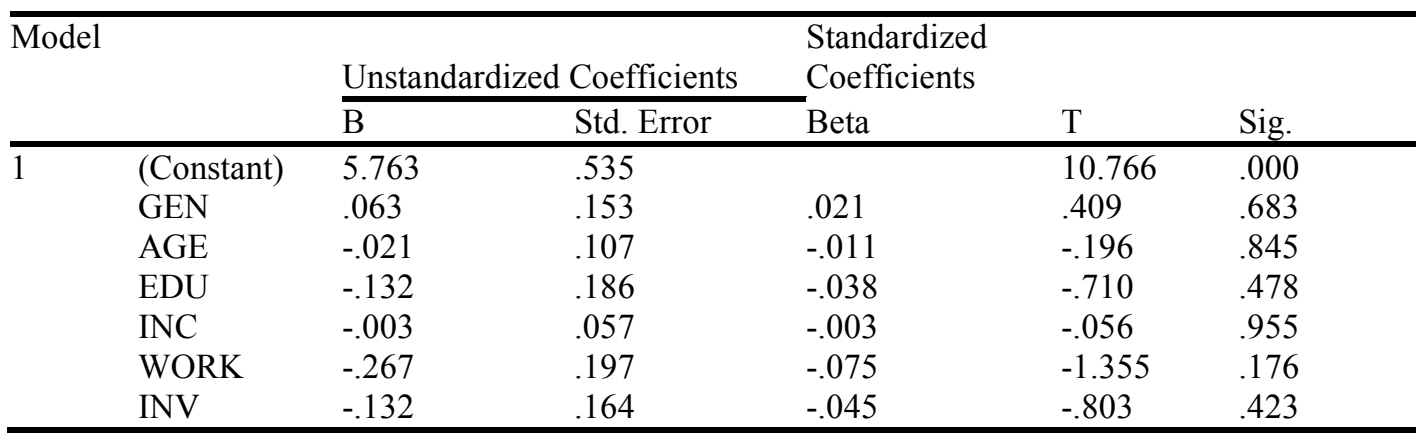

a.

Dependent Variable: RISK 
Table 12

Multiple Regression Analysis Predicting Time Horizon with Socio-demographic Variables

\begin{tabular}{|c|c|c|c|c|c|c|}
\hline \multirow{2}{*}{\multicolumn{2}{|c|}{ Model }} & \multicolumn{2}{|c|}{ Unstandardized Coefficients } & \multirow{2}{*}{$\begin{array}{l}\text { Standardized } \\
\text { Coefficients } \\
\text { Beta }\end{array}$} & \multirow[b]{2}{*}{$\mathrm{T}$} & \multirow[b]{2}{*}{ Sig. } \\
\hline & & $\mathrm{B}$ & Std. Error & & & \\
\hline \multirow[t]{7}{*}{1} & (Constant) & 5.925 & .540 & & 10.977 & .000 \\
\hline & GEN & .142 & .155 & .048 & .916 & .360 \\
\hline & AGE & .081 & .116 & .038 & .696 & .487 \\
\hline & EDU & -.198 & .190 & -.056 & -1.041 & .299 \\
\hline & INC & -.025 & .058 & -.023 & -.430 & .667 \\
\hline & WORK & -.443 & .200 & -.122 & -2.217 & .027 \\
\hline & INV & -.346 & .167 & -.116 & -2.066 & .039 \\
\hline
\end{tabular}

a. Dependent Variable: TIME

Table 13

Multiple Regression Analysis Predicting Estate Intentions with Socio-demographic Variables

\begin{tabular}{|c|c|c|c|c|c|c|}
\hline \multirow[t]{2}{*}{ Model } & & \multicolumn{2}{|c|}{ Unstandardized Coefficients } & \multirow{2}{*}{$\begin{array}{l}\text { Standardized } \\
\text { Coefficients } \\
\text { Beta }\end{array}$} & \multirow[b]{2}{*}{$\mathrm{t}$} & \multirow[b]{2}{*}{ Sig. } \\
\hline & & $\mathrm{B}$ & Std. Error & & & \\
\hline \multirow[t]{7}{*}{1} & (Constant) & 10.042 & .828 & & 12.132 & .000 \\
\hline & GEN & -.321 & .238 & -.069 & -1.348 & .179 \\
\hline & AGE & .536 & .175 & .167 & 3.068 & .002 \\
\hline & EDU & -.036 & .292 & -.007 & -.122 & .903 \\
\hline & INC & -.164 & .089 & -.098 & -1.842 & .066 \\
\hline & WORK & -.947 & .307 & -.169 & -3.086 & .002 \\
\hline & INV & -.181 & .256 & -.039 & -.706 & .480 \\
\hline
\end{tabular}

a. Dependent Variable: EST

Gender as an Independent Variable

Gender (GEN) had a beta of .409 with a $p$ value of .683 . The non-significant result implied risk tolerance scores did not vary based on gender. This result indicates no significant differences between male and female respondents. For time horizon gender had a beta of .916 and a $p$ value of .360 indicating no significant differences between male and female respondents. For estate intentions gender had a beta -.069 with a p value .179 , indicating no significant difference between male and female respondents.

1. Age as an Independent Variable

Age (AGE) had a beta of -.196 with a p value of .845. The non-significant result implied that the risk tolerance scores did not vary based on age. For time horizon age had a 
beta of .696 and a p value of .487, indicating no significant differences between respondents based on age. For estate intentions age had a beta of -.069 and a p value of .002 . This result indicates there was a significant difference in estate intentions between respondents based on age. Older respondents were actually less likely to score high on estate intentions, a result contrary to my expectation.

2. Education as an Independent Variable

The independent variable education (EDU) had a beta of .710 with a $p$ value of .478 . The non-significant result implied that risk tolerance did not vary based on the respondent's level of education. For time horizon education had a beta of -1.041 and a $p$ value of .299, indicating no significant difference in the time horizon score based on education. For estate intentions education had a beta of -.007 and $p$ value of .903 , indicating no significant difference in estate intentions based on education.

3. Household Income as an Independent Variable

The independent variable household income (INC) had a beta of -..056 with $p$ value of .955. The non-significant result implied that the risk tolerance scores did not vary based on the household income. For time horizon household income had a beta of -.430 and $p$ value of .667 , indicating no significant differences between respondents on the risk tolerance score based on household income. For estate intentions household income had a beta of -.098 and a $\mathrm{p}$ value of .066, indicating that household income did not relate to estate intentions.

4. Work Experience as an Independent Variable

The independent variable work experience (WORK) had a beta of -..075 with p value of .176. The non-significant result implied that the risk tolerance scores did not vary based on work experience. Time horizon had a beta of -2.217 and a $\mathrm{p}$ value of .027 , indicating a significant difference in time horizon based on work experience. However, more work experience was associated with a shorter time horizon, a surprising result since I expected to 
find a positive relationship between time horizon and work experience. Estate intentions had a beta of -.169 and $p$ value of .002 , indicating significant differences between respondents based on work experience, with more work experience associated with a lower score on the estate intentions scale. This result was the opposite of what I expected and is hard to explain.

5. Investment Experience as an Independent Variable

The independent variable investment experience (INV) had a beta of -.803 with a $p$ value of .423. It indicated that risk tolerance score did not vary based on investment experience. This was a surprising result since I expected respondents with more investment experience would have a higher score on risk tolerance. Time horizon had a beta of -.116 and $\mathrm{p}$ value of .039, indicating significant differences between respondents in time horizon based on investment experience, with more investment experience associated with a shorter time horizon. This negative significant relationship was a surprise since I expected to find a positive relationship. For estate intentions, investment experience had a beta -.039 and $p$ value of.480, indicating that the score on estate intentions did not vary based on investment experience.

Attitudinal Variables Regression Model

I added the attitudinal variables to find out if this would add more explanatory power to the model. For risk tolerance, the unstandardized regression analysis shown in Table 14 demonstrates that none of independent variables in the model was statistically significant, indicating that the score on risk tolerance did not vary based on the independent variables used in this model. Table 15 shows that for time horizon only hope was statistically significant with beta of 0.79 and $p=.006$ indicating that the score on time horizon scale varied based on hope. For estate intentions, the results show three out of the nine independent variables were significant. Age had a beta of .552 and $p=.002$, work experience had a beta of -1.082 , and $p=0.001$, and hope had a beta of .105 and $p=0.006$. These results indicated estate 
intentions varied based on these variables, that older respondents, those with less work experience, and those scoring higher on hope were more likely to place value on leaving a bequest.

\section{Table 14}

Multiple Regression Analysis Predicting Risk Tolerance with Socio-demographic Variables and Attitudinal Variables

\begin{tabular}{|c|c|c|c|c|c|c|}
\hline \multirow{2}{*}{\multicolumn{2}{|c|}{ Model }} & \multirow{2}{*}{\multicolumn{2}{|c|}{ Unstandardized Coefficients }} & \multirow{3}{*}{$\begin{array}{l}\text { Standardized } \\
\text { Coefficients } \\
\text { Beta }\end{array}$} & \multirow[b]{3}{*}{$\mathrm{t}$} & \multirow[b]{3}{*}{ Sig. } \\
\hline & & & & & & \\
\hline & & B & Std. Error & & & \\
\hline \multirow[t]{10}{*}{1} & (Constant) & 4.646 & .649 & & 7.162 & .000 \\
\hline & GEN & .016 & .157 & .005 & .100 & .920 \\
\hline & AGE & .066 & .114 & .032 & .576 & .565 \\
\hline & EDU & -.099 & 195 & -.029 & -.507 & 612 \\
\hline & INC & -.011 & .059 & -.010 & -.179 & .858 \\
\hline & WORK & -.192 & .213 & -.054 & -.902 & .368 \\
\hline & INV & -.123 & 186 & -.041 & -.659 & .510 \\
\hline & HOPE & .044 & .025 & 103 & 1.809 & .071 \\
\hline & OPEN & .054 & .029 & .106 & 1.836 & .067 \\
\hline & IDEO & -.081 & .077 & -.071 & -1.056 & .292 \\
\hline
\end{tabular}

a. Dependent Variable: RISK

Table 15

Multiple Regression Analysis Predicting Time Horizon with Socio-demographic Variables and Attitudinal Variables

\begin{tabular}{|c|c|c|c|c|c|c|}
\hline \multicolumn{2}{|c|}{ Model } & \multirow{2}{*}{\multicolumn{2}{|c|}{ Unstandardized Coefficients }} & \multirow{3}{*}{$\begin{array}{l}\text { Standardized } \\
\text { Coefficients } \\
\text { Beta }\end{array}$} & \multirow[b]{3}{*}{$\mathrm{t}$} & \multirow[b]{3}{*}{ Sig. } \\
\hline & & & & & & \\
\hline & & $\overline{\mathrm{B}}$ & Std. Error & & & \\
\hline \multirow[t]{10}{*}{1} & (Constant) & 4.484 & .646 & & 6.936 & .000 \\
\hline & GEN & .174 & .157 & .058 & 1.114 & .266 \\
\hline & AGE & .092 & .116 & .043 & .793 & .429 \\
\hline & EDU & -.135 & 195 & -.038 & -.696 & 487 \\
\hline & INC & -.022 & .059 & -.020 & -.366 & .714 \\
\hline & WORK & -.325 & 212 & -.090 & -1.534 & .126 \\
\hline & INV & -.360 & 187 & -.120 & -1.933 & .054 \\
\hline & HOPE & .079 & .024 & 181 & 3.244 & .001 \\
\hline & OPEN & .037 & .029 & .072 & 1.280 & .201 \\
\hline & IDEO & -.088 & .077 & -.076 & -1.152 & .250 \\
\hline
\end{tabular}

a. Dependent Variable: TIME 
Table 16

Multiple Regression Analysis Predicting Estate Intentions with Socio-demographic Variables and Attitudinal Variables

\begin{tabular}{|c|c|c|c|c|c|c|}
\hline \multicolumn{2}{|c|}{ Model } & \multicolumn{2}{|c|}{ Unstandardized Coefficients } & \multirow{2}{*}{$\begin{array}{l}\text { Standardized } \\
\text { Coefficients } \\
\text { Beta }\end{array}$} & \multirow[b]{2}{*}{$\mathrm{T}$} & \multirow[b]{2}{*}{ Sig. } \\
\hline & & $\overline{\mathrm{B}}$ & Std. Error & & & \\
\hline \multirow[t]{10}{*}{1} & (Constant) & 7.740 & .993 & & 7.792 & .000 \\
\hline & GEN & -.248 & .241 & -.053 & -1.028 & .305 \\
\hline & AGE & .552 & .175 & .172 & 3.162 & .002 \\
\hline & EDU & -.160 & .299 & -.029 & -.535 & .593 \\
\hline & INC & -.123 & .091 & -.073 & -1.355 & .176 \\
\hline & WORK & -1.082 & .325 & -.194 & -3.326 & .001 \\
\hline & INV & .093 & .286 & .020 & .327 & .744 \\
\hline & HOPE & .105 & .038 & .154 & 2.775 & .006 \\
\hline & OPEN & .059 & .045 & .074 & 1.312 & .190 \\
\hline & IDEO & .209 & .118 & .117 & 1.775 & .077 \\
\hline
\end{tabular}

a. Dependent Variable: EST

\section{Table 17}

Multiple Regression Analysis Predicting Risk tolerance with Socio-demographic Variables and Attitudinal Variables with Pro-social Attitudes as a Moderator Variable

\begin{tabular}{|c|c|c|c|c|c|c|}
\hline \multirow{2}{*}{\multicolumn{2}{|c|}{ Model }} & \multicolumn{2}{|c|}{ Unstandardized Coefficients } & \multirow{2}{*}{$\begin{array}{l}\text { Standardized } \\
\text { Coefficients } \\
\text { Beta }\end{array}$} & \multirow[b]{2}{*}{$\mathrm{t}$} & \multirow[b]{2}{*}{ Sig. } \\
\hline & & $\mathrm{B}$ & Std. Error & & & \\
\hline \multirow[t]{20}{*}{1} & (Constant) & 10.720 & 3.487 & & 3.075 & .002 \\
\hline & GEN & -1.122 & .786 & -.377 & -1.428 & .154 \\
\hline & AGE & .237 & .396 & .115 & .597 & .551 \\
\hline & EDU & -1.778 & .829 & -.513 & -2.146 & .033 \\
\hline & INC & .315 & .257 & .293 & 1.227 & .221 \\
\hline & WORK & -.742 & 1.071 & -.207 & -.693 & .489 \\
\hline & INV & -.025 & .861 & -.008 & -.028 & .977 \\
\hline & HOPE & .023 & .114 & .054 & .206 & .837 \\
\hline & OPEN & -.155 & .136 & -.306 & -1.134 & .258 \\
\hline & IDEO & -.358 & .364 & -.312 & -.984 & .326 \\
\hline & PRO & -.299 & .167 & -.914 & -1.792 & .074 \\
\hline & HOPR & .001 & .006 & .062 & .197 & .844 \\
\hline & OPPR & .010 & .007 & .503 & 1.549 & .122 \\
\hline & IDPRO & .014 & .017 & .273 & .818 & .414 \\
\hline & GENPRO & .055 & .038 & .479 & 1.445 & .149 \\
\hline & AGEPRO & -.009 & .020 & -.103 & -.427 & .670 \\
\hline & EDPRO & .089 & .042 & .552 & 2.098 & .037 \\
\hline & INCPRO & -.016 & .013 & -.339 & -1.274 & .203 \\
\hline & WORKPRO & .023 & .051 & .174 & .445 & .657 \\
\hline & INVPRO & -.006 & .042 & -.044 & -.148 & .883 \\
\hline
\end{tabular}

a. Dependent Variable: RISK

Pro-social Attitudes as a Moderator Variable

I argued that adding pro-social attitudes (PRO) as a moderator variable would increase the explanatory power of the model. However, Table 17 shows that adding pro- 
social attitudes results in an overall model that is not significant with $\mathrm{F}=1.67$ and $\mathrm{p}$ value $=0.086$. For risk I argued that the interaction between pro-social attitudes and the independent variables would add more explanatory power to the model to explain variance in investor preferences. Accordingly, I created new variables based on the interaction between the independent variables and pro-social attitudes indicating the risk tolerance score did not vary based on pro-social attitudes. For risk tolerance, the results show that adding pro-social attitudes as a moderator results in an overall significant model with $\mathrm{F}=1.79$ and $\mathrm{p}$ value $=$ 0.022. However, only the interaction between education and pro-social attitudes shows a significant result with beta $=.089$, and $\mathrm{p}$ value $=0.02$, indicating that the score on risk tolerance varied based on the interaction between education and pro-social attitudes.

Table 18

Multiple Regression Analysis Predicting Time Horizon with Socio-demographic Variables and Attitudinal Variables, with Pro-social Attitudes as a Moderator Variable

\begin{tabular}{|c|c|c|c|c|c|c|}
\hline \multicolumn{2}{|c|}{ Model } & \multicolumn{2}{|c|}{ Unstandardized Coefficients } & \multirow{2}{*}{$\begin{array}{l}\text { Standardized } \\
\text { Coefficients } \\
\text { Beta }\end{array}$} & \multirow[b]{2}{*}{$\mathrm{t}$} & \multirow[b]{2}{*}{ Sig. } \\
\hline & & $\mathrm{B}$ & Std. Error & & & \\
\hline \multirow[t]{20}{*}{1} & (Constant) & 10.099 & 3.534 & & 2.858 & .005 \\
\hline & GEN & -.284 & .795 & -.094 & -.357 & .722 \\
\hline & $\mathrm{AGE}$ & -.118 & .423 & -.055 & -.279 & .781 \\
\hline & EDU & -.981 & .845 & -.277 & -1.161 & .246 \\
\hline & INC & -.080 & .261 & -.073 & -.307 & .759 \\
\hline & WORK & -.355 & 1.082 & -.097 & -.328 & .743 \\
\hline & INV & -.855 & .889 & -.283 & -.962 & .337 \\
\hline & HOPE & -.094 & .115 & -.215 & -.817 & .415 \\
\hline & OPEN & -.024 & .138 & -.046 & -.172 & .864 \\
\hline & IDEO & -.267 & .370 & -.230 & -.721 & .471 \\
\hline & PRO & -.281 & .169 & -.841 & -1.663 & .097 \\
\hline & HOPR & .009 & .006 & .478 & 1.539 & .125 \\
\hline & OPPR & .003 & .007 & .127 & .395 & .693 \\
\hline & IDPRO & .009 & .018 & .174 & .518 & .605 \\
\hline & GENPRO & .022 & .038 & .185 & .562 & .574 \\
\hline & AGEPRO & .011 & .021 & .124 & .496 & .620 \\
\hline & EDPRO & .046 & .043 & .282 & 1.072 & .285 \\
\hline & INCPRO & .003 & .013 & .059 & .221 & .825 \\
\hline & WORKPRO & .001 & .052 & .007 & .018 & .986 \\
\hline & INVPRO & .024 & .044 & .169 & .560 & .576 \\
\hline
\end{tabular}

a. Dependent Variable: TIME 
For time horizon the results shown in Table 17 show that adding pro-social attitudes as a moderator variable produces a significant model with $\mathrm{F}=2.028$, and $\mathrm{p}$ value $=.007$. However, none of the independent variables shows significant results. For estate intentions the results shown in Table 19 indicate that adding pro-social attitudes as a moderator variable produces an overall significant model with $\mathrm{F}=2.386$, and $\mathrm{p}$ value $=.001$. However, none of the variables was statistically significant.

Correlation Divided by Gender

A number of regressions were run to reflect the research questions, but none of the regression models were found to be significant. Accordingly, I decided to disaggregate the data by males and females and run bivariate Pearson correlation analysis to see if there were any statistically significant differences based on gender.

Table 20 shows that for males age was positively correlated with education $(r=.148$, $\mathrm{p}=.022, \mathrm{n}=241)$, work experience $(\mathrm{r}=.177 \mathrm{p}=.006, \mathrm{n}=241)$, and investment experience $(\mathrm{r}=$ $.137, \mathrm{p}=.039, \mathrm{n}=229$ ), indicating that older males had more education, more work experience, and more investment experience. Education was negatively related to household income ( $\mathrm{r}=-$ $.156, \mathrm{p}=.019, \mathrm{n}=224$, pro-social attitude $(\mathrm{r}=-.216 \mathrm{p}=.001, \mathrm{n}=222)$, risk tolerance $(\mathrm{r}=-.144 \mathrm{p}=$ $.025, \mathrm{n}=240)$ and time horizon $(\mathrm{r}=-.170, \mathrm{p}=.011, \mathrm{n}=222)$, indicating that males with less education had less household income, higher scores on pro-social attitudes, and lower scores on risk tolerance and time horizon. Education was positively related to work experience $(\mathrm{r}=.200, \mathrm{p}=.002, \mathrm{n}=240)$ and (liberal) ideology $(\mathrm{r}=.269, \mathrm{p}=.000, \mathrm{n}=239)$. These results indicate that for males, those with more education had more work experience and were more liberal. 
Table 19

Multiple Regression Analysis Predicting Estate Intentions with Socio-demographic Variables and Attitudinal Variables, with Pro-social Attitudes as a Moderator Variable

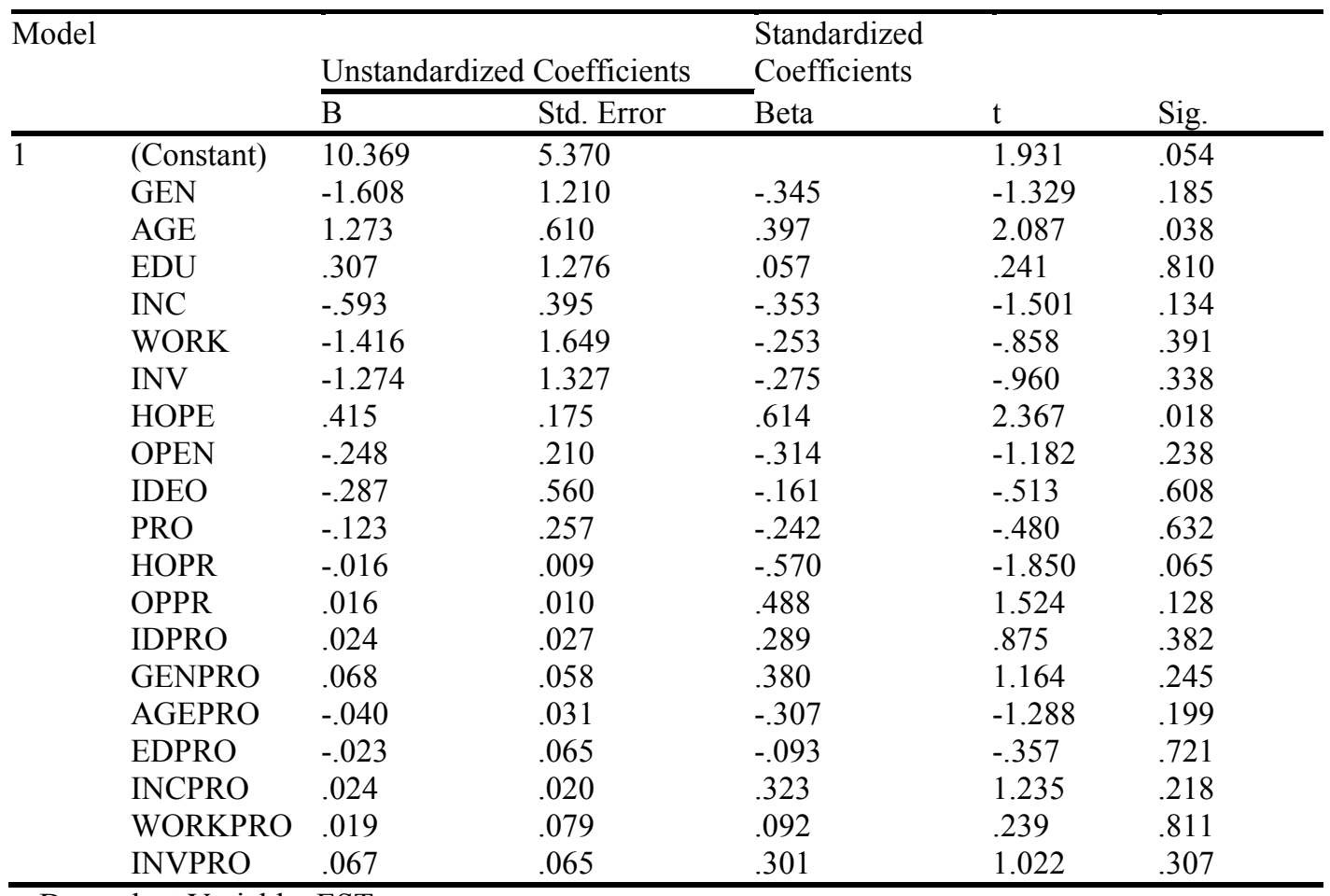

a. Dependent Variable: EST

The results showed that household income was positively correlated with investment experience $(\mathrm{r}=.307, \mathrm{p}=0.02, \mathrm{n}=222)$, and negatively correlated with openness $(\mathrm{r}=-.156, \mathrm{p}=$ $.02, \mathrm{n}=222)$, ideology $(\mathrm{r}=-.220, \mathrm{p}=.001, \mathrm{n}=225)$, and estate intentions $(\mathrm{r}=-.145, \mathrm{p}=.038$, $n=207)$. This indicates that males with higher household income had more investment experience, scored lower on openness, had more conservative ideology, and placed less value on leaving a bequest. Work experience was negatively related to investment experience $(\mathrm{r}=$ $.516, \mathrm{p}=.000, \mathrm{n}=220)$ and pro-social attitudes, $(\mathrm{r}=-.133, \mathrm{p}=.048, \mathrm{n}=222)$, but positively related to ideology $(r=.386, p=.000, n=240)$. These results indicated that males with more work experience had less investment experience, were more liberal, and scored lower on prosocial attitudes. 
Table 20

Correlation Matrix for Males

\begin{tabular}{|c|c|c|c|c|c|c|c|c|c|c|c|c|}
\hline \multirow{2}{*}{$\overline{\mathrm{AGE}}$} & \multirow{2}{*}{$\frac{\mathrm{AGE}}{1}$} & \multirow[t]{2}{*}{ EDU } & \multirow[t]{2}{*}{ INC } & \multicolumn{2}{|c|}{ WORK INV } & HOPE & OPEN & IDEO & \multirow[t]{2}{*}{ PRO } & \multirow[t]{2}{*}{ RISK } & \multirow[t]{2}{*}{ TIME } & \multirow[t]{2}{*}{ EST } \\
\hline & & & & & & & & & & & & \\
\hline & 242 & & & & & & & & & & & \\
\hline \multirow[t]{3}{*}{ EDU } & $.148^{*}$ & 1 & & & & & & & & & & \\
\hline & .022 & & & & & & & & & & & \\
\hline & 241 & 241 & & & & & & & & & & \\
\hline \multirow[t]{3}{*}{ INC } & .066 & $-.156^{*}$ & 1 & & & & & & & & & \\
\hline & .328 & .019 & & & & & & & & & & \\
\hline & 225 & 224 & 225 & & & & & & & & & \\
\hline \multirow[t]{3}{*}{ WORK } & $.177^{* *}$ & $.200^{* *}$ & -.047 & 1 & & & & & & & & \\
\hline & .006 & .002 & . 481 & & & & & & & & & \\
\hline & 241 & 240 & 225 & 241 & & & & & & & & \\
\hline \multirow[t]{3}{*}{ INV } & $.137^{*}$ & -.043 & $.307^{* *}$ & $-.153^{*}$ & 1 & & & & & & & \\
\hline & .039 & .522 & .000 & .020 & & & & & & & & \\
\hline & 229 & 228 & 213 & 228 & 229 & & & & & & & \\
\hline \multirow[t]{3}{*}{ HOPE } & -.026 & -.014 & -.098 & -.078 & -.050 & 1 & & & & & & \\
\hline & .702 & .837 & .161 & .248 & .459 & & & & & & & \\
\hline & 221 & 220 & 205 & 220 & 221 & 221 & & & & & & \\
\hline \multirow[t]{3}{*}{ OPEN } & -.015 & -.057 & $-.156^{*}$ & -.109 & -.074 & $.516^{* *}$ & 1 & & & & & \\
\hline & 820 & .378 & . 020 & .095 & 269 & .000 & & & & & & \\
\hline & 239 & 238 & 222 & 238 & 226 & 220 & 239 & & & & & \\
\hline \multirow[t]{3}{*}{ IDEO } & .005 & $.269^{*}$ & $-.220^{* *}$ & $.386^{* *}$ & $-.453^{*}$ & -.031 & -.036 & 1 & & & & \\
\hline & .943 & .000 & .001 & .000 & .000 & .643 & .581 & & & & & \\
\hline & 240 & 239 & 225 & 240 & 227 & 219 & 237 & 240 & & & & \\
\hline \multirow[t]{3}{*}{ PRO } & -.100 & $-.216^{* \pi}$ & .016 & $-.133^{*}$ & -.043 & -.095 & -.039 & -.083 & 1 & & & \\
\hline & .137 & .001 & .819 & .048 & .520 & .158 & .567 & .221 & & & & \\
\hline & 223 & 222 & 207 & 222 & 223 & 220 & 221 & 221 & 223 & & & \\
\hline \multirow[t]{3}{*}{ RISK } & -.005 & $-.144^{*}$ & .018 & $\begin{array}{l}-.003 \\
\end{array}$ & .046 & $.211^{* *}$ & $.183^{* *}$ & -.091 & -.036 & 1 & & \\
\hline & .935 & .025 & .794 & .962 & .489 & .002 & .005 & .161 & .593 & & & \\
\hline & 241 & 240 & 225 & 240 & 229 & 221 & 238 & 239 & 223 & 241 & & \\
\hline \multirow[t]{3}{*}{ TIME } & $\begin{array}{l}.079 \\
\end{array}$ & $-.170^{*}$ & $\begin{array}{l}.061 \\
\end{array}$ & -.090 & -.105 & $.278^{* *}$ & $.188^{* *}$ & $\begin{array}{l}.040 \\
\end{array}$ & .046 & $.450^{* *}$ & 1 & \\
\hline & .239 & 011 & .380 & .180 & .118 & .000 & .005 & .550 & .500 & .000 & & \\
\hline & 223 & 222 & 207 & 222 & 223 & 220 & 221 & 221 & 222 & 223 & 223 & \\
\hline \multirow[t]{3}{*}{ EST } & .082 & .043 & $-.145^{*}$ & -.066 & -.035 & $.160^{\circ}$ & $.137^{*}$ & .043 & -.091 & .047 & .106 & 1 \\
\hline & 222 & .521 & .038 & .327 & .607 & .018 & .042. & .520 & 177 & .489 & .114 & \\
\hline & 223 & 222 & 207 & 222 & 223 & 220 & 222 & 221 & 222 & 223 & 222 & 223 \\
\hline
\end{tabular}

* Correlation is significant at the 0.05 level (2-tailed).

** Correlation is significant at the 0.01 level (2-tailed).

Investment experience was negatively related to ideology $(r=-.453, p=.000, n=227)$

indicating that males with more investment experience were more conservative. Hope was positively related to openness, $(\mathrm{r}=.386, \mathrm{p}=.000, \mathrm{n}=240)$, risk tolerance $(\mathrm{r}=.211, \mathrm{p}=.002$, $\mathrm{n}=221)$, and estate intentions, $(\mathrm{r}=.160, \mathrm{p}=.018, \mathrm{n}=220)$, indicating that males with higher 
hope were more risk tolerant, intended to invest with a longer time horizon, and placed higher value on leaving a bequest. Openness was positively related to risk tolerance $(r=.183, p=.005$, $\mathrm{n}=238)$, time horizon $(\mathrm{r}=.188, \mathrm{p}=.005, \mathrm{n}=221)$, and estate intentions $(\mathrm{r}=.137, \mathrm{p}=.042, \mathrm{n}=222)$, indicating that males with more openness were more risk tolerant, invested with a longer time horizon, and placed higher value on leaving a bequest. Finally, risk tolerance was positively related to time horizon $(\mathrm{r}=.450, \mathrm{p}=.000, \mathrm{n}=223)$, indicating that males with more risk tolerance invested with a longer time horizon.

Table 21 shows that age was positively correlated with education $(r=.166, p=.016$, $\mathrm{n}=209)$, household income $(\mathrm{r}=.206, \mathrm{p}=.004, \mathrm{n}=197)$, investment experience $(\mathrm{r}=.209, \mathrm{p}=.003$, $\mathrm{n}=198)$, and liberal ideology $(\mathrm{r}=.171, \mathrm{p}=.013, \mathrm{n}=211)$, indicating that older females were more educated, had more household income, and were more liberal. Education was positively correlated to work experience $(r=.200, p=.004, n=209)$, liberal ideology $(r=.224, p=.001$, $\mathrm{n}=208)$, and risk tolerance $(\mathrm{r}=.150, \mathrm{p}=.000, \mathrm{n}=208)$, indicating that females who were more educated had more work experience, were more liberal, and were more risk tolerant. For females, household income was positively related to investment experience $(r=.294, p=.000$, $\mathrm{n}=184)$, and negatively related to ideology $(\mathrm{r}=.-249, \mathrm{p}=.000, \mathrm{n}=196)$, indicating that females with higher household income had more investment experience and were more conservative. Work experience was negatively correlated with investment experience $(r=-.302, p=.000$, $\mathrm{n}=198)$, but positively correlated with liberal ideology $(\mathrm{r}=.528, \mathrm{p}=.000, \mathrm{n}=211)$, indicating that females with more work experience had less investment experience and were more liberal. Investment experience was negatively related to openness $(r=.-179, p=.012, n=196)$ and liberal ideology $(\mathrm{r}=.-533, \mathrm{p}=.000, \mathrm{n}=197)$, indicating that females with more investment experience were lower on openness and more conservative. Hope was positively related to openness $(\mathrm{r}=.304, \mathrm{p}=.000, \mathrm{n}=189)$, time horizon $(\mathrm{r}=.182, \mathrm{p}=.012, \mathrm{n}=191)$, and estate intentions, $(r=.248, p=.001 \mathrm{n}=194)$, but negatively related to pro-social attitudes $(\mathrm{r}=.-190$, 
$\mathrm{p}=.000, \mathrm{n}=189)$, indicating that females with higher hope were more open, anticipated investing with a longer time horizon, and placed high value on leaving a bequest, but scored lower on pro-social issues..

Table 21

Correlation Matrix for Female Investors

\begin{tabular}{|c|c|c|c|c|c|c|c|c|c|c|c|c|}
\hline & AGE & EDU & INC & WORK & INV & HOPE & OPEN & IDEO & PRO & RISK & TIME & EST \\
\hline \multirow[t]{2}{*}{$\overline{\mathrm{AGE}}$} & 1 & & & & & & & & & & & \\
\hline & 212 & & & & & & & & & & & \\
\hline \multirow[t]{3}{*}{$\overline{\mathrm{EDU}}$} & $.166^{*}$ & 1 & & & & & & & & & & \\
\hline & .016 & & & & & & & & & & & \\
\hline & 209 & 209 & & & & & & & & & & \\
\hline \multirow[t]{3}{*}{$\overline{\mathrm{INC}}$} & $.206^{* *}$ & -.062 & 1 & & & & & & & & & \\
\hline & .004 & .388 & & & & & & & & & & \\
\hline & 197 & 195 & 197 & & & & & & & & & \\
\hline \multirow[t]{3}{*}{$\overline{\text { WORK }}$} & K.244 ${ }^{* *}$ & $.200^{* *}$ & -.117 & 1 & & & & & & & & \\
\hline & .000 & .004 & .100 & & & & & & & & & \\
\hline & 212 & 209 & 197 & 212 & & & & & & & & \\
\hline \multirow[t]{3}{*}{$\overline{\mathrm{INV}}$} & $.209^{* *}$ & \begin{tabular}{|l|}
-.093 \\
\end{tabular} & $.294^{* *}$ & $-.302^{* *}$ & 1 & & & & & & & \\
\hline & .003 & .193 & .000 & .000 & & & & & & & & \\
\hline & 198 & 196 & 184 & 198 & 198 & & & & & & & \\
\hline \multirow[t]{3}{*}{$\overline{\mathrm{HOPE}}$} & $\begin{array}{l}-.049 \\
\end{array}$ & .051 & .063 & .037 & -.095 & 1 & & & & & & \\
\hline & .497 & .490 & .406 & .607 & .190 & & & & & & & \\
\hline & 191 & 189 & 177 & 191 & 191 & 191 & & & & & & \\
\hline \multirow[t]{3}{*}{$\overline{\mathrm{OPEN}}$} & -.035 & -.015 & .016 & .050 & $-.179^{*}$ & $.304^{* *}$ & 1 & & & & & \\
\hline & .619 & .827 & .825 & .469 & .012 & .000 & & & & & & \\
\hline & 210 & 207 & 195 & 210 & 196 & 189 & 210 & & & & & \\
\hline \multirow[t]{3}{*}{$\overline{\mathrm{IDEO}}$} & $.171^{*}$ & $.224^{* *}$ & $-.249^{* *}$ & $.528^{* *}$ & $-.533^{* *}$ & .081 & .095 & 1 & & & & \\
\hline & .013 & .001 & .000 & .000 & .000 & .265 & .170 & & & & & \\
\hline & 211 & 208 & 196 & 211 & 197 & 190 & 209 & 211 & & & & \\
\hline \multirow[t]{3}{*}{$\overline{\mathrm{PRO}}$} & .085 & -.107 & .053 & -.053 & .109 & $-.190^{* *}$ & $\begin{array}{l}-.019 \\
\end{array}$ & -.036 & 1 & & & \\
\hline & .241 & .140 & .477 & .465 & .131 & .009 & .798 & .622 & & & & \\
\hline & 193 & 191 & 180 & 193 & 193 & 189 & 191 & 192 & 193 & & & \\
\hline \multirow[t]{3}{*}{$\overline{\text { RISK }}$} & .046 & $.150^{*}$ & .007 & -.094 & -.122 & .007 & .070 & -.004 & .067 & 1 & & \\
\hline & .506 & .031 & .926 & .173 & .087 & .928 & .312 & .952 & .353 & & & \\
\hline & 211 & 208 & 196 & 211 & 197 & 190 & 209 & 210 & 192 & 211 & & \\
\hline \multirow[t]{3}{*}{ TIME } & .048 & .086 & -.014 & -.066 & -.061 & $.182^{*}$ & .100 & $\begin{array}{l}-.074 \\
\end{array}$ & -.013 & $.513^{* * 3}$ & 1 & \\
\hline & .507 & .235 & .854 & .360 & .394 & .012 & .165 & .305 & .859 & .000 & & \\
\hline & 196 & 194 & 182 & 196 & 196 & 191 & 194 & 195 & 193 & 195 & 196 & \\
\hline \multirow[t]{3}{*}{$\overline{\mathrm{EST}}$} & .076 & .033 & .007 & -.101 & -.016 & $.248^{* *}$ & .099 & .082 & -.003 & -.059 & .062 & 1 \\
\hline & .290 & .651 & .926 & .160 & .826 & .001 & .171 & .258 & .967 & .417 & .390 & \\
\hline & 194 & 192 & 180 & 194 & 194 & 189 & 192 & 193 & 191 & 193 & 194 & 194 \\
\hline
\end{tabular}

* Correlation is significant at the 0.05 level (2-tailed).

** Correlation is significant at the 0.01 level (2-tailed). 
The Components of Estate Intentions Scale

The estate intentions scale was developed for the purpose of this study. Therefore, I decided to test if the independent variables correlate differently with the components of the scale (leaving an inheritance to a religious organization, to charity, and to family members) rather than the total score. Accordingly, I ran the correlation matrix using the three components, first for the whole sample, and then divided by gender.

Table 22 shows the socio-demographic variables that significantly correlated with the three estate intentions components for males. For males, age was positively correlated with charity $(r=.161, p=.012, n=242)$, indicating that older males were more inclined to leave an inheritance to charity. Household income was negatively correlated with leaving an inheritance to religious organizations and to charity $(r=.-157, p=.015, n=240)$, indicating that males with more household income were less inclined to leave an inheritance to religious groups and to charity. Hope was also positively related to charity $(r=.165, p=0.14, n=221)$, indicating that males with more hope were more inclined to leave an inheritance to charity.

Table 23 shows the variables that significantly correlated with the three components of estate intentions for females. Hope was positively correlated with giving to religious organizations $(r=199, p=0.004 . n=190)$, and giving to charity $(r=.213, p=0.003, n=191)$ indicating that females with more hope placed more value on leaving a bequest to religious organizations and to charity. For females, the only variables that correlated with placing value on leaving a bequest to family members were the other components of the estate intentions scale.

There are differences between males and females regarding the three components of estate intentions. For females only, hope and openness were significantly correlated with wanting to leave a bequest to religious group and charity but not family (see Table 23), while for males intent to leave a bequest to religious group and charity, but not family, age, 
household income, work experience, hope, and time horizon, were significantly associated

with the components of estate intentions.

Table 22

Male Estate Intention Scale Correlations

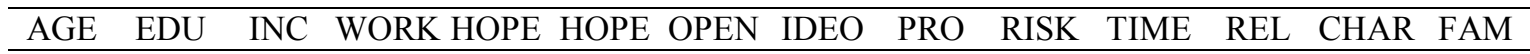

AGE $\quad 1$

\begin{tabular}{|c|c|c|c|c|c|c|c|c|c|c|c|c|c|c|}
\hline$\overline{\mathrm{EDU}}$ & $\begin{array}{c}242 \\
.148^{*} \\
.022 \\
241\end{array}$ & 241 & & & & & & & & & & & & \\
\hline \multirow[t]{3}{*}{$\overline{\mathrm{INC}}$} & .066 & $-.156^{*}$ & 1 & & & & & & & & & & & \\
\hline & .328 & .019 & & & & & & & & & & & & \\
\hline & 225 & 224 & 225 & & & & & & & & & & & \\
\hline \multirow[t]{3}{*}{ WORK } & $.272^{* *}$ & $.254^{* *}$ & -.025 & 1 & & & & & & & & & & \\
\hline & .000 & .000 & .714 & & & & & & & & & & & \\
\hline & 241 & 240 & 225 & 241 & & & & & & & & & & \\
\hline \multirow[t]{3}{*}{$\overline{\mathrm{INV}}$} & $.137^{*}$ & -.043 & $.307^{* *}$ & -.046 & 1 & & & & & & & & & \\
\hline & .039 & .522 & .000 & .486 & & & & & & & & & & \\
\hline & 229 & 228 & 213 & 228 & 229 & & & & & & & & & \\
\hline \multirow[t]{3}{*}{ HOPE } & -.026 & -.014 & -.098 & $-.180^{* *}$ & -.050 & 1 & & & & & & & & \\
\hline & .702 & .837 & .161 & .008 & .459 & & & & & & & & & \\
\hline & 221 & 220 & 205 & 220 & 221 & 221 & & & & & & & & \\
\hline \multirow[t]{3}{*}{ OPEN } & -.015 & -.057 & $-.156^{*}$ & $-.216^{* *}$ & -.074 & $.516^{* *-}$ & 1 & & & & & & & \\
\hline & .820 & .378 & .020 & .001 & .269 & .000 & & & & & & & & \\
\hline & 239 & 238 & 222 & 238 & 226 & 220 & 239 & & & & & & & \\
\hline \multirow[t]{3}{*}{ IDEO } & .005 & $.269^{* *}$ & $-.220^{* *}$ & $.279^{* *}$ & $-.453^{* *}$ & -.031 & -.036 & 1 & & & & & & \\
\hline & .943 & .000 & .001 & .000 & .000 & .643 & .581 & & & & & & & \\
\hline & 240 & 239 & 225 & 240 & 227 & 219 & 237 & 240 & & & & & & \\
\hline \multirow[t]{3}{*}{$\overline{\mathrm{PRO}}$} & -.100 & $-.216^{* *}$ & .016 & $-.194^{* *}$ & -.043 & -.095 & -.039 & -.083 & 1 & & & & & \\
\hline & .137 & .001 & .819 & .004 & .520 & .158 & .567 & .221 & & & & & & \\
\hline & 223 & 222 & 207 & 222 & 223 & 220 & 221 & 221 & 223 & & & & & \\
\hline \multirow[t]{3}{*}{ RISK } & -.005 & $-.144^{*}$ & .018 & .004 & .046 & $.211^{* *-}$ & $.183^{* *}$ & -.091 & -.036 & 1 & & & & \\
\hline & .935 & .025 & .794 & .949 & .489 & .002 & .005 & .161 & .593 & & & & & \\
\hline & 241 & 240 & 225 & 240 & 229 & 221 & 238 & 239 & 223 & 241 & & & & \\
\hline \multirow[t]{3}{*}{ TIME } & -.079 & $-.170^{*}$ & -.061 & -.111 & -.105 & $.278^{* *-}$ & $.188^{* *}$ & -.040 & .046 & $.450^{* *}$ & 1 & & & \\
\hline & .239 & .011 & .380 & .098 & .118 & .000 & .005 & .550 & .500 & .000 & & & & \\
\hline & 223 & 222 & 207 & 222 & 223 & 220 & 221 & 221 & 222 & 223 & 223 & & & \\
\hline \multirow[t]{3}{*}{$\overline{\mathrm{REL}}$} & -.025 & .018 & $-.163^{*}$ & -.011 & -.087 & $.165^{*-}$ & .096 & .093 & -.057 & .053 & .095 & 1 & & \\
\hline & .699 & .779 & .015 & .861 & .188 & .014 & .139 & .152 & .395 & .416 & .156 & & & \\
\hline & 242 & 241 & 225 & 241 & 229 & 221 & 239 & 240 & 223 & 241 & 223 & 242 & & \\
\hline \multirow[t]{3}{*}{$\overline{\mathrm{CHAR}}$} & $.161^{*}$ & .104 & $-.149^{*}$ & .017 & -.057 & .076 & .118 & .085 & -.074 & -.046 & .008 & $.419^{* *}$ & 1 & \\
\hline & .012 & .109 & .025 & .790 & .392 & .263 & .068 & .187 & .273 & .473 & .905 & .000 & & \\
\hline & 242 & 241 & 225 & 241 & 229 & 221 & 239 & 240 & 223 & 241 & 223 & 242 & 242 & \\
\hline \multirow[t]{3}{*}{$\overline{\text { FAM }}$} & -.004 & -.022 & .002 & $-.185^{* *}$ & .089 & .112 & .103 & -.104 & -.074 & .069 & $.140^{*}$ & $.213^{* *}$ & $.266^{* *}$ & \\
\hline & .945 & .732 & .974 & .004 & .180 & .097 & .114 & .107 & .270 & .285 & .037 & .001 & .000 & \\
\hline & 241 & 240 & 224 & 240 & 228 & 220 & 239 & 239 & 222 & 240 & 222 & 241 & 241 & 24 \\
\hline
\end{tabular}

* Correlation is significant at the 0.05 level (2-tailed).

** Correlation is significant at the 0.01 level (2-tailed). 
Table 23

Female Estate Intention Scale Correlations

\begin{tabular}{|c|c|c|c|c|c|c|c|c|c|c|c|c|c|c|}
\hline & AGE & EDU & INC & WORK & INV & HOPE & OPEN & IDEO & PRO & RISK & TIME & REL & CHAR & FAM \\
\hline \multirow[t]{2}{*}{$\overline{\mathrm{AGE}}$} & 1 & & & & & & & & & & & & & \\
\hline & 212 & & & & & & & & & & & & & \\
\hline \multirow[t]{3}{*}{$\overline{\mathrm{EDU}}$} & $.166^{*}$ & 1 & & & & & & & & & & & & \\
\hline & .016 & 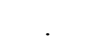 & & & & & & & & & & & & \\
\hline & 209 & 209 & & & & & & & & & & & & \\
\hline \multirow[t]{3}{*}{$\overline{\mathrm{INC}}$} & $.206^{* *}$ & -.062 & 1 & & & & & & & & & & & \\
\hline & .004 & .388 & & & & & & & & & & & & \\
\hline & 197 & 195 & 197 & & & & & & & & & & & \\
\hline \multirow{3}{*}{$\overline{\text { WORK }}$} & $.387 * *$ & $.250 * *$ & -.016 & 1 & & & & & & & & & & \\
\hline & .000 & .000 & .824 & & & & & & & & & & & \\
\hline & 212 & 209 & 197 & 212 & & & & & & & & & & \\
\hline \multirow[t]{3}{*}{$\overline{\mathrm{INV}}$} & $.209 * *$ & -.093 & $.294 * *$ & $-.142 *$ & 1 & & & & & & & & & \\
\hline & .003 & .193 & .000 & .046 & & & & & & & & & & \\
\hline & 198 & 196 & 184 & 198 & 198 & & & & & & & & & \\
\hline \multirow[t]{3}{*}{$\overline{\mathrm{HOPE}}$} & -.049 & .051 & .063 & -.044 & -.095 & 1 & & & & & & & & \\
\hline & .497 & .490 & .406 & .542 & .190 & & & & & & & & & \\
\hline & 191 & 189 & 177 & 191 & 191 & 191 & & & & & & & & \\
\hline \multirow[t]{3}{*}{$\overline{\mathrm{OPEN}}$} & -.035 & -.015 & .016 & -.022 & $-.179 *$ & $.304 * *$ & 1 & & & & & & & \\
\hline & .619 & .827 & .825 & .750 & .012 & .000 & & & & & & & & \\
\hline & 210 & $\begin{array}{l}.021 \\
207 \\
\end{array}$ & $\begin{array}{l}.025 \\
195 \\
\end{array}$ & 210 & 196 & 189 & 210 & & & & & & & \\
\hline \multirow[t]{3}{*}{$\overline{\mathrm{IDEO}}$} & $.171^{*}$ & $.224 * *$ & $-.249 * *$ & $.468 * *$ & $-.533 * *$ & .081 & .095 & 1 & & & & & & \\
\hline & .013 & .001 & .000 & .000 & .000 & .265 & .170 & & & & & & & \\
\hline & 211 & 208 & 196 & 211 & 197 & 190 & 209 & 211 & & & & & & \\
\hline \multirow[t]{3}{*}{$\overline{\mathrm{PRO}}$} & .085 & -.107 & .053 & -.055 & .109 & $-.190^{* * *}$ & -.019 & -.036 & 1 & & & & & \\
\hline & .241 & .140 & .477 & .451 & .131 & .009 & .798 & .622 & & & & & & \\
\hline & 193 & 191 & 180 & 193 & 193 & 189 & 191 & 192 & 193 & & & & & \\
\hline \multirow[t]{3}{*}{$\overline{\text { RISK }}$} & .046 & $.150^{*}$ & .007 & -.077 & -.122 & .007 & .070 & -.004 & .067 & 1 & & & & \\
\hline & .506 & .031 & .926 & .263 & .087 & .928 & .312 & .952 & .353 & & & & & \\
\hline & 211 & 208 & 196 & 211 & 197 & 190 & 209 & 210 & 192 & 211 & & & & \\
\hline \multirow[t]{3}{*}{ TIME } & .048 & .086 & -.014 & -.063 & -.061 & $.182 *$ & .100 & -.074 & -.013 & $.513 * *$ & 1 & & & \\
\hline & .507 & .235 & .854 & .380 & .394 & .012 & .165 & .305 & .859 & .000 & . & & & \\
\hline & 196 & 194 & 182 & 196 & 196 & 191 & 194 & 195 & 193 & 195 & 196 & & & \\
\hline \multirow[t]{3}{*}{$\overline{\mathrm{REL}}$} & .043 & .026 & .080 & -.050 & .058 & $.255^{* *}$ & $.199 * *$ & .080 & .120 & -.102 & -.049 & 1 & & \\
\hline & .536 & .710 & .263 & .473 & .416 & .000 & .004 & .249 & .096 & .143 & .499 & . & & \\
\hline & 211 & 208 & 196 & 211 & 197 & 190 & 209 & 210 & 192 & 210 & 195 & 211 & & \\
\hline \multirow[t]{3}{*}{$\overline{\text { CHAR }}$} & .109 & .043 & .026 & -.074 & -.044 & $.213 * *$ & $.178 * *$ & .075 & -.105 & -.055 & .097 & $.501 * *$ & 1 & \\
\hline & .113 & .541 & .713 & .285 & .536 & .003 & .010 & .281 & .145 & .429 & .177 & .000 & . & \\
\hline & 212 & 209 & 197 & 212 & 198 & 191 & 210 & 211 & 193 & 211 & 196 & 211 & 212 & \\
\hline \multirow[t]{3}{*}{$\overline{\text { FAM }}$} & -.058 & .012 & -.110 & -.056 & -.053 & .108 & -.119 & .044 & -.035 & .021 & .140 & $.165^{*}$ & $.250 * *$ & 1 \\
\hline & .404 & .865 & .124 & .417 & .458 & .136 & .087 & .524 & .631 & .765 & .051 & .017 & .000 & \\
\hline & 211 & 208 & 196 & 211 & 197 & 190 & 209 & 210 & 192 & 210 & 195 & 210 & 211 & 211 \\
\hline
\end{tabular}

* Correlation is significant at the 0.05 level (2-tailed).

** Correlation is significant at the 0.01 level (2-tailed). 


\section{CHAPTER V}

\section{DISCUSSION AND CONCLUSION}

This study was explorative and descriptive in nature, and built on literature from several different disciplines including finance, political science, psychology, and consumer behavior. The findings of the study were reported in Chapter 4. Previous studies on investor preferences have attributed differences in investor behavior to socio-demographic variables such age, gender, education, and income. However, recent studies in behavioral finance as well as in management have begun to pay more attention to the role attitudes play in making financial decisions. The present study helps to fill this gap. To my knowledge, no previous study has examined how investor preferences are influenced by attitudinal variables such as positive psychology attitudes (e.g., hope, openness), political ideology, and pro-social attitudes. The results showed significant correlations among some of the attitude variables used in the study, especially hope and openness, with the dependent variables. This chapter discusses the findings and concludes the study. In the first part, I consider the findings and compare them to previous research. I discuss the limitations of the study, and then I present a future research agenda as well as the implications of this study for both academicians and practitioners. Finally, a conclusion of the study will be provided at the end of the chapter.

I started out with a model that turned out to be severely inadequate in understanding investor preferences. The data suggest that psychological variables should receive much more attention than they have received in the past, and that pro-social attitudes may not be a useful variable to consider in future studies. While I found socio-demographic variables to be of little importance in affecting investor preferences, the nature of my sample precludes a definitive statement in this regard.

Discussion

This study used statistical analysis to answer the following research questions. 
- Are socio-demographic variables sufficient to predict investor preference? Is there a difference between males and females?

- How much additional variance is explained by attitudinal variables including political ideology, positive psychology, and pro-social attitudes?

- Are these attitudinal variables simply additive or are they interactive?

Q1: Are Socio-demographic variables sufficient to predict investor preference?

In this study I first examined whether the variables age, gender, education, household income, work experience, and investment experience were adequate to predict investor preferences. As would be expected, age, education, work experience, and investment experience were associated with one another. I expected these socio-demographic variables to be significant in predicting investor preferences. For investor preferences, I used existing scales on risk tolerance and time horizon, and developed a scale for estate intentions. Numerous studies have found that socio-demographic variables play a role in predicting risk tolerance. For example, Grable (2000) found gender and educational level were the two socio-demographic variables most correlated with risk tolerance. However, my regression analysis showed that only age and work experience were significant in predicting estate intentions, while none of the socio-demographic variables was significant in predicting risk tolerance or time horizon. Possibly, the differences between these results and previous results might be attributed to the nature of the sample, which consisted of MBA and senior undergraduate students in the business school. Since the regression model showed only a few variables were significant in predicting investor preferences, I also used the Pearson's correlations matrix to test the socio-demographic variables. In the first step I used the whole sample to determine the bivariate relationships among all variables. In the next step I divided the sample into two groups based on gender to see if there were any differences between males and females. 
I expected to find a significant correlation between gender and the dependent variables. Researchers and financial practitioners have reported that women are more risk averse than men (Grable, 2000; Hallahan, Faff, \& McKenzie, 2004; Hinz, McCarthy, \& Turner, 1997). However, these findings from my study were not consistent with these previous studies. My results showed that gender was positively correlated only with time horizon, with females preferring to invest with a longer time horizon. I believe the similarity of males and females can be attributed to the fact that the sample consisted of males and females who had the same level of education. Recent studies have found that as education and knowledge increase in financial decision making, the gender differences regarding risk attitudes diminish (Gysler, Kruse, Schuber, \& Schubert, 2002).

I expected age to be significantly correlated with investor preferences. Previous research investigating the role of age in predicting risk tolerance produced contradictory findings. One study found that younger individuals were more risk tolerant, presumably because they had time to recover in case of losses (Clark, Caerlewy-Smith, \& Marshall, 2006). However, Grable and Joo (2000) found that older investors had higher risk tolerance than younger individuals and therefore invested with a longer time horizon. It is possible, however, that these effects were observed because older individuals had more wealth accumulation. Other studies have failed to reveal any effect of age on risk tolerance (Gollier, 2002; Grable, 2000; Grable \& Lytton, 1999; Hanna, Gutter, \& Fan, 2001; Hariharan, Chapman, \& Domian, 2000; Wang \& Hanna 1997). I found no significant relationship between age and investor preferences. Accordingly, my results were more consistent with the recent studies where age had no effect on investor preferences.

I expected education to be positively correlated with the investor preferences. Previous studies showed the level of education seems to increase risk-taking behavior, because individuals with higher education have more skills to assess risk than individuals 
with less education. This argument is supported by several studies (Haliassos \& Bertaut, 1995; Sung \& Hanna, 1996; Zhong \& Xiao, 1995). However, the Pearson's Correlation Coefficient indicated that education was not correlated significantly with investor preferences in my study. I believe this is observed because this sample consisted of individuals with little variation in the level or type of education.

I expected household income to be significantly correlated with investor preferences. Previous studies produced contradictory results regarding the relationship between income and risk tolerance. Some studies have found that income and wealth are two related factors having positive relationship to risk tolerance (Cohn et al., 1975; Grable \& Lytton, 1999; Riley \& Chow, 1992; Schooley \& Worden, 1996). On the other hand, some studies have found that wealthy individuals are more risk averse than less wealthy individual (Hallahan et al., 2004). The latter may view risky investments as a form of lottery ticket and be more willing to bear the risk associated with such payoffs. The study found no significant relationship between household income and risk tolerance. I believe these findings were affected by the way respondents interpreted "household income." I observed a fairly differentiated distribution of reported household income, but some respondents probably considered their household income to include their parents, while others may have thought of themselves with a partner or spouse, and others may have thought of themselves alone as a household.

I expected work experience to be positively correlated with investor preferences. Previous studies have found that individuals employed in occupations like management, medicine, and law are willing to take more financial risks than individuals employed as clerical workers and laborers (Haliassos \& Bertaut, 1995; Sung \& Hanna, 1996). Surprisingly, in this study work experience was not correlated with investor preferences. 
Possibly I did not find any significant results because I had few respondents with extensive full-time work experience.

I expected investment experience to be positively correlated with investor preferences. However, I did not find a positive relationship between investment experience and investor preferences, possibly because relatively few participants had significant investment experience, and almost none had extensive investment experience.

In summary, socio-demographic variables were generally not associated with investor preferences in this study.

\section{Gender Differences in Investor Preferences}

To see if there were differences in the socio-demographic variables based on gender, I decided to split the sample into two groups. Splitting the sample based on gender showed some differences between males and females in the correlation of several variables. Most striking was the finding that males with more education were more risk averse, while females with more education were less risk averse. Previous research has found education to be positively correlated with risk tolerance and males to be more risk tolerant than females. The findings of my study suggest that females with higher education may acquire more skills in assessing risk and accordingly they accept more risk when they make investment decisions. Paradoxically, males with higher education may acquire more skills in assessing risk tolerance and these may lessen their inclination to accept a high level of risk. For males, household income was negatively correlated with estate intentions. This is consistent with previous studies which found individuals with higher income give less to charity. The matrix did not show any significant results for females with the socio-demographic variables other than education. The socio-demographic characteristics appear to have little power in explaining investor preferences. 
Since the estate intentions scale was developed for this study, and never tested before, I decided to see if the three items of the scale correlated differently for males and females. The correlation matrix for females showed none of the items of the scale correlated significantly with the socio-demographic variables. The data showed similar results for males.

Q2: How much additional variance is explained by attitudinal variables including political ideology, positive psychology attitudes, and pro-social attitudes?

Next I considered the importance of the attitudinal variables, (hope, openness, ideology, and pro-social attitudes) in explaining investor preferences. I expected to find hope and openness positively correlated with investor preferences. This expectation was based on a logical analysis of the likely influence of these constructs, since no previous studies were available. However, several related studies were considered. Researchers from several disciplines have found positive psychology to be significantly correlated with outcomes such as performance (Adams et al., 2002; Luthans \& Peterson, 2003; Peterson \& Luthans, 2003). These studies suggest that those who score high on hope are more confident and more motivated to do the task. Luthans \& Jensen (2002) argue that high-hope individuals are especially needed for today's extremely turbulent organizational environment. They suggest that developing hope in employees can help these individuals cope with uncertain environment and therefore make more effective performers. Using a similar argument I propose that high openness indicates that individuals are more able to cope with uncertain environments. Accordingly, these arguments are consistent with the findings that individuals with high scores on hope and openness are more risk tolerant, invest with a longer time horizon, and give more importance to leaving a bequest to a religious organization, charity, and family. 
I expected to find ideology to be significantly correlated with investor preferences. Kaustia and Torstila (2010) assert that liberal investors are more risk averse than conservative investors, because liberal investors invest less in the stock market. However, my data showed that political ideology did not correlate significantly with any investor preferences. However, ideology was significantly associated with most of the socio-demographic variables. Being liberal rather than conservative was positively correlated with age, education, and work experience, but negatively correlated with household income and investment experience. Clearly, ideology is an important variable, but it was not associated with investor preferences. The association between socio-demographic variables and ideology was similar for males and females.

I expected to find a positive correlation between pro-social attitudes and the dependent variables. Previous studies have found that a significant portion of investors consider a company's social and environmental behavior when making investment decisions (Nilsson, 2008, 2009). However, I did not find support for this argument. Moderating Effect of Pro-social Attitudes

I expected that pro-social attitudes would moderate the relationship between the independent variables and the dependent variables, but the statistical results do not support the argument. Pro-social attitudes do not seem to interact with the relationship between the socio-demographic variables and the dependent variables. Also, the findings show that prosocial attitudes do not moderate the relationship between hope and openness and investor preferences. Furthermore, pro-social attitudes do not moderate the relationship between political ideology and investor preferences. These results contradict Nilsson's (2009) findings regarding three types of investors. He distinguished between those "primarily concerned about profit", those "primarily concerned about social responsibility" and those who were 
“socially responsible and return driven." Each segment, according to Nilsson, displays distinct differences with regard to various profiling variables.

However, in recent years scholars have started to argue that differences between investors regarding social issues are diminishing, with nearly all investors motivated by similar values. Lydenberg (2007) argues that differences between rational and societal investors are diminishing in today's investor population. The findings of my study contradict Nilsson but give support to Lydenverg's argument that differences in pro-social attitudes are not very important in affecting investor preferences.

\section{Limitations}

The findings and limitations of this study can provide opportunities for future research. As mentioned earlier, the purpose of the study was to examine the effect of adding attitudinal variables to socio-demographic variables when studying investor preferences, rather than depending solely on socio-demographic variables. Although I found interesting results, I need to acknowledge the limitations associated with this study, as the validity of the results depends on several key research design and method-related issues.

The first limitation is related to the nature of the study. This cross sectional study relies on self-reported data where dependent and independent variables were collected from the same person at the same time. Like the vast majority of research reviewed in this area, this study is subject to social desirability bias and mono-method bias. While the subjective nature of self-reported data is well understood to be often unavoidable, it is also acknowledged to be statistically reliable when measuring socio-demographic variables and individual attitudes or perceptions (Zhu, McKnight, Stergachis, Daling, \& Levine, 1999).

Another potential limiting factor is related to the generalizability of the results. The results of this study might not be generalizable to a more general population since I was not able to collect data from real investors because of logistical issues. My sample consisted of 
MBA and senior undergraduate students from the business school in a leading research university in South Florida. Although the use of a student sample was appropriate (Ferber, 1977; Vitell, \& Hidalgo 2006), for an exploratory study, the results might not represent a more general population. Future research should be conducted with a population of real investors distributed in different geographical areas.

Another potentially limiting factor for this study is the socio-demographic characteristics of the sample, including age, education, income, work experience, and investment experience. The majority of this sample reported investments under $\$ 10,000$ in holdings, so their experience and expertise are limited, and the population is relatively young compared to real investors.

Another potential limiting factor was discovered during the data analysis phase. For two of the positive psychology constructs (resiliency and optimism), the exploratory factor analysis produced factors that were inconsistent with the original scales. As a result I had to drop some items from the analysis and create a new factor I called openness.

Conclusion

This paper adds political ideology, positive psychology attitudes, and pro-social attitudes as new dimensions to the study of investor preferences. In addition, I defined a variable called estate intentions. Since there is no scale available for measuring estate intentions, I designed, tested and validated a scale for this construct. Furthermore, although positive psychology has been studied widely in psychology, organizational behavior, and management, this is the first time positive psychology attitudes have been considered in studying investor preferences, and the author found that these constructs significantly correlated with investor preferences. I believe these findings can be used to push investor preferences studies into new frontiers and many new research topics can be developed as areas for future research. 
This study suggests that socio-demographic characteristics do not relate to investor preferences. Since previous studies have found significant relationships between some sociodemographic variables such as age, gender, and education with risk tolerance, future research is needed in this area.

Investment literature rarely discusses any relationship between political ideology and investor preferences. In this study I used political ideology as a predictor of investor preferences. Despite the importance of this construct, it is largely neglected in management studies. Although this construct was not significantly correlated with the dependent variables, I observed its significant correlation with several independent variables. Further studies may lead to additional insights into the place of ideology in management studies.

I have demonstrated that pro-social attitudes have little impact on investor preferences. Pro-social attitudes did not significantly moderate the relationship between the independent variables and the dependent variables. These results are consistent with Lydenberg's (2007) perspective that differences between the conventional investor and the socially responsible investor are becoming less salient at the present time, and both types of investor are motivated by similar values. I found some differences between males and females regarding their attitudes towards risk tolerance, time horizon, and estate intentions. Most striking was the observation that education increases risk tolerance for females, but decreases risk tolerance for males. Additional research involving comparisons of the differences between males and females may indicate the convergence of other attitudes. As sex role differentiation lessens, the educational and work experience of men and women becomes more similar, and their attitudes and preferences might become more similar as well. 


\section{Recommendations for Future Research}

As indicated above, this study was conducted on a sample consisted of MBA and senior undergraduate students in the business school. Future research might replicate this study with real investors distributed over an expanded geographical area with greater variation in work experience, investment experience, and household income. I would caution the researchers to be more detailed in asking respondents about the specific type of household whose income or wealth is being reported. Another potential area for this study is to examine how cultural differences influence the findings in different countries. The researcher also recommends conducting a longitudinal study to examine the influence of attitudinal variables on investor preferences over a longer period of time. Following investors over a long period of time could illuminate additional information on the process by which attitudinal variables influence investor preferences, and would enable us to assess the interaction between internal (psychological) variables and external (economic or business cycle) variables.

The current study examined two dimensions of positive psychology, hope and openness. Since these two dimensions were significant in predicting investor preferences, the researcher recommends that the focus of future research could be extended to include other positive psychology constructs. For example, this study can be used as a starting point for further research to investigate how positive emotion, gratitude, resilience, and flourishing influence investor preferences.

Implications

The purpose of this study was to determine how adding attitudinal variables to sociodemographic variables would improve the explanatory power in explaining investor preferences. On a more general level, this study was an attempt to bring research on investors into stakeholder theory and research. 
I expect that both practitioners and academicians will benefit from these findings. The results show that hope and openness are two important factors in differentiating among investors regarding investment preferences. In general, financial managers depend on age as the main factor in determining risk tolerance, but these findings suggest that it would be beneficial for them to take a more comprehensive approach. Furthermore, the results indicated some differences between males and females regarding risk tolerance, suggesting greater similarities with more education. The following summarizes the main implications of these findings:

(a) Individuals with greater levels of attained hope and openness are proportionately more likely to have higher risk tolerance, invest with a longer time horizon, and attach more importance to leaving a bequest to religious organizations, charity, and family, than individuals with lower scores on hope and openness.

(b) In previous studies gender has seldom been considered. In this study I split the sample into two groups based on gender. The results showed that for females risk tolerance becomes higher as education increases, but for males risk tolerance becomes lower as education increases.

I believe this study represents a step toward the goal of having a more complete picture of the factors determining investor preferences. Future studies should continue to examine investor preferences from various perspectives and particularly to include more psychological variables. Future research is needed in these areas to identify what other factors determine investor preferences, under what conditions, and in what psychological or personality types 
Contribution to Research

Although the population used in this research is a rough proxy for real investors, this study provides additional insights into investor preferences research. The following summarizes the main contribution of this dissertation:

The main contribution of this dissertation is the significant correlation I found between positive psychology attitudes and investor preferences. I believe this is the first study to examine how positive psychology variables influence investor preferences. The findings that hope and openness are positively correlated with dependent variables, while sociodemographic variables have little influence, is a contribution to the literature on investor preferences.

I found differences between males and females regarding risk tolerance. I developed a scale to measure estate intentions, a construct never before studied in the management literature. Furthermore, I included political ideology in this study. That construct has been neglected in most management studies, but the data show that political ideology correlated positively with several independent variables.

This study supports Lydenberg's (2007) argument that pro-social attitudes are not a very important factor in investment preferences. Finally, this study brings investors back into the stakeholder model. Investors as a stakeholder have seldom been studied in the management literature, except in the context of ethical investment. This study demonstrates how much we have to learn about investors as an important element in stakeholder theory and research. 


\section{LIST OF REFERENCES}

Aaker, D. A., \& Bagozzi, R. P. 1982. Attitudes toward public policy alternatives to reduce air pollution. Journal of Marketing \& Public Policy, 1(1): 85-94.

Adams, V. H., Snyder, C. R., Rand, K. L., King, E. A., Sigmon, D. R., \& Pulvers, K, M. 2002. Hope in the workplace. In R. Giacolone \& C. Jurkiewicz (Eds.), Handbook of workplace spirituality and organizational performance: 367-377. New York: Sharpe.

Alpizar, F., Carlsson, F., \& Johansson-Stenman, O. 2008. Anonymity, reciprocity, and conformity: Evidence from voluntary contributions to a national park in Costa Rica. Journal of Public Economics, 92(5-6): 1047-1060.

Anderson, W. T., \& Cunningham, W. H. 1972. The socially conscious consumer. The Journal of Marketing, 36(3): 23-31.

Anderson, W. T., Cox, E. P., \& Fulcher, D. G. 1976. Bank selection decisions and market segmentation. The Journal of Marketing, 40(1): 40-45.

Andersson, L. M., Giacalone, R. A., \& Jurkiewicz, C. L. 2007. On the relationship of hope and gratitude to corporate social responsibility. Journal of Business Ethics, 70(4): 401-409.

Andreoni, J., \& Miller, J. 2002. Giving according to GARP: An experimental test of the consistency of preferences for altruism. Econometrica, 70(2): 737-753.

Andreoni, J., \& Petrie, R. 2004. Public goods experiments without confidentiality: A glimpse into fund-raising. Journal of Public Economics, 88(7-8): 1605-1623.

Antil, J. H. 1984. Socially responsible consumers: Profile and implications for public policy. Journal of Macromarketing, 4(2): 18-39.

Auten, G., \& Joulfaian, D. 1996. Charitable contributions and intergenerational transfers. Journal of Public Economics, 59(1): 55-68.

Bailey, T. C., Eng, W., Frisch, M. B., \& Snyder, C. R. 2007. Hope and optimism as related to life satisfaction. The Journal of Positive Psychology, 2(3): 168-175.

Bajtelsmit, V. L. 2006. Gender, the family, and economy. In Clark, G. L.,, Munnell, A. H. \& Orszag, J.M. (Eds.), The Oxford handbook of pensions and retirement income: 12140. Oxford: Oxford University Press.

Bajtelsmit, V. L., Bernasek, A., \& Jianakoplos, N. A. 1999. Gender differences in defined contribution pension decisions. Financial Service Review, 8: 1-10.

Bajtelsmit, V. L., \& VanDerhei, J. L. 1997. Risk aversion and pension investment choices. In M. S. Gordon, O.S. Mitchell \& M. M. Twinney (Eds.), Positioning pensions for the twenty-first century: 45-66. Philadelphia: University of Pennsylvania Press. 
Baker, H. K., \& Haslem, J. A. 1974. The impact of investor socioeconomic characteristics on risk and return preferences. Journal of Business Research, 2(4): 469-476.

Bakker, A. B., \& Schaufeli, W. B. 2008. Positive organizational behavior: Engaged employees in flourishing organizations. Journal of Organizational Behavior, 29(2): 147-154.

Bakshi, G. S., \& Chen, Z. 1994. Baby boom, population aging, and capital markets. Journal of Business, 67(2): 165-202.

Banks, J., \& Tanner, S. 1999. Patterns in household giving: Evidence from UK data. International Journal of Voluntary and Nonprofit Organizations, 10(1): 167-178.

Barber, B. M., \& Odean, T. 2001. Boys will be boys: Gender, overconfidence, and common stock investment. Quarterly Journal of Economics, 116(91): 261-292.

Baumeister, R. F., Bratslavsky, E., Finkenauer, C., \& Vohs, K. D. 2001. Bad is stronger than good. Review of General Psychology, 5(4): 323-370.

Beal, D. J., Goyen, M., \& Philips, P. 2005. Why do we invest ethically? The Journal of Investing, 14(3): 66-78.

Beekun, R., \& Badawi, J., 2005. Balancing ethical responsibility among multiple organizational stakeholders: The Islamic perspective. .Journal of Business Ethics, 60(2): 131-145.

Bekkers R. 2004. Giving and Volunteering in the Netherlands: Sociological and Psychological Perspectives. Dissertation, Department of Sociology, Utrecht University, Utrecht, the Netherlands. Retrieved on August 9, 2011, from http://www.fss.uu.nl/soc/homes/bekkers/diss.pdf.

Bekkers, R., \& Schuyt, T. 2008. And who is your neighbor? Explaining denominational differences in charitable giving and volunteering in the Netherlands. Review of Religious Research, 50(1): 74-96.

Bendheim, C. L., Waddock, S. A., \& Graves, S. B. 1998. Determining best practice in corporate-stakeholder relations using data envelopment analysis. Business \& Society, 37(3): 306-338.

Berger, I. E., \& Corbin, R. M. 1992. Perceived consumer effectiveness and faith in others as moderators of environmentally responsible behaviors. Journal of Public Policy \& Marketing, 11(2): 79-89.

Bernasek, A., \& Shwiff, S. 2001. Gender, risk, and retirement. Journal of Economics, 2: 345-356.

Bierman, Jr., H. 1997. Portfolio management allocation and the investment horizon. The Journal of Portfolio Management, 23(4): 51-55. 
Block, J., \& Kremen, A. M. 1996. IQ and ego-resiliency: Conceptual and empirical connections and separateness. Journal of Personality and Social Psychology, 70(2): 349-361.

Board of Governors of the Federal Reserve System. 1997. Codebook for the 1995.Survey of Consumer Finances. Washington, D.C. Retrieved on July 20, 2011, from http://fmwww.bc.edu/ec-p/data/scf/95/codebk95.txt

Bodie, Z., \& Crane B. 1997. Personal investing: Advice, theory and evidence. Financial Analysts Journal 53(6): 13-23.

Bodie, Z., Merton, R. C., \& Samuelson, W. F. 1992. Labor supply flexibility and portfolio choice in a life cycle model. Journal of Economic Dynamics and Control, 16: 427449.

Bollen, K. A. 1990. Overall fit in covariance structure models: Two types of sample size effects. Psychological Bulletin, 107(2): 256-259.

Bollen, P.B. 2007. Mutual fund attributes and investor behavior. Journal of Financial and Quantitative Analysis, 42: 683-708

Bonanno, G. A. 2004. Loss, trauma, and human resilience: Have we underestimated the human capacity to thrive after extremely aversive events? American Psychologist, 59(1): 20-28.

Bonaparte, Y., Kumar, A., \& Page, J. 2010. Political climate, optimism, and investment decisions. Working Paper. Retrieved on November 10, 2011, from http://papers.ssrn.com/sol3/papers.cfm?abstract_id=1509168.

Borgonovi, F. 2008. Doing well by doing good: The relationship between formal volunteering and self-reported health and happiness. Social Science \& Medicine, 66(11): 2321-2334.

Brennan, M. J., \& Kraus, A. 1976. The geometry of separation and myopia. Journal of Financial and Quantitative Analysis, 11(2): 171-193.

Brinson, G. Hood, R., \& Beebower, G.1986. Determinants of portfolio performance. Financial Analysts Journal, 42(4): 39-44.

Brooks, A. C. 2004. What do "don't know" responses really mean in giving surveys? Nonprofit and Voluntary Sector Quarterly, 33(3): 423-434.

Brown, E., \& Ferris, J. M. 2007. Social capital and philanthropy: An analysis of the impact of social capital on individual giving and volunteering. Nonprofit and Voluntary Sector Quarterly, 36(1): 85-99.

Bryant, F. B., \& Cvengros, J. A. 2004. Distinguishing hope and optimism: Two sides of a coin, or two separate coins? Journal of Social and Clinical Psychology, 23(2): 273 302. 
Bryman, A. \& Cramer, D. 2005. Quantitative Data Analysis with SPSS for Windows: A Guide for Social Scientists. London: Routledge.

Butler, K. C., \& Domian, D. L. 1991. Risk, diversification, and the investment horizon. The Journal of Portfolio Management, 17(3): 41-47.

Buttel, F. H., \& Flinn, W. L. 1976. Environmental politics: The structuring of partisan and ideological cleavages in mass environmental attitudes. Sociological Quarterly, 17(4): 477-490.

Buttel, F. H., \& Flinn, W. L. 1978. Social class and mass environmental beliefs. Environment and Behavior, 10(3): 433-450.

Cameron, K. S., Bright, D., \& Caza, A. 2004. Exploring the relationships between organizational virtuousness and performance. American Behavioral Scientist, 47(6): 766-790.

Cameron, K. S. 2003. Organizational virtuousness and performance. In K.S. Cameron, J. E. Dutton, \& R. E. Quinn (Eds.), Positive organizational scholarship: Foundations of a new discipline: 48-65. San Francisco, CA: Berrett-Koehler Publishers Inc.

Campbell, J. 2006. Household finance. Journal of Finance, 61:1553-604.

Canner, N. Mankiw, G., \& Weil, D. 1997. An asset allocation puzzle. American Economic Review, 87(1): 181-191.

Carney, D. R., Jost, J. T., Gosling, S. D., \& Potter, J. 2008. The secret lives of liberals and conservatives: Personality profiles, interaction styles, and the things they leave behind. Political Psychology, 29(6): 807-840.

Carroll, A. B. 1991. The pyramid of corporate social responsibility: Toward the moral management of organizational stakeholders. Business Horizons, 34(4): 39-48.

Carver, C. 2003. Pleasure as a sign you can attend to something else: Placing positive feelings within a general model of affect. Cognition \& Emotion, 17(2): 241-261.

Catton, Jr., W. R., \& Dunlap, R. E. 1978. Environmental sociology: A new paradigm. The American Sociologist, 13: 41-49.

Chang, E. C., Maydeu-Olivares, A., \& D'Zurilla, T. J. 1997. Optimism and pessimism as partially independent constructs: Relationship to positive and negative affectivity and psychological well-being. Personality and Individual Differences, 23(3): 433-440.

Cheier, M. F., \& Carver, C. S. 1985. Optimism, coping, and health: Assessment and implications of generalized outcome expectancies. Health Psychology, 4(3): 219-247.

Chemers, M. M., Hu, L., \& Garcia, B. F. 2001. Academic self-efficacy and first year college student performance and adjustment. Journal of Educational Psychology, 93(1): 5564. 
Chin, Y.M., \& Parwada, T. 2009, Red-blooded Republican or true-blue Democrat? The influence of political preferences on money managers' portfolio decision, Working Paper. Retrieved on July 10, 2011, from http://papers.ssrn.com/abstract.

Chin-Loy, C., \& Mujtaba, B. G. 2007.Organizational Learning and Knowledge. In B. G. Mujtaba (Ed.).Workforce diversity management: Challenges, competencies and strategies: 207-229. Miami, FL: Llumina Press.

Chow, K. V., Riley, W. B., \& Formby, J. P. 1992. International portfolio selection and efficiency analysis. Review of Quantitative Finance and Accounting, 2(1): 47-67.

Chyz, J. A. 2010. Personally tax aggressive managers and firm level tax avoidance. Working paper, University of Arizona. Retrieved on August 11, 2011, from http://www.nd.edu/ carecob/Workshops/09-10Recruiting/Chyz2010.pdf.

Clark, G. L., Caerlewy-Smith, E., \& Marshall, J. C. 2006. Pension fund trustee competence: Decision making in problems relevant to investment practice. Journal of Pension Economics and Finance, 5(1): 91-110.

Cleveland, M., Laroche, M., \& Papadopoulos, N. 2009. Cosmopolitanism, consumer ethnocentrism, and materialism: An eight-country study of antecedents and outcomes. Journal of International Marketing, 17(1): 116-146.

Clinton, M., Totterdell, P., \& Wood, S. 2006. A grounded theory of portfolio working. International Small Business Journal, 24(2): 179-203.

Cohn, R. A., Lewellen, W. G., Lease, R. C., \& Schlarbaum, G. G. 1975. Individual investor risk aversion and investment portfolio composition. The Journal of Finance, 30(2): 605-620.

Cohen, J. 1988. Statistical power analvsis for the behavioral sciences (2nd ed.). HIllsdale, NJ Erlbaum.

Converse, P.E. 1964. The nature of belief systems in mass publics. In E. Apter (Eds.), Ideology and Discontent: 75-169 New York: Free Press.

Cooper, D. R., \& Emory, C. W. (Eds.), 1995. Business research methods. Boston, MA: Richard D. Irwin, Inc.

Cooper, D.R. \& Schindler, P.S. 2006. Marketing Research. Boston: MA.McGraw-Hill Irwin.

Coutu, D. L. 2002. How resilience works. Harvard Business Review, 80(5): 46-55.

Cowe, R., \& Williams, S. 2001. Who are the ethical consumers? Manchester: The Cooperative Bank.

Cox, P., Brammer, S., \& Millington, A. 2004. An empirical examination of institutional investor preferences for corporate social performance. Journal of Business Ethics, 52(1): 27-43. 
Creyer, E. H. 1997. The influence of firm behavior on purchase intention: Do consumers really care about business ethics? Journal of Consumer Marketing, 14(6): 421-432.

Cronqvist, H., Makhija, K., \& Yonker, S. 2012. Behavioral consistency in corporate finance: CEO personal and corporate leverage. Journal of Financial Economics ,103(1): 121.

Cullis, J. G., Lewis, A., \& Winnett, A. 1992. Paying to be good? U.K. ethical investments. Kyklos, 45(1): 3-23.

Cunningham, H., Anderson, T., \& Murphy, J. 1974. Are students real people? The Journal of Business, 47(3): 399-409.

Curry, L. A., Snyder, C. R., Cook, D. L., Ruby, B. C., \& Rehm, M. 1997. Role of hope in academic and sport achievement. Journal of Personality and Social Psychology, 73(6): 1257-1267.

Daneshvary, N., \& Luksetich, W. A. 1997. Income sources and declared charitable tax deductions. Applied Economics Letters, 4(5): 271-274.

Dehne, A., Friedrich, P., Nam, C. W., \& Parsche, R. 2008. Taxation of nonprofit associations in an international comparison. Nonprofit and Voluntary Sector Quarterly, 37(4): 709-729.

Diamantopoulos, A., Schlegelmilch, B. B., Sinkovics, R. R., \& Bohlen, G. M. 2003. Can socio-demographics still play a role in profiling green consumers? A review of the evidence and an empirical investigation. Journal of Business Research, 56(6): 465 480 .

Direnfeld, D. M., \& Roberts, J. E. 2006. Mood congruent memory in dysphoria: The roles of state affect and cognitive style. Behavior Research and Therapy, 44(9): 1275-1285.

Dubinsky, A.J., \& Rudelius, W. (1980). Ethical beliefs: How students compare with industrial salespeople. In R.P. Bagozzi (Ed.), Marketing in the 80's: Changes and challenges: 73-76. Chicago, IL: American Marketing Association.

Fredrickson, B. L. 2001. The role of positive emotions in positive psychology: The broadenand-build theory of positive emotions. American Psychologist, 56(3): 218.

Freeman, R. E. 1984. Strategic management: A stakeholder approach. Boston: Pitman.

Friedman M. 1970. The social responsibility of business is to increase its profits. The New York Times Magazine, 13 September, 122-126.

Friend, I., \& Blume, M. E. 1975. The demand for risky assets. The American Economic Review, 65(5): 900-922.

Gable, S., \& Haidt, J. 2005. Positive psychology. Review of General Psychology, 9:10892680. 
Gardner, R. C. 2001. Psychological statistics using SPSS for Windows. New Jersey: Prentice Hall.

Garman, E. T., \& Forgue, R. E. 1997. Personal finance (4th ed.). Boston: Houghton Mifflin Company.

Gefen, D., Straub D., \& Boudreau, M. 2000. "Structural equation modeling techniques and regression: Guidelines for research practice," Communications of the Association For Information Systems, 7(7): 1-78.

Gervais, S., Heaton, T. \& Odean, T. 2003. Overconfidence, investment policy, and executive stock option. Working paper Duke University. Retrieved on July 10, 2011, from http://papers.ssrn.com/sol3/papers.cfm?abstract id=361200.

Getzner, M., \& Grabner-Kräuter, S. 2004. Consumer preferences and marketing strategies for "green shares": Specifics of the Austrian market. International Journal of Bank Marketing, 22(4): 260-278.

Gervais, S., Heaton, J., \& Odean, T. 2003. Overconfidence. Investment Policy, and Executive Stock Options, 73(1):52-62.

Giacalone, R. A., Paul, K., \& Jurkiewicz, C. L. 2005. A preliminary investigation into the role of positive psychology in consumer sensitivity to corporate social performance. Journal of Business Ethics, 58(4): 295-305.

Giacalone, R. A., \& Thompson, K. R. 2006. Business ethics and social responsibility education: Shifting the worldview. The Academy of Management Learning and Education, 5(3): 266-277.

Gillies, J., \& Campbell, S. 1985. Conservatism and poetry preferences. British Journal of Social Psychology, 24(3): 223-227.

Gollier, C. 2002. Time horizon and the discount rate. Journal of Economic Theory, 107(2): 463-473.

Grable, J. E. 2000. Financial risk tolerance and additional factors that affect risk taking in everyday money matters. Journal of Business and Psychology, 14(4): 625-630.

Grable, J., Lytton, R., \& O'Neill, B. 2004. Projection bias and financial risk tolerance. The Journal of Behavioral Finance, 5(3): 142-147.

Grable, J., \& Lytton, R. H. 1999. Financial risk tolerance revisited: The development of a risk assessment instrument. Financial Service Review, 8: 163-181.

Grable, J. E., \& Joo, S. 2000. A cross-disciplinary examination of financial risk tolerance. Consumer Interests Annual, 46(91): 151-157.

Grable, J. E., \& Roszkowski, M. J. 2008. The influence of mood on the willingness to take financial risks. Journal of Risk Research, 11(7): 905-923. 
Gardberg, N., \& Newburry, W. 2010. Who boycotts whom? Marginalization, company knowledge, and strategic issues. Business \& Society, 1-39. Retrieved on November 10, 2011 from

http://bas.sagepub.com/content/early/2010/03/04/0007650309352507.full.pdf + html.

Graham, J. R., \& Kumar, A. 2006. Do dividend clienteles exist? Evidence on dividend preferences of retail investors. The Journal of Finance, 61(3): 1305-1336.

Graves, S. B., \& Waddock, S. A. 1994. Institutional owners and corporate social performance. Academy of Management Journal, 37(4): 1034-1046.

Grey, R. J., \& Gordon, G. G. 1978. Risk-taking managers: Who get the top jobs? Management Review, 67: 8-13.

Griffin, D., \& Tversky, A. 1992. The weighing of evidence and the determinants of confidence. Cognitive Psychology, 24(3): 411-435.

Gron, A., \& Winton, A. 2001. Risk overhang and market behavior. The Journal of Business, 74(4): 591-612.

Groth, J. C., Lewellen, W. G., Schlarbaum, G. G., \& Lease, R. C. 1979. An analysis of brokerage house securities recommendations. Financial Analysts Journal, 4: 32-40.

Gysler, M., Brown Kruse, J. and Schubert, R. 2002. Ambiguity and gender differences in financial decision making: An experimental examination of competence and confidence effects. Center for Economic Research, Swiss Federal Insti tute of Technology, Working Paper. Retrieved on July 20, 2011 from http://e-collection.library.ethz.ch/eserv/eth:25290/eth-25290-01.pdf.

Hair, J. F., Black, W. C., Babin, B. J., Anderson, R. E., \& Tatham, R. L. 2006. Multivariate data analysis (6th ed.). NJ: Pearson Prentice.

Haliassos, M., \& Bertaut, C. C. 1995. Why do so few hold stocks? The Economic Journal, 105(432): 1110-1129.

Hallahan, T. A., Faff, R. W., \& McKenzie, M. D. 2004. An empirical investigation of personal financial risk tolerance. Financial Service Review, 13(1): 57-78.

Hallman, G. V. \& Rosenbloom, J.S. 1987. Personal financial planning (4th ed.). New York: McGraw Hill.

Hamel, G., \& Valikangas, L. 2003. The quest for resilience. Harvard Business Review, 81(9): 52-65.

Hanna, S., \& Chen, P. 1997. Subjective and objective risk tolerance: Implications for optimal portfolios. Financial Counseling and Planning, 8(2): 17-26.

Hanna, S., Gutter, M., \& Fan, J. 1998. A theory based measure of risk tolerance. Proceedings of the Academy of Financial Services, 15: 10-21. 
Hanna, S. D., Gutter, M. S., \& Fan, J. X. 2001. A measure of risk tolerance based on economic theory. Financial Counseling and Planning, 12(2): 53-60.

Hanna, S. D., \& Lindamood, S. 2004. An improved measure of risk aversion. Financial Counseling and Planning, 15(2): 27-38.

Hariharan, G., Chapman, K. S., \& Domian, D. L. 2000. Risk tolerance and asset allocation for investors nearing retirement. Financial Service Review, 9: 159-17.

Harrison, T.1995. Segmenting the market for retail financial services. International Review of Retail, Distribution \& Consumer Research, 5(3): 271-286.

Hawley, J., \& Williams, A. 2007. Universal owners: Challenges and opportunities. Corporate Governance: An International Review, 15(3): 415-420.

Hayes, D., \& Lingard, B. 2003. Introduction: Rearticulating gender agendas in schooling: an Australian perspective. International Journal of Inclusive Education, 7(1): 1-6.

Hayes, J. 2001. The greater good: How ethical investment pays off. Australian Financial Review, 26(27): 29-31.

Herzberg, F.I. 1966. Work and nature of man. New York: Thomas Y. Crowell.

Hill, P. C., \& Pargament, K. I. 2003. Advances in the conceptualization and measurement of religion and spirituality: Implications for physical and mental health research.

American Psychologist, 58(1): 64-74.

Hinz, R.P., McCarthy, D.D. and Turner, J. A. 1997. Are women conservative investors? Gender differences in participant-directed pension in investments. In M.S. Gordon, O.S. Mitchell and M.M. Twinney (Eds.), Positioning Pensions for the Twenty-first Century:91-103. Philadelphia: University of Pennsylvania.

Home, J. F., \& Orr, J. E. 1997. Assessing behaviors that create resilient organizations. Employment Relations Today, 24(4): 29-39.

Hong, H., \& Kostovetsky, L. 2011. Red and blue investing: Political values and finance. Journal of Financial Economics, 103(1):1-19.

Hounshell, P. B., \& Liggett, L. 1973. Assessing the effectiveness of environmental education. Journal of Environmental Education, 5(2): 28-30.

Houston, D. J. 2006. "Walking the walk" of public service motivation: Public employees and charitable gifts of time, blood, and money. Journal of Public Administration Research and Theory, 16(1): 67-86.

Hutton, I., Jiang, D., \& Kumar, A. 2011. Conservative or liberal? Managerial political orientation and corporate policies. Unpublished working paper. Retrieved on October 10, 2011 from http://papers.ssrn.com/sol3/papers.cfm?abstract_id=1573167 
Isen, A. M., \& Shalker, T. E. 1982. The effect of feeling state on evaluation of positive, neutral, and negative stimuli: When you" accentuate the positive," do you" eliminate the negative"? Social Psychology Quarterly, 11: 58-63.

James Iii, R. N., \& Sharpe, D. L. 2007. The nature and causes of the U-shaped charitable giving profile. Nonprofit and Voluntary Sector Quarterly, 36(2): 218-238.

Janoski, T., Musick, M., \& Wilson, J. 1998. Being volunteered? The impact of social participation and pro-social attitudes on volunteering. Sociological Forum, 13 (3): 495-519.

Jensen, M. 2002. Value maximization, stakeholder theory, and the corporate objective function. Business Ethics Quarterly, 12(2): 235-256.

Jianakoplos, N. A., \& Bernasek, A. 1998. Are women more risk averse? Economic Inquiry, 36(4): 620-630.

Johnson, E. J., \&Tversky, A. 1983. Affect, generalization, and the perception of risk. Journal of Personality and Social Psychology, 45(1): 20-31.

Jones, A., \& Posnett, J. 1991. Charitable donations by UK households: Evidence from the Family Expenditure Survey. Applied Economics, 23(2): 343-351.

Joo, S., \& Garman, E. T. 1998. The potential effects of workplace financial education based on the relationship between personal financial wellness and worker job productivity. Personal Finances and Worker Productivity, 2(1): 163-174.

Joo, S., \& Grable, J. E. 2004. An exploratory framework of the determinants of financial satisfaction. Journal of Family and Economic Issues, 25(1): 25-50.

Jost, J. T. 2006. The end of the end of ideology. American Psychologist, 61(7): 651-670.

Jost, J. T., Glaser, J., Kruglanski, A. W., \& Sulloway, F. J. 2003. Political conservatism as motivated social cognition. Psychological Bulletin, 129(3): 339-375.

Jost, J. T., Nosek, B. A., \& Gosling, S. D. 2008. Ideology: Its resurgence in social, personality, and political psychology. Perspectives on Psychological Science, 3(2): 126-136.

Jost, J.T., \& Van der Toorn, J. 2012. System justification theory. In P.A.M. van Lange, A.W. Kruglanski, \& E.T. Higgins (Eds.), Handbook of theories of social psychology:313343, London: Sage.

Kahneman, D., \& Lovallo, D. 1993. Timid choices and bold forecasts: A cognitive perspective on risk taking. Management Science, 39(1): 17-31.

Kahneman, D., \& Tversky, A. 1979. Prospect theory: An analysis of decision under risk. Econometrica: Journal of the Econometric Society, 47 (2): 263-291. 
Kam, C. D., \& Simas, E. N. Risk orientations and policy frames. The Journal of Politics, 2(2): 381-396.

Kassarjian, H. H. 1971. Personality and consumer behavior: A review. Journal of Marketing Research, 8(94): 409-418.

Kaustia, M., \& Torstila, S. 2010.Stock market aversion? Political preferences and stock market participation. Journal of Financial Economics, 100(1): 98-112.

Kerlinger, F., \& Lee, H. 2000. Foundations of behavioral research (4th ed.). Holt, NY: Harcourt

Kiernan, B., D. J., Goyen, M., \& Philips, P. 2007. Why do we invest ethically? The Journal of Investing, 14(3): 66-78.

Kinnear, T. C., Taylor, J. R., \& Ahmed, S. A. 1974. Ecologically concerned consumers: Who are they? The Journal of Marketing, 36(2): 20-24.

Klos, A., Weber, E. U., \& Weber, M. 2005. Investment decisions and time horizon: Risk perception and risk behavior in repeated gambles. Management Science, 51 (12): $1777-1790$.

Knoke, D.1990. Organizing for collective action: The political economies of associations. New York: Aldine de Gruyter.

Kraus, A., \& Litzenberger, R. H. 1976. Skewness preference and the valuation of risk assets. The Journal of Finance, 31(4): 1085-1100.

Kritzman, M. 1994. What practitioners need to know about time diversification. Financial Analysts Journal, 50(1): 14-8.

Kruglanski, A. W., \& Stroebe, W. 2005. The influence of beliefs and goals on attitudes: Issues of structure, function, and dynamics. In D. Albarracín, B. T. Johnson, \& M. P. Zanna (Eds.), The handbook of attitudes: 323-368. Mahwah, NJ: Erlbaum.

Kuratko, D. F. 2005. The emergence of entrepreneurship education: Development, trends, and challenges. Entrepreneurship Theory and Practice, 29(5): 577-598.

Laroche, M., Bergeron, J., \& Fareleo, B. 2001. Targeting consumers who are willing to pay more for environmentally friendly products. Journal of Consumer Marketing, 18(6): 503-520.

Laroche, M., Papadopoulos, N., Heslop, L., \& Bergeron, J. 2003. Effects of subcultural differences on country and product evaluations. Journal of Consumer Behavior, 2(3): 232-247.

Lascu, D. N., Babb, H. W., \& Phillips, R. W. 1997. Gender and investment: The influence of gender on investment preferences and practices. Managerial Finance, 23(10): 69-83. 
Leedy, P. D., \& Ormrod, J. E. 2005. Practical research: Planning and design (8th ed.). Upper Saddle River, NJ: Prentice Hall.

Leith, K. P., \& Baumeister, R. F. 1996. Why do bad moods increase self-defeating behavior? Emotion, risk tasking, and self-regulation. Journal of Personality and Social Psychology, 71(6): 1250-1267.

Leonard, D. 1995. Doctor, heal thyself. Smart Money, 4: 91-96.

Leonard-Barton, D. 1981. Voluntary simplicity lifestyles and energy conservation. Journal of Consumer Research, 8 (1): 243-252.

Lerner, J. S., Small, D. A., \& Loewenstein, G. 2004. Heart strings and purse strings: Carryover effects of emotions on economic decisions. Psychological Science, 15(5): 337-341.

Leung, B. W. C., Moneta, G. B., \& McBride-Chang, C. 2005. Think positively and feel positively: Optimism and life satisfaction in late life. The International Journal of Aging and Human Development, 61(4): 335-36.

Lewis, A., \& Webley, P. 1994. Social and ethical investing: Beliefs, preferences and the willingness to sacrifice financial return. In A. Lewis \& K-E.Wärneryd (Eds.), Ethics and economic affairs, 171-182. London: Routledge.

Lin, Q. \& Lee, J. 2004. Consumer information search when making investment decisions. Financial Services Review, 13(1): 319-332.

Loibl, C., \& Hira, T. K. 2009. Investor information search. Journal of Economic Psychology, 30(1): 24-41.

Lopez, S. J., \& Snyder, C. R. 2003. Positive psychological assessment: A handbook of models and measures. Washington, D. C.: American Psychological Association.

Lorie, J. H., \& Brealey, R. A. 1978. Modern developments in investment management: A book of readings. New York: Harcourt School.

Lounsbury, J. W., Sundstrom, E., Loveland, J. L., \& Gibson, L. W. 2002. Broad versus narrow personality traits in predicting academic performance of adolescents. Learning and Individual Differences, 14(1): 65-75.

Lusardi, A., Olivia S. \& Mitchell, C. 2010. Financial literacy among the young: Evidence and implications for consumer policy. Journal of Consumer Affairs, 44(2): 358-380.

Luthans, F. 2002. The need for and meaning of positive organizational behavior. Journal of Organizational Behavior, 23(6): 695-706.

Luthans, F., Avolio, B. J., Avey, J. B., \& Norman, S. M. 2007. Positive psychological capital: Measurement and relationship with performance and satisfaction. Personnel Psychology, 60(3): 541-572. 
Luthans, F., Avolio, B. J., Walumbwa, F. O., \& Li, W. 2005. The psychological capital of Chinese workers: Exploring the relationship with performance. Management and Organization Review, 1(2): 249-271.

Luthans, F., \& Jensen, S. M. 2002. Hope: A new positive strength for human resource development. Human Resource Development Review, 1(3): 304-322.

Luthans, F., Norman, S. M., Avolio, B. J., \& Avey, J. B. 2008. The mediating role of psychological capital in the supportive organizational climate employee performance relationship. Journal of Organizational Behavior, 29(2): 219-238.

Luthans, F., \& Peterson, S. J. 2003. 360 degree feedback with systematic coaching: Empirical analysis suggests a winning combination. Human Resource Management, 42(3): 243-256.

Luthans, F., Van Wyk, R., \&Walumbwa, F. O. 2004. Recognition and development of hope for South African organizational leaders. Leadership \& Organization Development Journal, 25(6): 512-527.

Luthans, F., Vogelgesang, G. R., \& Lester, P. B. 2006. Developing the psychological capital of resiliency. Human Resource Development Review, 5(1): 25.

Luthans, F., \& Youssef, C. M. 2007. Emerging positive organizational behavior. Journal of Management, 33(3): 321-349.

Lydenberg, S. 2007. Universal investors and socially responsible investors: A tale of emerging affinities. Corporate Governance: An International Review, 15(3): 467477.

Lyons, E., \& Breakwell, G. M. 1994. Factors predicting environmental concern and indifference in 13-to 16-year-olds. Environment and Behavior, 26(2): 223-238.

Lyons, M., \& Nivison-Smith, I. 2006. Religion and giving in Australia. Australian Journal of Social Issues, 41(60): 419-436.

MacCrimmon, K. R., \& Wehrung, D. A. 1990. Characteristics of risk taking executives. Management Science, 36(4): 422-435.

Magaletta, P. R., \& Oliver, J. M. 1999. The hope construct, will, and ways: Their relations with self-efficacy, optimism, and general well-being. Journal of Clinical Psychology, 55(5): 539-551.

Mahoney, A., Pargament, K. I., Murray-Swank, A., \& Murray-Swank, N. 2003. Religion and the sanctification of family relationships. Review of Religious Research, 44(3): 220236.

Malkiel, B.1973. A random walk down Wall Street. New York: W. W. Norton \& Co. 
Maloney, M. P., Ward, M. P., \& Braucht, G. N. 1975. A revised scale for the measurement of ecological attitudes and knowledge. American Psychologist, 30 (7): 787.

Manaktola, K., \& Jauhari, V. 2007. Exploring consumer attitude and behavior towards green practices in the lodging industry in India. International Journal of Contemporary Hospitality Management, 19(5): 364-377.

Markowitz, H. 1952. The utility of wealth. The Journal of Political Economy, 60(2): 151158.

Markowitz, H. M. 1999. The early history of portfolio theory: 1600-1960. Financial Analysts Journal, 55(4): 5-16.

Moreschi, R.W. 2005. An analysis of the ability of individuals to predict their own risk tolerance. Journal of Business \& Economics Research, 3(2): 39-48.

Maslow, A. H. 1954. Motivation and personality. New York: Harper \& Brothers.

Mason, C. M., \& Harrison, R. T. 1995. Closing the regional equity capital gap: The role of informal venture capital. Small Business Economics, 7(2): 153-172.

Masten, A. S. 2001. Ordinary magic: Resilience processes in development. American Psychologist, 56(3): 227-238.

Mayo, E. 2005. Shopping generation, London: National Consumer Council.

Mehrens, W. A. \& Lehmann, I. J. 1987. Using standardized tests in education. New York: Longman.

McAllister, P. O., \& Anderson, A. 1991. Conservatism and the comprehension of implausible text. European Journal of Social Psychology, 21(2): 147-164.

McInish, T. H. 1982. Individual investors and risk-taking. Journal of Economic Psychology, 2(2): $125-136$.

McInish, T. H., Ramaswami, S. N., \& Srivastava, R. K. 1993. Do more risk-averse investors have lower net worth and income? Financial Review, 28(1): 91-106.

McLachlan, J., \& Gardner, J. 2004. A comparison of socially responsible and conventional investors. Journal of Business Ethics, 52(1): 11-25.

McNeil, K., Newman, I., \& Kelly F. J. 2011. Testing research hypotheses with the general linear model. Carbondale, IL: Southern Illinois University Press.

Miller, M. H., \& Modigliani, F. 1961. Dividend policy, growth, and the valuation of shares. The Journal of Business, 34(4): 411-433. 
Mitchell, R. K., Agle, B. R., \& Wood, D. J. 1997. Toward a theory of stakeholder identification and salience: Defining the principle of who and what really counts. Academy of Management Review, 22 (4): 853-886.

Mohai, P., \& Bryant, B. 1998. Is there a "race" effect on concern for environmental quality? Public Opinion Quarterly, 62(4): 475-505.

Morin, R. A., \& Suarez, A. F. 1983. Risk aversion revisited. Journal of Finance, 38(4): 1201-1216.

Munnell, A. H. 2006. "Employer-sponsored plans: The shift from defined benefit to defined contribution." In G. L. Clark, A. H. Munnell, J. M. Orszag (Eds.), The Oxford handbook of pensions and retirement income: $359-380$, Oxford: Oxford University Press.

Napier, J. L., \& Jost, J. T. 2008. Why are conservatives happier than liberals? Psychological Science, 19(6): 565-572.

Nelson, D., \& Cooper, C. L. (Eds.). 2007. Positive organizational behavior. Thousand Oaks, CA: Sage.

Newell, S. J., \& Green, C. L. 1997. Racial differences in consumer environmental concern. Journal of Consumer Affairs, 31(1): 53-69.

Newman, I., Newman, C., Brown, R., \& McNeely, S. 2006. Conceptual statistics for beginners $\left(3^{\text {rd }}\right.$ ed.). Lanham, MD: University Press of America.

Newman, I., Ridenour, C. S., Newman, C., \& DeMarco, G. M. P. 2003. A typology of research purposes and its relationship to mixed methods. In A. Tashakkori \& C. Teddlie (Eds.), Handbook of mixed methods in social and behavioral research:189208. Thousand Oaks, CA: Sage.

Nielsen, K., Randall, R., Yarker, J., \& Brenner, S. O. 2008. The effects of transformational leadership on followers perceived work characteristics and psychological well-being: A longitudinal study. Work \& Stress, 22(1): 16-32.

Nilsson, J. 2008. Investment with a conscience: Examining the impact of pro-social attitudes and perceived financial performance on socially responsible investment behavior. Journal of Business Ethics, 83(2): 307-325.

Nilsson, J. 2009. Segmenting socially responsible mutual fund investors: The influence of financial return and social responsibility. International Journal of Bank Marketing, 27(1): 5-31.

Nunnally, J. \& Bernstein, I. 1994. Psychometric theory (3rd ed.). New York: McGraw Hill.

O'Neill, O. 1996. Towards justice and virtue: A constructive account of practical reasoning. Cambridge: University Press. 
Palsson, A. M. 1996. Does the degree of relative risk aversion vary with household characteristics? Journal of Economic Psychology, 17(6): 771-787.

Pallant, J. 2005. SPSS survival guide: New York: Open University Press.

Park, N., Peterson, C., \& Seligman, M. E. P. 2004. Strengths of character and well-being. Journal of Social and Clinical Psychology, 23(5): 603-619.

Pasewark, W. R., \& Riley, M. E. 2009. It is a matter of principle: The role of personal values in investment decisions. Journal of Business Ethics, 93(2): 237-253.

Paul, K., Zalka, L. M., Downes, M., Perry, S., \& Friday, S. 1997. U.S. consumer sensitivity to corporate social performance: Development of a scale. Business \& Society, 36(4): 408-418.

Peattie, K. 1995. Environmental marketing management: Meeting the green challenge. London: Pitman.

Peterson, C. 2006. A primer in positive psychology. Oxford: University Press.

Peterson, R. L. 2002. "Buy on the rumor": Anticipatory affect and investor behavior. The Journal of Psychology and Financial Markets, 3(4): 218-226.

Peterson, S. J., \& Luthans, F. 2003. The positive impact and development of hopeful leaders. Leadership \& Organization Development Journal, 24(1): 26-31.

Petrakis, P. E. 2007. The effects of risk and time on entrepreneurship. International Entrepreneurship and Management Journal, 3(3): 277-291.

Pharoah, C., \& Tanner, S. 1997. Trends in charitable giving. Fiscal Studies, 18(4): 427-443.

Powell, M., \& Ansic, D. 1997. Gender differences in risk behavior in financial decisionmaking: An experimental analysis. Journal of Economic Psychology, 18(6): 605628.

Putnam, R. 2001. Social capital: Measurement and consequences. Canadian Journal of Policy Research, 2(1): 41-51.

Reivich, K., \& Shatt, A. 2002. The resilience factor: 7 essential skills for overcoming life's inevitable obstacles. New York: Broadway Books.

Ricciardi, V. 2003. A research starting point for the new scholar: A unique perspective of behavioral finance. FSR Forum, 6(1): 6-17. (Special Academic Journal Issue in Behavioral Finance).

Ricciardi, V. 2004. A risk perception primer: A narrative research review of the risk perception literature in behavioral accounting and behavioral finance. Retrieved on June 10, 2011, from http://papers.ssrn.com/sol3/papers.cfm?abstract id=566802. 
Ricciardi, V. \& Simon, H. 2000. "What is behavioral finance?" The Business, Education and Technology Journal, 2(1): 26-34.

Riley, W.B. \& Chow, K.V., 1992. Asset allocation and individual risk tolerance.Financial Analyst Journal, 48(6): 32-37.

Roberts, J. A. 1996. Will the real socially responsible consumer please step... Business Horizons, 39(1): 79-83.

Roberts, J. A., \& Bacon, D. R. 1997. Exploring the subtle relationships between environmental concern and ecologically conscious consumer behavior. Journal of Business Research, 40(1): 79-89.

Rosen, B. N., Sandler, D. M., \& Shani, D. 1991. Social issues and socially responsible investment behavior: A preliminary empirical investigation. Journal of Consumer Affairs, 25(2): 221-234.

Roszkowski, M. J., Snelbecker, G. E. \& Leimberg, S. R. 1993. Risk tolerance and risk aversion. In S. R., Leimberg, M. J., Satinsky, R. T., Le Clair, \& R. J. Doyle (Eds.), The tools and techniques of financial planning:213-226. Cincinnati, $\mathrm{OH}$ : National Underwriter.

Ruegger, D. and E. King: 1992. A study of the effect of age and gender upon student business ethics. Journal of Business Ethics, 11(2): 179-186.

Ryan, L. V., \& Schneider, M. 2002. The antecedents of institutional investor activism. Academy of Management Review, 27(4): 554-573.

Samdahl, D. M., \& Robertson, R. 1989. Social determinants of environmental concern. Environment and Behavior, 21(1): 57-81.

Samuelson, P. A. 1969. Lifetime portfolio selection by dynamic stochastic programming. The Review of Economics and Statistics, 51(3): 239-246.

Schervish, P. G., \& Havens, J. J. 1997. Social participation and charitable giving: A multivariate analysis. Voluntas: International Journal of Voluntary and Nonprofit Organizations, 8(3): 235-260.

Scheier. M. \& Carver, S. 1992. Effects of optimism on psychological and physical wellbeing: Theoretical overview and empirical update. Cognitive Therapy and Research, 16: 201-228.

Schmuck, P. E., \& Sheldon, K. M. 2001. Life goals and well-being: Towards a positive psychology of human striving. Seattle: Hogrefe \& Huber Publishers.

Schneider, S. L. 2001. In search of realistic optimism: Meaning, knowledge, and warm fuzziness. American Psychologist, 56(3): 250-263. 
Schooley, D. K., \& Worden, D. D. 1996. Risk aversion measures: Comparing attitudes and asset allocation. Financial Services Review 5: 87-100.

Schueth, S. 2003. Socially responsible investing in the United States. Journal of Business Ethics, 43(3): 189-194.

Schwarz, N., \& Clore, G. L. 1983. Mood, misattribution, and judgments of well-being: Informative and directive functions of affective states. Journal of Personality and Social Psychology, 45(3): 513-523.

Schwarz, N., \& Clore, G. L. 1996. Feelings and phenomenal experiences. Social psychology: Handbook of basic principles, 2: 385-400.

Schwarz, N., \& Clore, G. L. 2003. Mood as information: 20 years later. Psychological Inquiry, 14(3-4): 296-303.

Seligman, M.E.P. 2006. Learned optimism: How to change your mind and your life. New York: Vintage Books.

Seligman, M. E. P. 1998. Building human strength: Psychology forgotten mission. $\boldsymbol{A P A}$ monitor, 29(1): 2.

Seligman, M.E.P. 2002. Authentic happiness: Using the new positive psychology to realize your potential for lasting fulfillment. New York: Free Press.

Seligman, M. E. P., \& Csikszentmihalyi, M. (2000). Positive psychology: An introduction. American Psychologist, 55(1): 5-14.

Serwinck, P. J. 1992. Demographic and related differences in ethical views among small businesses. Journal of Business Ethics, 11(4): 555-566.

Shah, D. V., McLeod, D. M., Friedland, L., \& Nelson, M. R. 2007. The politics of consumption/the consumption of politics. The Annals of the American Academy of Political and Social Science, 611(1): 6-15.

Sharpe, W. F. 1964. Capital asset prices: A theory of market equilibrium under conditions of risk. The Journal of Finance, 19(3): 425-442.

Shaw, D., \& Clarke, I. 1999. Belief formation in ethical consumer groups: An exploratory study. Marketing Intelligence \& Planning, 17(2): 109-120.

Shefrin, H., \& Statman, M. 1994. Behavioral capital asset pricing theory. Journal of Financial and Quantitative Analysis, 29(3): 323-349.

Sheldon, K., Frederickson, B., Rathunde, K., Csikszentmihalyi, M., \&Haidt, J. 2000. Positive psychology manifesto. Retrieved on July 10, 2011 from http://www.positivepsychology. org/akumalmanifesto. htm. 
Sheldon, K. M., \& King, L. 2001. Why positive psychology is necessary. American Psychologist, 56(3): 216-217.

Shifren, K., \& Hooker, K. 1995. Stability and change in optimism: A study among spouse caregivers. Experimental Aging Research, 21(1): 59-76.

Sidanius, J. 1988. Intolerance of ambiguity, conservatism, and racism: Whose fantasy, whose reality? A reply to Ray. Political Psychology, 9: 309-316.

Simmons, W. O., \& Emanuele, R. 2004. Does government spending crowd out donations of time and money? Public Finance Review, 32(5): 498-512.

Smith, S. M., \& Beik, L. L. 1982. Market segmentation for fundraisers. Journal of the Academy of Marketing Science, 10(3): 208-216.

Snyder, C. R., Harris, C., Anderson, J. R., Holleran, S. A., Irving, L. M., Sigmon, S. T., Yoshinobu, L., Gibb, J., Langelle, C., \& Harney, P. 1991. The will and the ways: Development and validation of an individual-differences measure of hope. Journal of Personality and Social Psychology, 60(4): 570-585.

Snyder, C. R., Hoza, B., Pelham, W. E., Rapoff, M., Ware, L., Danovsky, M., Highberger, L., Ribinstein, H., \& Stahl, K. J. 1997. The development and validation of the Children's Hope Scale. Journal of Pediatric Psychology, 22(3): 399-421.

Snyder, C.R., Irving, L.M., \&Anderson J. 1998. Hope and health. In C.R. Snyder \& D.R. Forsyth (Eds.), Handbook of social and clinical psychology: 285-305. Elmsford, NY: Pergamon Press.

Snyder, C. R., Lopez, S. J., \& Pedrotti, J. T. 2010. Positive psychology: The scientific and practical explorations of human strengths. Thousand Oaks, CA.: Sage Publications.

Snyder, C. R., Lopez, S. J., Shorey, H. S., Rand, K. L., \& Feldman, D. B. 2003. Hope theory, measurements, and applications to school psychology. School Psychology Quarterly, 18(2): 122-139.

Snyder, C. R., \& McCullough, M. E. 2000. A positive psychology field of dreams: If you build it, they will come. Journal of Social and Clinical Psychology, 19(1): 151-160.

Snyder, C. R., Rand, K. L., King, E. A., Feldman, D. B., \& Woodward, J. T. 2002. A false hope. Journal of Clinical Psychology, 58(9): 1003-1022.

Snyder, J. L. 2000. From voting to violence: Democratization and nationalist conflict. New York: Norton.

Sortino, F.A., \& Satchell, S. 2001. Managing downside risk in financial markets: Theory, practice and implementation. Oxford: Butterworth Heinemann. 
Sparkes, R., \& Cowton, C. J. 2004. The maturing of socially responsible investment: a review of the developing link with corporate social responsibility. Journal of Business Ethics, 52(1): 45-57.

Statman, M. 2004. Modern portfolio theory and behavioral finance. The Journal of Wealth Management, (fall):16-22.

Statman, M. 2005. Normal investors, then and now. Financial Analysts Journal, 61(1):3137.

Statman, M. 2006. Socially responsible indexes. The Journal of Portfolio Management, 32(3): 100-109.

Stern, P. C., Dietz, T., \& Kalof, L. 1993. Value orientations, gender, and environmental concern. Environment and Behavior, 25(5): 322-348.

Straughan, R. D., \& Roberts, J. A. 1999. Environmental segmentation alternatives: A look at green consumer behavior in the new millennium. Journal of Consumer Marketing, 16(6): 558-575.

Sunden, A. E., \& Surette, B. J. 1998. Gender differences in the allocation of assets in retirement savings plans. The American Economic Review, 88(2): 207-211.

Sung, J., \& Hanna, S. 1996. Factors related to risk tolerance. Financial Counseling and Planning, 7(1): 11-20.

Tabachnick, B. G., Fidell, L. S., \& Osterlind, S. J. 2001.Using multivariate statistics $\left(4^{\text {th }}\right.$ ed.). New York: Allyn \& Bacon.

Tetlock, P. E. 1983. Accountability and the perseverance of first impressions. Social Psychology Quarterly, 46(4) 285-292.

Tetlock, P. E. 1986. A value pluralism model of ideological reasoning. Journal of Personality and Social Psychology, 50(4): 819-827.

Tetlock, P. E., Bernzweig, J., \& Gallant, J. L. 1985. Supreme Court decision making: Cognitive style as a predictor of ideological consistency of voting. Journal of Personality and Social Psychology, 48(5): 1227-1239.

Thaler, R. H., \& Williamson, J. P. 1994. College and university endowment funds. The Journal of Portfolio Management, 21(1): 27-37.

Thorley, S. R. 1995. The time-diversification controversy. Financial Analysts Journal, 51 (3) 68-76.

Tiehen, L. 2001. Tax policy and charitable contributions of money. National Tax Journal, 54(4): 707-724. 
Timmons, J.A., \& S. Spinelli. 2007. New venture creation, entrepreneurship for the 21st Century, (7th ed.). New York: McGraw Hill-Irwin.

Totterdell, P., Wood, S., \& Wall, T. 2006. An intra-individual test of the demands control model: A weekly diary study of psychological strain in portfolio workers. Journal of Occupational and Organizational Psychology, 79(1): 63-84.

Tsalikis, J., \& Ortiz-Buonafina, M. 1990. Ethical beliefs' differences of males and females. Journal of Business Ethics, 9(6): 509-517.

Van de Venter, G. and Michayluk, D. 2009. A longitudinal study of financial risk tolerance Technical Report. Retrieved on June 20, 2011, from http://www.fma.org/Reno/Papers/Longitudinal Financial Risk Tolerance.pdf.

Van Hiel, A., Pandelaere, M., \& Duriez, B. 2004. The impact of need for closure on conservative beliefs and racism: Differential mediation by authoritarian submission and authoritarian dominance. Personality and Social Psychology Bulletin, 30(7): 824-837.

Van Liere, K. D., \& Dunlap, R. E. 1981. Environmental concern. Environment and Behavior, 13(6): 651-676.

Vining, J., \& Ebreo, A. 1990. What makes a recycler? Environment and Behavior, 22(1): $55-73$.

Vitell, S. J., \& Hidalgo, E. R. 2006. The impact of corporate ethical values and enforcement of ethical codes on the perceived importance of ethics in business: A comparison of US and Spanish managers. Journal of Business Ethics, 64(1): 31-43.

Waddock, S. A., \& Graves, S. B. 1997. The corporate social performance. Strategic Management Journal, 8(4): 303-319.

Wallach, M .A.,\& Kogan, N. 1961. Aspects of judgment and decision making: Interrelationships and changes with age. Behavioral Science, 6: 23-36.

Walls, M. R., \& Dyer, J. S. 1996. Risk propensity and firm performance: A study of the petroleum exploration industry. Management Science, 42(7): 1004-1021.

Wang, H., \& Hanna, S. 1997. Does risk tolerance decrease with age? Financial Counseling and Planning, 8(2): 27-31.

Webley, P., Lewis, A., \& Mackenzie, C. 2001. Commitment among ethical investors: An experimental approach. Journal of Economic Psychology, 22(1): 27-42.

Weerts, D. J., \& Ronca, J. M. 2007. Profiles of supportive alumni: Donors, volunteers, and those "who do it all" International Journal of Educational Advancement, 7(1): 2034. 
Wiepking, P., \& Maas, I. 2009. Resources that make you generous: Effects of social and human resources on charitable giving. Social Forces, 87(4): 1973-1995.

Williamson, O. E. 1996. Economic organization: The case for candor. The Academy of Management Review, 21(1): 48-57.

Wilson, G. D. 1973. The psychology of conservatism. London: Academic Press.

Wilson, J., \& Musick, M. 1997. Who cares? Toward an integrated theory of volunteer work. American Sociological Review, 62(5): 694-713.

Wilson, J., \& Musick, M. 1998. The contribution of social resources to volunteering. Social Science Quarterly, 79(4): 799-814.

Wood, R., \& Zaichkowsky, J. L. 2004. Attitudes and trading behavior of stock market investors: A segmentation approach. The Journal of Behavioral Finance, 5(3): 170179.

Wright, T. A. 2003. Positive organizational behavior: An idea whose time has truly come. Journal of Organizational Behavior, 24(4): 437-442.

Wunderley, L. J., Reddy, W. B., \& Dember, W. N. 1998. Optimism and pessimism in business leaders. Journal of Applied Social Psychology, 28(9): 751-760.

Yao, R., Gutter, M., \& Hanna, S. 2005. The financial risk tolerance of Blacks, Hispanics and Whites. Financial Counseling and Planning 16(1): 51-62.

Yen, S. T. 2002. An econometric analysis of household donations in the USA. Applied Economics Letters, 9(13): 837-841.

Youssef, C. M., \& Luthans, F. 2007. Positive organizational behavior in the workplace. Journal of Management, 33(5): 774-800.

Yuh, Y., Hanna, S., \& Montalto, C. P. 1998. Mean and pessimistic projections of retirement adequacy. Financial Service Review, 7: 175-194.

Zalka, L., Downes, M., \& Paul, K. 1997. Measuring consumer sensitivity to corporate social performance across cultures. Journal of Global Marketing, 11(1): 29-48.

Zhong, L. X., \& Xiao, J. J. 1995. Determinants of family bond and stock holdings. Financial Counseling and Planning, 6(1): 107-114.

Zhu, K., McKnight, B., Stergachis, A., Daling, J. R., \& Levine, R. S. 1999. Comparison of self-report data and medical records data: Results from a case-control study on prostate cancer. International Journal of Epidemiology, 28(3): 409-417.

Zinnbauer, B.J., \& Pargament, K.I. 2005. Religiousness and spirituality. In R.F. Paloutzian \& C.L. Park (Eds.), Handbook of the psychology of religion and spirituality: 21-42. New York: Guilford Press. 
APPENDIX 
Appendix 1 - The Survey Used in the Study 
The purpose of this study is to describe investor sensitivity toward corporate social performance. Following a list of items that may be used to describe investors attitudes towards CSP. Although some items may appear similar, they express differences that are important in the description of investor attitudes.

The information we obtained will be used for academic research, I would like to assure you, that the information obtained here would be treated strictly anonymously and confidentially. No other source will be informed of any individual firm's responses or participation in this survey.

Instructions: Please complete the following questions to reflect your opinions as accurately as possible .Your information will be kept strictly confidential.

\#

1 I would prefer to invest in a company that protects the environment above and beyond current environment regulations.

2 I would prefer to invest in a company that values being environmentally sustainable.

3 I would prefer to invest in a company that supports diversity in the workplace.

4 I would prefer to invest in a company that supports minorities in their workforce.

5 I would prefer to invest in a company that does not resist unionization of its workforce.

6 I would prefer to invest in a company that tries to protect the quality of the life of their employees.

$7 \quad$ I would prefer to invest in a company that does not outsource to countries with poor working conditions.

8 I would prefer not to invest in a company accused of human rights violations.

\section{Strongl \\ $\mathrm{y}$ agree}

Agree Neither

Dis
e $y$
Disagre

e

1

2

3

4

5

1

2

3

4

5

1

2

3

4

5

1

2

3

4

5

1

2

3

4

1

2

3

4

5

(

1

1

2

3

4

5

1

2

3

4 
9 I would prefer to invest in a company that

improves the living conditions in the

communities where they operate.

10 I would not like to invest in a company that produces harmful products like weapons or tobacco.

11 I would prefer to invest in a company that is socially responsible.

12 I would prefer to invest in a company that markets its products in a responsible way.

13 I would prefer to invest in a company that provides leadership for community organizations.

14 I would prefer to invest in a company that supports charities in its communities.

15 I would not invest in a company that had poor environmental practices even if it had good financial performance.

16 I would not invest in a company that had poor records in hiring and promoting ethnic minorities even it had good financial performance.

17 When I invest in a company, social responsibility is not a big concern.

18 I would prefer to invest in a company whose primary concern is to maximize return to shareholders.

19 I would not invest in a company that discriminates against minorities.

20 I would not invest in a company that discriminates against disabled employees.

21 I would not invest in a company that discriminates against women.

22 I would accept a little less financial return to invest in a company that has a good record in hiring and promoting women. 
23 I would accept a little less financial return

1

2

3

4

5

from a company I invest in if it has good

environmental practices.

24 I would not be willing invest in a company with a poor reputation for social responsibility.

25 It would bother me to invest in a company with a poor reputation for social responsibility.

26 I would prefer to invest in a company whose television advertising does not glamorize violence.

27 I would prefer to invest in a company that

1

2

3

4

5 does not use animal testing for products.

28 I would prefer to invest in a company that

1

2

3

4 creates new jobs rather than downsizing.

29 The only objective of a business should be to make a profit.

30 I would prefer to invest in a company that recycles as much waste as possible.

23

4

\section{Please tell us a little bit about yourself (Please check the appropriate box)}

- I am: $\square$ male $\square$ female

\section{- My age is:}

$\square \quad$ Under 20

$\square \quad 20-25$

$\square \quad 26-30$

$\square$ 31-35

Over 35

- My ethnicity is:
$\square$ Caucasian
$\square \quad$ African American
$\square$ Hispanic
$\square$ Other

- My educational level is:

$\square$ High school $\quad \square$ Bachelor's $\square$ Master's $\square$ Others
$\begin{array}{cccc}\text { Very } & \text { Somewhat Middle of } & \text { Somewhat } & \text { Very } \\ \text { liberal } & \text { liberal the road conservative conservative }\end{array}$


is:

- Do you have work experience?

$\square$ Full time $\quad \square \quad$ Part Time $\quad \square \quad$ Internship $\square$ None others

$\square$ Less than 1 year $\quad \square$ Less than 1 year
$\square$ 1-5 years $\quad \square$ 1-5 years
$\square$ Over 5 years $\quad \square$ Over 5 years

- What types of savings or investments do you have?

$\square$ Bank accounts

$\square \quad$ Certificates of deposits

$\square$ Retirement account or annuity

$\square \quad$ Stock portfolio

$\square$ Mutual funds

- The amount of your savings or investments is:

$\square$ Under $10,000 \quad \square$ Over 10,000-30,000 $\square \quad$ Over 30,000

- Please rank the following factors from 1 to 5 according to their relevant to you when you choose investments ( 5 is the most relevant, and 1 is the lowest)

Ecosystems (e.g. eco-efficiency and conservation, recycling, pollution, control, environmental sustainability)

$\square$ Customers (e.g. avoidance of harmful and addictive products, commitment to safety responsible marketing practice)

Financial performance (e.g. high return on investment)

$\square$ Employees (e.g. fair and just compensation, commitments to diversity)

$\square$ Others (please specify)

Gender:

Age:

Education:

Ethnic Group:

National Origin: 
VITA

Abdul-Rahman Beydoun

1983-1987

B.A., Business Administration

1987-1989

Administrative Director, Jordan

$1989-2000$

Liaison Officer, Ministry of Planning Jordan

1993-1994

Master of Business Administration

Birmingham University

Birmingham, U.K.

$1994-2006$

Lecturer

Yarmouk University, Jordan

2006-2012

Ph.D.

Florida International University

\section{PUBLICATIONS AND PRESENTATIONS}

Morris Kalliny, Abdul Beydoun, Anshu Saran and Lance Gentry 2009.

"Cultural differences in television celebrity use in the United States and Lebanon." Journal of International Business Research, 8 (1), 91-106.

Karen Paul \& Abdul Beydoun, 2011. A stakeholder approach to investor preference: The significance of demographic, ideological, and attitudinal factors. International Association for Business and Society, 2011, Bath, England.

Abdul Beydoun. The moderator role of task environment on the relationship between SME foreign entry mode and performance. Academy of International Business Conference 2008, San Diego, California.

Abdul Beydoun A, \& Haiben Young. Resource development and organization task environment" Midwest Academy of Management Meeting, 2003, Minneapolis, Minnesota. 